\title{
Development of a micro-depth sensing indentation technique with constant load control
}

\author{
AiLing Lin \\ West Virginia University
}

Follow this and additional works at: https://researchrepository.wvu.edu/etd

\section{Recommended Citation}

Lin, AiLing, "Development of a micro-depth sensing indentation technique with constant load control" (2008). Graduate Theses, Dissertations, and Problem Reports. 4396.

https://researchrepository.wvu.edu/etd/4396

This Thesis is protected by copyright and/or related rights. It has been brought to you by the The Research Repository @ WVU with permission from the rights-holder(s). You are free to use this Thesis in any way that is permitted by the copyright and related rights legislation that applies to your use. For other uses you must obtain permission from the rights-holder(s) directly, unless additional rights are indicated by a Creative Commons license in the record and/ or on the work itself. This Thesis has been accepted for inclusion in WVU Graduate Theses, Dissertations, and Problem Reports collection by an authorized administrator of The Research Repository @ WVU. For more information, please contact researchrepository@mail.wvu.edu. 


\title{
Development of a Micro-depth Sensing Indentation Technique with Constant Load Control
}

\author{
AiLing Lin \\ Thesis submitted to the \\ at West Virginia University \\ In partial fulfillment of the requirements \\ for the degree of \\ Master of Science \\ in \\ Mechanical Engineering \\ Bruce Kang, Ph. D., Chair \\ Gary J. Morris, Ph. D. \\ Larry E. Banta, Ph. D. \\ Chuanyu Feng, Ph. D.
}

College of Engineering and Mineral Resources

Department of Mechanical Engineering

Morgantown, West Virginia

2008

Keywords: Micro-depth Sensing Indentation, Constant Load Control Copyright 2008 AiLing Lin 


\title{
ABSTRACT \\ Development of a Micro-depth Sensing Indentation Technique with Constant Load Control
}

\begin{abstract}
AiLing Lin
In material nano- and micro-indentation research, Young's modulus can be obtained based on the initial unloading stiffness of the load-depth curve. The accurate load and displacement measurement as well as high precision position control of the indenter are needed to achieve the required measurement resolution. The application of PZT actuator is often used to perform the indentation experiment. However, conventional PZT controllers can only provide displacement control. Furthermore, each PZT actuator only serves a specific PZT controller using its unique calibration factor. Thus, it is beneficial to develop a controller, which can carry out both load and displacement control algorithm, and also applicable to different PZT actuators. Development of the load-controlled system will be the focus of this study. Valid experiment results of load-control design indentation application using microprocessor are presented in this thesis research.
\end{abstract}




\section{ACKNOWLEDGEMENTS}

I would like to express my sincere thanks and appreciation to my research advisor and committee chairman, Dr. Bruce Kang, for the guidance and support he has provided during the course of his research. I would also like to thank Dr. Morris, Dr. Banta and Dr. Feng for serving on my thesis committee and providing constructive suggestions relating to this work.

Additionally, I would like to express my gratitude to Wayne, John, Jared, Srik and Ashley for providing support and suggestion in my thesis.

I cannot finish without saying how grateful I am to my family. With their constant encouragement and love, I have relied throughout my time at the Academy. I would also like to express my thankful to my friends in WVU. They always inspire me, and provide inspiration throughout the course of my study at WVU. To them I dedicate this thesis. 


\section{TABLE OF CONTENTS}

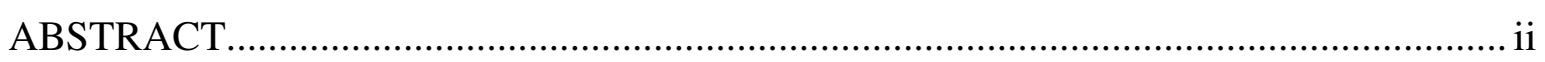

ACKNOWLEDGEMENTS .................................................................................. iii

TABLE OF CONTENTS .................................................................................. iv

NOMENCLATURE SECTION ......................................................................... vi

LIST OF FIGURES .................................................................................... viii

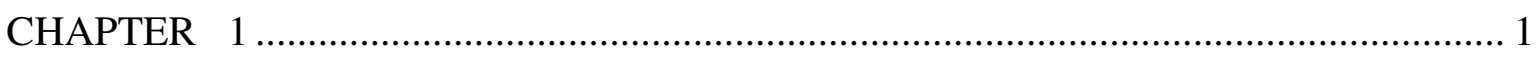

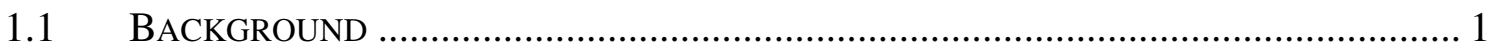

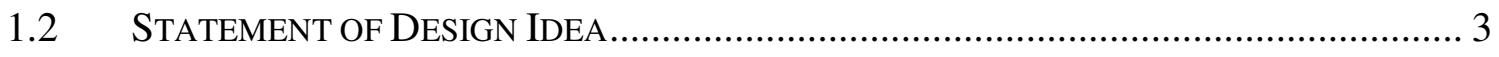

1.3 RESEARCH OBJECTIVE .......................................................................... 4

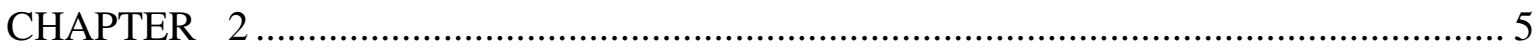

2.1 CREEP BEHAVIOR .................................................................................. 5

2.2 Multipartial UnLOADING INDENTATION TECHNIQUE .................................. 9

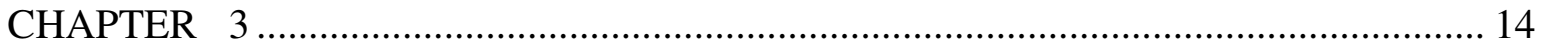

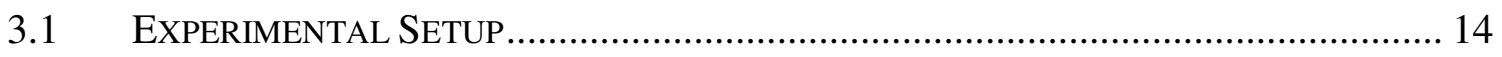

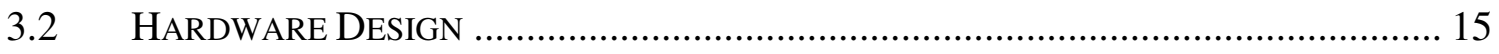

3.2.1 Micro-Control Unit and the I/O Arrangement ........................................ 17

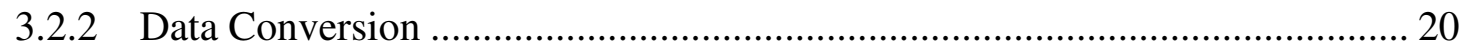

3.2.2.1 Digital to Analog Converter ........................................................... 20

3.2.2.2 Analog to Digital Converter ............................................................. 21 


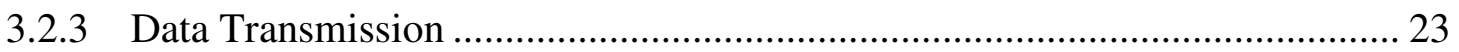

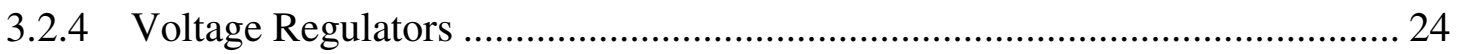

3.2.5 System Design …………………………………................................. 26

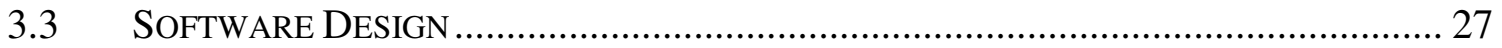

3.3.1 Load Control Algorithm for Creep Experiment ………………………….... 28

3.3.2 Load Control Algorithm for Multi-Partial Unloading Indentation Experiment 31

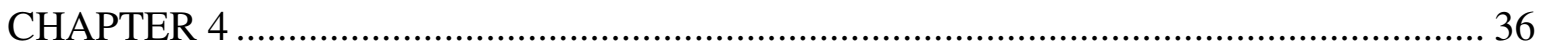

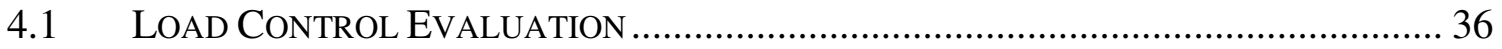

4.2 STRESS EXPONENT MEASUREMENT ............................................................... 41

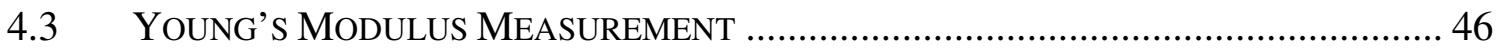

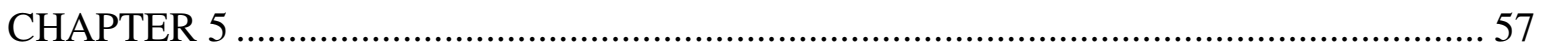

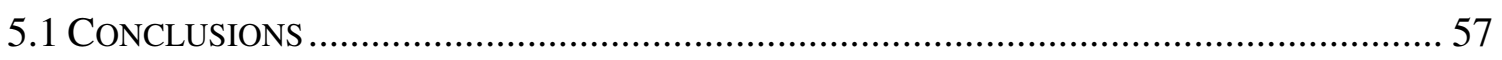

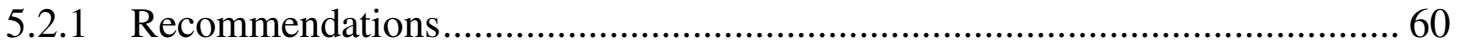

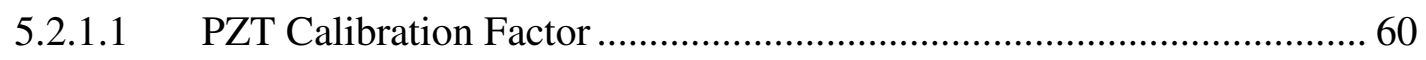

5.2.1.2 The Application of Creep and Material Properties Evaluation................. 62

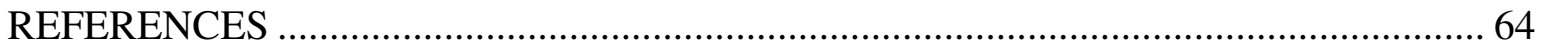




\section{NOMENCLATURE SECTION}

\begin{tabular}{|c|c|}
\hline $\mathrm{D}$ & Diffusion Rate \\
\hline $\mathrm{D}_{0}$ & Constant \\
\hline Q & Activation Energy for Atomic Motion \\
\hline $\mathrm{R}$ & Universal Gas Constant \\
\hline $\mathrm{T}$ & Absolute Temperature \\
\hline$\varepsilon$ & Strain \\
\hline$\varepsilon_{0}$ & Strain at Transient Creep \\
\hline$\varepsilon_{\mathrm{t}}$ & Strain at the transition from Primary to Secondary Creep \\
\hline $\mathrm{k}$ & Constant \\
\hline $\mathrm{t}$ & Time \\
\hline$\dot{\mathcal{E}}_{s s}$ & Steady-state Strain Rate \\
\hline $\mathrm{B}, \alpha, \beta$ & Empirical Constant \\
\hline $\mathrm{R}$ & Radius of the Spherical Punch \\
\hline$v$ & Poisson's Ratio of the specimen \\
\hline $\mathrm{E}$ & Young's Modulus of the specimen \\
\hline$v_{\mathrm{i}}$ & Poisson's Ratio of the Indenter \\
\hline $\mathrm{E}_{\mathrm{i}}$ & Young's Modulus of the Indenter \\
\hline$h_{e}$ & Elastic Indentation Depth \\
\hline$h_{s}$ & System Deformation \\
\hline$h$ & Indenter Depth \\
\hline
\end{tabular}


$\mathrm{E}_{\mathrm{r}} \quad$ Young's Modulus of the Experiment

d

Diameter of Contact Area

A

Project Area 


\section{LIST OF FIGURES}

Figure No.

Title

Page No.

$2.1 \quad$ Creep Deformation Curve Illustration 6

$\begin{array}{lll}2.2 & \text { Sudden Strain } & 7\end{array}$

$\begin{array}{lll}2.3 & \text { Transient Creep } & 7\end{array}$

$\begin{array}{lll}2.4 & \text { Viscous Creep } & 7\end{array}$

2.5 Minimum Creep Strain Rate vs. Applied Stress 8

2.6 Effect of Stress on Strain Time Creep Curve 9

2.7 Effect of Temperature on Strain Time Creep Curve 9

2.8 A Single Indentation Test with Pre-defined Multiple 12

Partial Unloading

3.1 Multiple Partial Unloading Indentation Test Setup 14

$3.2 \quad$ Creep Indentation Test Setup 15

3.3 Conventional Indentation System using Digital Control method 16

3.4 Research Circuit Board Indentation System using Analog 16

Control method

3.5 Block Diagram of Hardware Setting 17

3.6 Connection Diagram of MCU AT89C51 18

3.7 Basic Architectural Structure of MCU 19

$\begin{array}{lll}3.8 & \text { Connection Diagram of DAC715 } 20\end{array}$

3.9 DAC715 Command Truth Table 21 
3.10 Digital Input and Analog Output Voltage Calibration 21

3.11 Connection Diagram of AD7951 22

3.12 Parallel Data Timing for Reading of AD7951 22

3.13 AD7951 Output Code and Input Voltage 23

3.14 RS232 Pin Assignment and Reference Function 24

3.15 Connection diagram of MAX232 24

3.16 Connection diagram of Regulator 78xx 25

3.17 The Application of Converter LT1054 25

3.18 The Photograph of the Circuit Board Layout 26

3.19 Block Diagram Comparison of Positioning Control 27

and Load Control

3.20 Main Flow Chart of Software Function 28

3.21 Load vs. Time under Load Control in Creep Test 29

3.22 Creep Test Program Flow Chart 30

3.23 The Example of Parameter Setup for Creep Test 31

3.24 Driving Voltage vs. Time of Constant Load Multi-Partial 32

Unloading Indentation Experiment

3.25 Load vs. Displacement in Multi-Partial Unloading Indentation 32

3.26 Lad-Controlled Algorithm of Multi-Partial Unloading 33

Indentation Flow Chart

3.27 Driving Voltage vs. Time under Multi-Partial 35

Unloading Indentation

4.1 Elastic Properties of Sn-37Pb (eutectic) and Sn-3.5Ag 36 
4.2 Parameter for Strain Rate (Norton Equation, 36 $\mathrm{de} / \mathrm{dt} \mathrm{A} \cdot \mathrm{sn} \cdot \exp (-\mathrm{Q} / \mathrm{RT})$

4.3 $\quad 1.5 \mathrm{lbs}$ Applied Load vs. Time in Constant Load Control 37

4.4 The Enlarged Plot of 1.5 lbs Applied Load vs. Time in 37

Constant Load Control

4.5 2.0 lbs Applied Load vs. Time in Constant Load Control 38

4.6 The Enlarged Plot of 2.0 lbs Applied Load vs. Time in 38

Constant Load Control

4.7 2.5 lbs Applied Load vs. Time in Constant Load Control 39

4.8 The Enlarged Plot of 2.5 lbs Applied Load vs. Time in 39

Constant Load Control

4.9 3.0 lbs Applied Load vs. Time in Constant Load Control 40

4.10 The Enlarged Plot of 3.0 lbs Applied Load vs. Time in 40

Constant Load Control

4.11 Displacement vs. Time under Solder Creep 41

4.12 Contact Radius vs. Time under Solder Creep 42

4.13 Strain vs. Time under Solder Creep 43

4.14 $\log (\varepsilon)$ vs. $\log (\mathrm{t})$ under Solder Creep 44

4.15 Plot of $\log (\varepsilon)$ vs. $\log (\sigma) \quad 45$

4.16 The Stress Exponent Comparison of Book Value and 45

Experiment Value for $\mathrm{Sn}-37 \mathrm{~Pb}$ under Creep

4.17 Elastic Properties of Selected Engineering Materials 46 
4.18 Parameter and Process setup for Aluminum Multi-Partial

Unloading Indentation Algorithm

4.19 The First Unloading Curve which dh/dp $=0.1483 \quad 47$

4.20 The Second Unloading Curve which $\mathrm{dh} / \mathrm{dp}=0.1325$

4.21 The Third Unloading Curve which $\mathrm{dh} / \mathrm{dp}=0.131$

4.22 The Fourth Unloading Curve which dh/dp $=0.1195$

4.23 The Fifth Unloading Curve Which $\mathrm{dh} / \mathrm{dp}=0.120749$

4.24 Slope C Derived from Curve dh/dp vs. $\mathrm{P}^{-(1 / 3)}$

4.25 The Result of Multi-Partial Unloading Indentation for Test1 50

4.26 The Result of Multi-Partial Unloading Indentation for Test2 51

4.27 The Result of Multi-Partial Unloading Indentation for Test3 51

4.28 The Result of Multi-Partial Unloading Indentation for Test4 52

4.29 Comparison Young's Modulus of Book Value and Experiment 52

Result for Aluminum Indentation

4.30 Parameter and Process setup for Steel Multi-Partial 53

Indentation Algorithm

4.31 The Result of Steel Indentation for Test1 54

4.32 The Result of Steel Indentation for Test2 55

4.33 Steel Young's Modulus Comparison of Book Value 56

and Experiment Result

5.1 Connections with Ground Effect $\quad 58$

5.2 Connections without Ground Effect $\quad 58$

5.3 Voltage vs. Time under Ground Effect 59 
5.4 Voltage vs. Time under Ground Effect prevention 59

5.5 Displacement-Driving Voltage Curve of 40um Travel Range $\quad 60$

Controller Matched with 40um Travel Range Actuator

5.6 Displacement-Driving Voltage Curve of 180um Travel Range $\quad 61$

Controller Matched with 40um Travel Range Actuator

5.7 Displacement-Driving Voltage Curve of 120um Travel Range 61

Controller Matched with 40um Travel Range Actuator

5.8 The Application of Creep and Material properties Evaluation 63 


\section{CHAPTER 1}

\section{INTRODUCTION}

\subsection{Background}

Much research has recently been devoted to improving measurement techniques in order to accurately obtain mechanical properties. Indentation is one of the more mature techniques being developed. In material nano- and micro-indentation research, load-depth relation and unloading characteristics are among the indentation parameters that have been studied extensively either experimentally or numerically to determine the relevant mechanical behavior or properties. The use of the initial unloading stiffness of the loaddepth curve to determine the material's Young's modulus ${ }^{[1-4]}$ is well accepted. This approach can be traced back to Sneddon's ${ }^{[1]}$ classical elastic indentation solutions which describe the general relationship among the load, displacement, and contact area for any punch that can be treated as a solid of revolution of a smooth function. In the 1970s, Bulychev and his co-workers ${ }^{[2]}$ defined the initial unloading slope and reduced modulus, thus proving a theoretically sound methodology for determining the Young's modulus. This method is applicable to both spherical and pyramidal indentations. Using instrumented indentations, Doerner and Nix ${ }^{[3]}$ further investigated the unloading characteristics. In 1992 , Oliver and Pharr ${ }^{[4]}$ showed that Bulychev's technique can be applied to any indenter that can be described as a body of revolution of a smooth function. 
When determining the Young's modulus by indentation techniques, the contact area and initial unloading stiffness are the key parameters to be identified. In most cases, however, direct measurement of the contact area is not feasible. Therefore the unloading stiffness is typically used to estimate the contact area through some iterative algorithm ${ }^{[5-7]}$. Furthermore, high-precision displacement sensors are needed in order to accurately obtain the load-depth curve and the unloading stiffness data ${ }^{[2-4]}$. As for the direct measurement of the contact area, Kleesattel ${ }^{[8]}$ designed a special apparatus for direct measurement of the contact region through a spherical sapphire indenter while conducting indentation tests. Unfortunately, the scanning method yields only one line for the contact region, and realtime access of the indented surface is not possible. By applying a special lighting technique, Frank ${ }^{[9]}$ developed a transpyramidal indentation viewing system. It was also implemented by Sakaia et al ${ }^{[10]}$ using a similar technique. Recently, the Transparent Indenter Measurement (TIM) technique has been developed ${ }^{[11,12]}$. By integrating a Twyman-Green type interferometer into the spherical transparent indenter head, the TIM system can directly measure the indentation-induced out-of-plane deformation as well as the indented surface. It was found that by using the difference of out-of-plane deformations, Young's modulus can be evaluated without unloading stiffness measurement. Recently, a similar TIM approach was also done by Miyajima and Sakia ${ }^{[13]}$ using sapphire spherical indenters on Aluminum and Zirconium oxide materials.

Based on the experience learned from the research and development of the TIM technique, further development of a simple multiple partial unloading micro-indentation method for material's Young's modulus measurement is under investigation. Instead of applying displacement control to the sensor, indentation measurement can also be obtained 
by controlling the load. A micro-control unit will be developed to achieve this goal. This unit, which is an integrated circuit controlled unit, has the capabilities to execute both constant-load and constant-displacement control functionalities. The application of load control will then be more effective on the fatigue and high temperature creep experiment under indentation method. Valid experimental results of load-control design indentation application are presented in this thesis.

\subsection{Statement of Design Idea}

Due to the effect of hysteresis and thermal effect on piezoelectric materials, its expansion curve exhibits a non-linear behavior. Therefore, to obtain accurate properties of the materials, the development of closed-loop load / displacement control for precise measurement and analysis is the necessary principal procedure. Piezoelectric controllers traditionally used in indentation research are all based on constant displacement closedloop control. It is, therefore, valuable to investigate a control system which is capable of executing both constant-load and constant-displacement control functionalities. With the development of this two-function control system, it is not only possible to carry out the analysis with different methods of indentation but it can also be utilized in many other applications that require constant-load-control.

Application of a Micro-control unit is one of the preferred methods to satisfy these specific requirements. The Micro-control unit is a tiny, integrated circuit that is cheaper, simpler and smaller than a computer. In an industrial setting, the Micro- control unit has a long history with extensive usage in basic control requirements. With the proper 
combinations of other integrated circuit functions, load control algorithms can be achieved through this thesis.

\subsection{Research Objective}

The objective of this research is to develop an indentation system that provides closed-loop control for constant load. Traditionally, displacement control is used in indentation experiments to obtain material properties. However, one is unable to perform fatigue and creep experiments when utilizing this method. Furthermore, the PZT is only calibrated to a specific range of travel, making it not only inconvenient but also costly. The closed-loop load control system will be smaller and more cost effective. This thesis demonstrates the experimental results of the indentation and creep tests utilizing the load control algorithm. Aside from that, the calibration function can also be found by the application of the system. It is possible that the different travel range calibration can be achieved by one controller. 


\section{CHAPTER 2}

\section{LITERATURE REVIEW}

\subsection{Creep Behavior}

Creep is a time-dependent behavior that is a process of plastic deformation under applied stress less than the yield stress. This phenomenon occurs in homologous temperatures (actual temperature divided by the melting temperature) greater than 0.4 . In general, the elastic modulus and strength decrease with increasing temperature. The atomic mobility is related to diffusion that can be described using Ficks law:

$$
D=D_{0} \exp \left(-\frac{Q}{R T}\right)
$$

Where $\mathrm{D}$ is the diffusion rate, $\mathrm{D}_{0}$ is a constant, $\mathrm{Q}$ is the activation energy for atomic motion, $\mathrm{R}$ is the universal gas constant $(8.314 \mathrm{~J} / \mathrm{mole} \mathrm{K})$, and $\mathrm{T}$ is the absolute temperature [14]. Therefore, diffusion-controlled mechanisms will have significant effect on high temperature mechanical properties and performances. Increased mobility of the atoms in a material can lead to creep deformation.

The goal of creep test is to predict the variation of stress and strain at hightemperatures. The experiment is normally carried out by applying a loading force to a specimen and observing the development of strain $(\varepsilon)$ as a function of time $(t)$, for a given fixed temperature and stress. Figure (2.1) shows the plot of strain $(\varepsilon)$ versus time (t) for a typical creep behavior. The curve consists of three parts: Primary Creep, Steady-state Creep and Tertiary Creep ${ }^{[15]}$. 


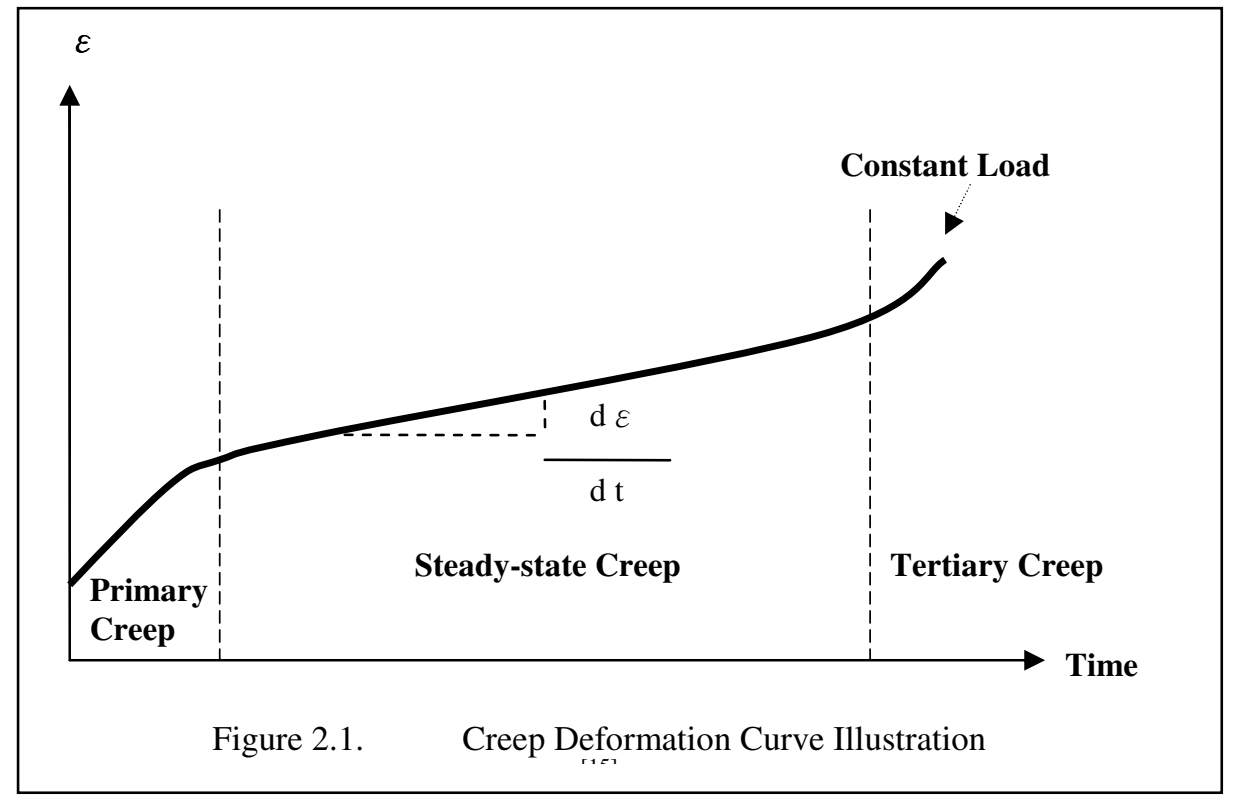

Primary creep occurs when a load is applied with the initial strain followed by the development of creep strain $(\varepsilon)$. Steady-state creep is the secondary creep; the trend is linear with constant rate. Tertiary Creep is a rapid acceleration in creep ending with failure of the specimen.

The steady-state region of the curve is the most important section of the creep deformation curve because it indicates how long the material can be used safely. The strain rate of steady-state region can be derived by using superposition of various strain-time curves as shown in Figures (2.2), (2.3), and (2.4) ${ }^{[14]}$.

Total creep curve $\quad=$ Sudden Strain + Transient Creep + Viscous Creep

Figure (2.1) $\quad=$ Figure $(2.2) \quad+$ Figure $(2.3) \quad+$ Figure $(2.4)$ 


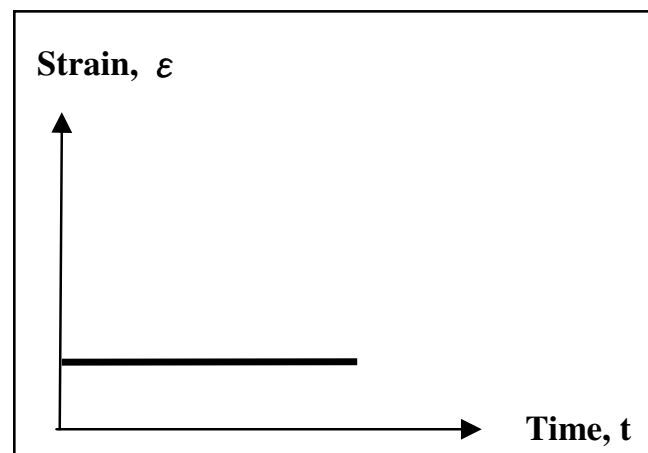

Figure 2.2 Sudden Strain

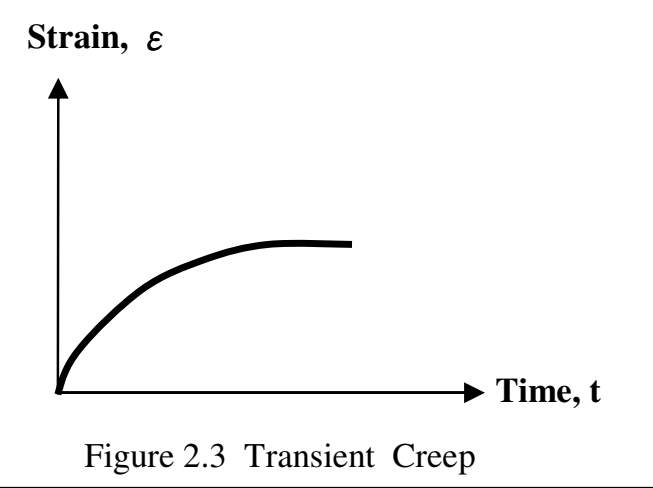

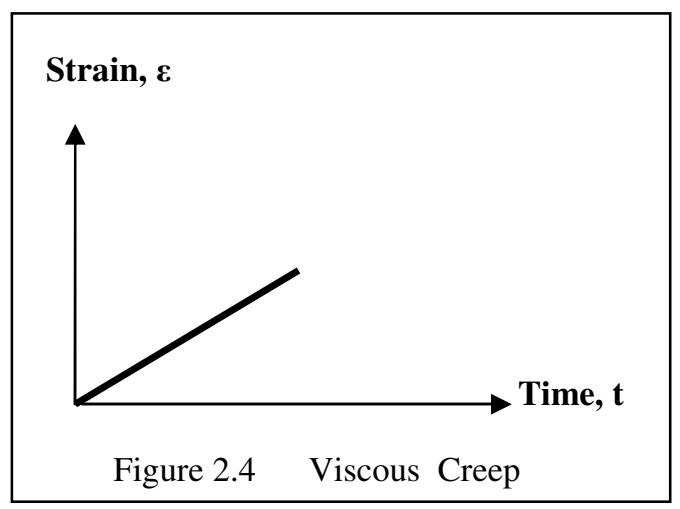

The strain-time relation can be described as:

$$
\mathcal{E}=\varepsilon_{i}+\varepsilon_{t}\left(1-\exp (-k t)+t \dot{\mathcal{E}}_{s s}\right)
$$

where $k$ is a constant, $t$ is time, $\varepsilon_{i}$ is the strain at the transient creep, $\varepsilon_{t}$ is the strain at the transition from primary to secondary creep, and $\dot{\varepsilon}_{s s}$ is the steady-state strain rate ${ }^{[14]}$. There also exists a relation between strain and nonlinear strain-time:

$$
\varepsilon=\varepsilon_{i}+B \sigma^{n} t+D \sigma^{\alpha}\left(1-\exp \left(-\beta \frac{t}{\tau}\right)\right)
$$

Where $\mathrm{B}, \mathrm{n}, \mathrm{D}, \alpha$, and $\beta$ are empirical constants. If $\mathrm{t}>\mathrm{t}$ transient, then

$$
\varepsilon=\varepsilon_{i}+B \sigma^{n} t+D \sigma^{\alpha}
$$

the strain rate is the steady-state or minimum strain rate : 


$$
\frac{d \varepsilon}{d t}=B \sigma^{n}=\dot{\varepsilon}_{s s}
$$

To consider the temperature effect, the model of equation (2.1-5) can be rewritten as an Arrhenius-type model:

$$
\frac{d \varepsilon}{d t}=B \sigma^{n}=\dot{\mathcal{\varepsilon}}_{s s}=A \exp \left(-\frac{Q}{R T}\right) \sigma^{n}
$$

where $\mathrm{Q}$ is the activation energy of creep, $\mathrm{R}$ is the universal gas constant, $\mathrm{T}$ is the absolute temperature, and $\mathrm{n}$ is the stress exponent ${ }^{[14]}$. In an isothermal test, the exponential function of equation (2.1-6) becomes a constant resulting in the following relation:

$$
\dot{\mathcal{E}}_{s s}=\dot{\mathcal{\varepsilon}}_{\min }=B \sigma^{n}
$$

Taking logarithms of both sides, equation (2.1-7) can be rewritten as (2.1-8)

$$
\log \dot{\mathcal{E}}_{s s}=\log \dot{\mathcal{E}}_{\min }=\log B+n \log \sigma
$$

then

$$
\frac{\log \dot{\mathcal{E}}_{s s}-\log B}{\log \sigma}=n
$$

From equation (2.1-9), the stress exponent $\mathrm{n}$ can be obtained using log-log plot from Figure $(2.5)^{[14]}$.

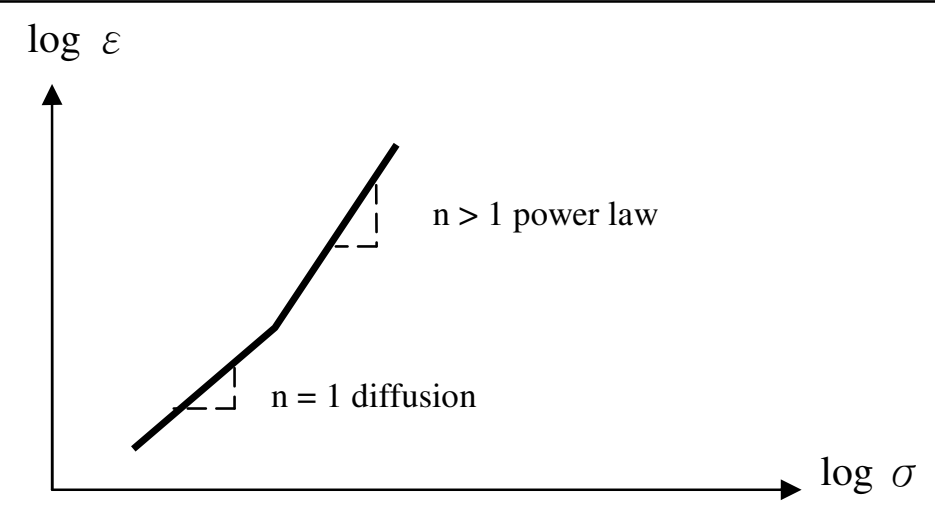

Figure 2.5 Minimum Creep Strain Rate vs. Applied Stress ${ }^{[14]}$ 
The steady-state creep is measured. The strain $(\varepsilon)$ can be converted to the stressexponent after calculation. In principle, the creep deformation is linked to an applied stress. Therefore, as the specimen indentation area increases, the applied load needs to be increased to maintain a constant stress at the area of interest. The effects of increasing stress or increasing temperature on the strain-time curve can be seen in Figure (2.6) and Figure (2.7).
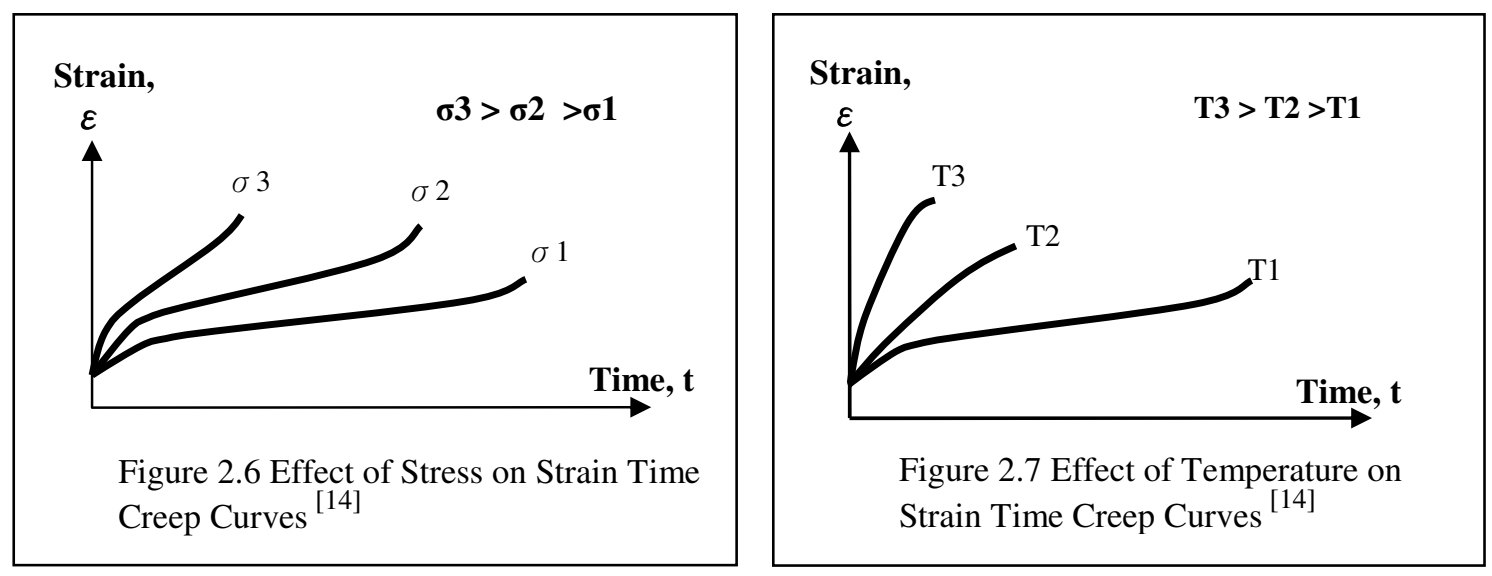

\subsection{Multipartial Unloading Indentation Technique}

Young's modulus measurement from indentation is derived from the unloading data of a load-depth sensing indentation test. The method of using the unloading process has been studied both theoretically and experimentally by different investigators, such as Lure ${ }^{[15]}$, Bulychev et al ${ }^{[2]}$, Oliver and Pharr ${ }^{[4]}$, etc. Experimental results were initially obtained through a flat punch model. Lure ${ }^{[15]}$ also showed the following result for a spherical indenter under idealized conditions and obtained the same formula:

$$
P=\frac{4}{3} \frac{\sqrt{R}}{k_{0}} h_{e}^{3 / 2}
$$


For a deformable spherical indenter, $P=\frac{4}{3} E_{r} \sqrt{R} h_{e}^{\frac{3}{2}}$

where $k_{0}=\left(1-v^{2}\right) / E, v$ and $E$ are Poisson's ratio and Young's modulus of the specimen, $h_{e}$ is elastic indentation depth, $R$ is the radius of the spherical punch, and $E_{r}$ is defined as $\frac{1}{E_{r}}=\frac{1-v^{2}}{E}+\frac{1-v_{i}^{2}}{E_{i}}$ where $E_{i}$ and $v_{i}$ are Young's modulus, and Poisson's ratio of the indenter.

Equation (2.2-2) then leads to the well-accepted equation for Young's modulus evaluation: $\frac{d P}{d h}=\frac{d}{k_{0}}$ where $d$ is the diameter of the contact area. In terms of the projected area,

$$
\frac{d P}{d h}=\frac{2}{\sqrt{\pi}} \frac{\sqrt{\mathrm{A}}}{k_{0}} \text { or } \frac{d P}{d h}=\frac{2}{\sqrt{\pi}} E_{r} \sqrt{A}
$$

For a nano- or micro- load-depth sensing indentation, the projected area $A$ is either directly measured or calibrated as a function of indentation depth; thus it requires the precise measurement of indentation depth and/or projected area in order to obtain Young's modulus accurately.

$$
\text { Re-writing Equation (2.2-2) as } P=\alpha h_{e}{ }^{m} \text {, where } \alpha=\frac{4}{3} E_{r} \sqrt{R} \text {, and } m=\frac{3}{2} \text {. Solving }
$$

for $h_{e}$ and taking the derivative with respect to $P$ on both sides, yields:

$$
\frac{d h_{e}}{d P}=\frac{1}{m} \alpha^{\frac{-1}{m}} P^{\frac{1}{m}-1} \quad \text { or } \quad \frac{d h_{e}}{d P}=C P^{\frac{1}{m}-1}
$$

Where $C=\frac{1}{m} \alpha^{-\frac{1}{m}}$ is a function of the indenter size and mechanical properties of the material. 
It should be noted that Equation (2.2-4) is only valid for the elastic indentation process. As the indentation unloading is elastic, this compliance $\frac{d h_{e}}{d P}$ is the same as the measured unloading compliance $\frac{d h}{d P}$. Therefore, Equation (2.2-4) can be further rewritten as,

$$
\frac{d h}{d P}=C P^{\frac{1}{m}-1}
$$

Thus, without any direct contact area measurement, an alternative theoretical solution for Young's modulus measurement is obtained. Specifically for a deformable spherical indenter of radius, $R$ :

$$
\begin{aligned}
& R=\frac{d h}{d P}=\frac{2}{3}\left(\frac{4}{3} E_{r} \sqrt{R}\right)^{\frac{-2}{3}} P^{\frac{2}{3}-1}=\left(6 E_{r}{ }^{2} R\right)^{\frac{-1}{3}} P^{\frac{-1}{3}} \\
& \frac{d h}{d P}=C P^{\frac{-1}{3}}
\end{aligned}
$$

Where $C=\left(6 E_{r}^{2} R\right)^{\frac{-1}{3}}$ is related to the elastic modulus.

Equation (2.2-7) establishes a load-based algorithm in which only the unloading stiffness and load are required to determine Young's modulus. In a typical load-depth sensing indentation system, the indentation depth is usually determined using high precision displacement sensors. This requirement can be circumvented for the proposed load-based algorithm coupled with a multiple-partial unloading technique.

During an indentation test, the loading apparatus is also subjected to the indentation load, thus the total displacement $h_{\text {total }}$ includes indentation depth and system deformation,

$$
h_{\text {total }}=h+h_{s}
$$


Where $h$ is the indentation depth, and $h_{s}$ is the deformation of the indentation system caused by the indentation load. Taking the derivative on both sides,

$$
\frac{d h_{t o t a l}}{d P}=\frac{d h}{d P}+\frac{d h_{s}}{d P}
$$

$\frac{d h_{s}}{d P}$ represents the system compliance, i.e. $\frac{d h_{s}}{d P}=C_{s}$. Substituting Equation (2.2-8) into Equation (2.2-9) to obtain the following equation,

$$
\frac{d h_{\text {total }}}{d P}=C P^{\frac{-1}{3}}+C_{s}
$$

Equation (2.2-10) shows an important feature of the load-based algorithm. With the total displacement $h_{\text {total }}$ available, the direct indentation depth measurement is no longer a necessity if the system compliance can be measured simultaneously or calibrated automatically.

However, calibration of the system compliance is not easy. For example, as the specimen size varies, the system compliance will also change. Thus, when using Equation $(2.2-10)$, it is desirable to find an in-situ measurement of the system compliance. This may be achieved by using the proposed multiple-partial unloading approach ${ }^{[13,14]}$, which is briefly explained in the following paragraphs.

To measure the system compliance, it is necessary to perform the indentation test with pre-defined multiple partial-unloading. Figure (2.8) shows a schematic loaddisplacement curve in which multiple partial-unloading during a single indentation test was introduced. 


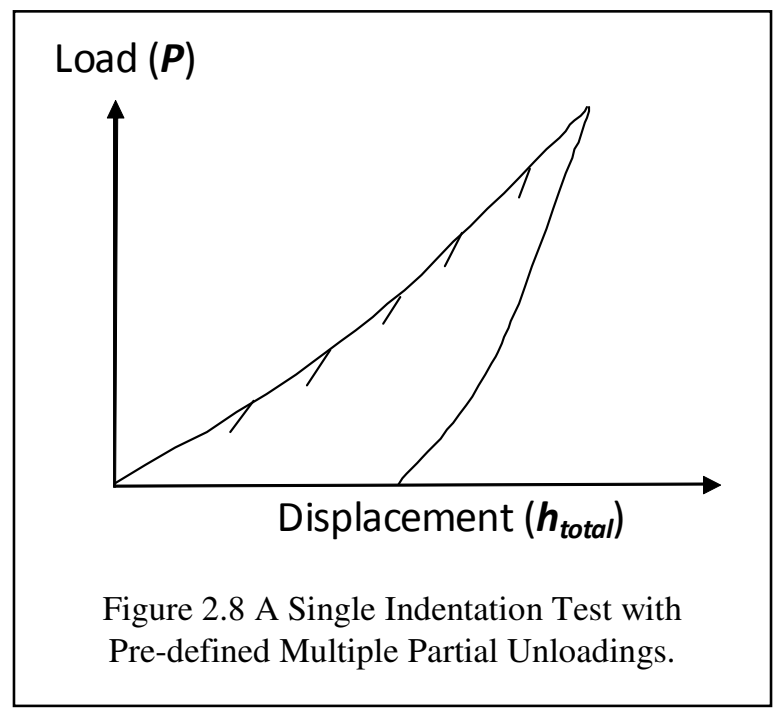

For a spherical indenter at each unloading step, from Equation (2.2-10), the unloading compliance is written as:

$$
\left(\frac{d h_{\text {total }}}{d P}\right)_{i}=C \times P_{i}^{\frac{-1}{3}}+C_{s}
$$

Equation (2.2-11) clearly shows that $\left(\frac{d h_{\text {total }}}{d P}\right)_{i}$ and $P_{i}^{\frac{-1}{3}}$ have a linear relationship if $C_{s}$ remains a constant during these multiple partial unloading steps, and $C$ is the slope to be determined for Young's modulus measurement. Thus direct indentation depth measurement is not necessary.

Equation (2.2-11) also provides a direct check for the validity of the proposed algorithm. That is, if the system compliance does change during the indentation, the linear relationship depicted in Equation (2.2-11) will not be maintained and vice versa. It should be noted that, after obtaining Young's modulus, other mechanical properties, such as hardness and stress-strain curve, can also be determined using methods developed by other researchers ${ }^{[16,17]}$. 


\section{CHAPTER 3}

\section{EXPERIMENT PROGRAM}

\subsection{Experimental Setup}

Figure (3.1) shows the multiple partial unloading indentation test setup. It has a spherical tungsten indenter of diameter $1.58 \mathrm{~mm}$ and a $100 \mathrm{lbs}$ stainless steel compression load cell. The frame is fixed by clamping screws which will stabilize the system as the PZT actuator is generating vertical force toward the specimen. There are three control wires for the signal transmissions as shown in Figure (3.1). Wire 1 is for the strain gage output of the load cell. The strain gage will transfer the compression force into electrical signal which is only several micro-volts. This small signal is then enlarged by the load cell amplifier to a maximum of $+5 \mathrm{~V}$. Wire 2 carries the high-current driving voltage ranging approximately from 0 to $+1000 \mathrm{~V}$. Wire 3 provides a voltage range from 0 to $+10 \mathrm{~V}$, which is corresponding to travel range of the PZT actuator.

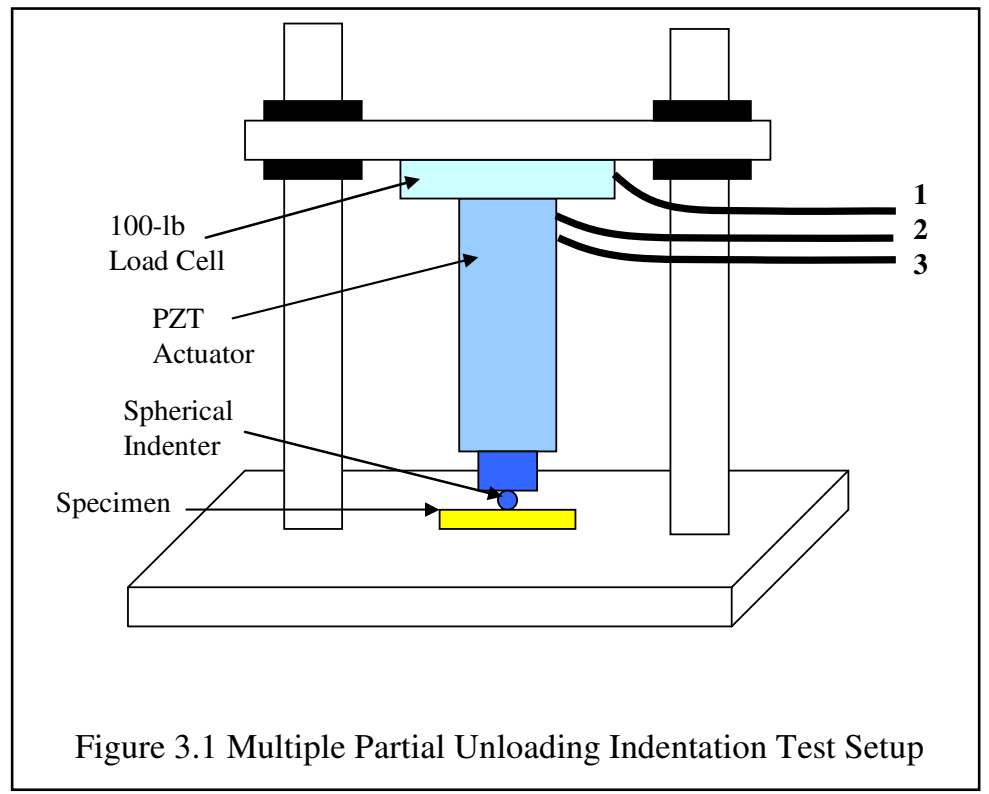


Figure (3.2) shows the indentation creep test setup. A 5-lb compression load cell is used due to the smaller strain generated during indentation creep testing. The frame and the indenter have the same setup as the former multiple partial unloading indentation testing.

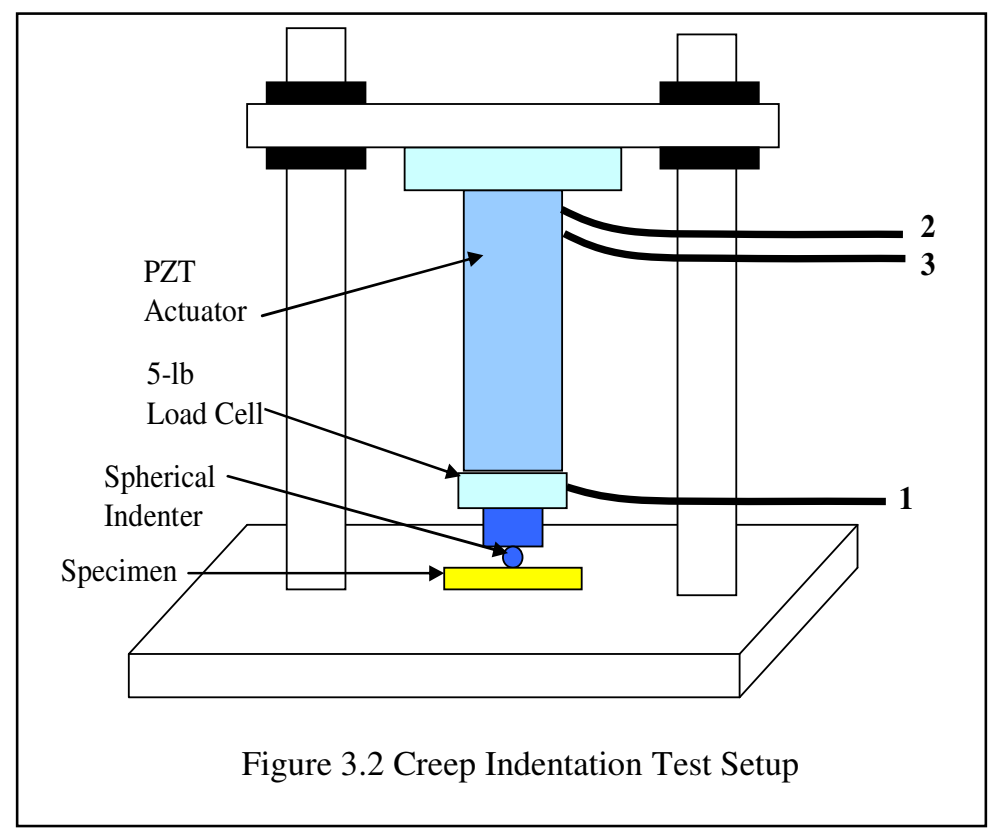

\subsection{Hardware Design}

Figure (3.3) shows the conventional indentation system setup while Figure (3.4) shows the research circuit board indentation system. The conventional control method is using digital interface to control the actuator. The digital input data will be transferred into voltage signal by control box and will be amplified as the driving voltage. The strain gage can sense the PZT displacement. The positioning signal will be passed to the computer by digital interface. The research circuit board control system is using the analog control which is from 0 to $+10 \mathrm{~V}$. This analog signal will pass through a high-voltage amplifier to drive the PZT actuator to expand. The analog displacement and load signal can be directly 
received by circuit board. Therefore, the load or displacement control can be achieved by one single control unit in stead of a computer and a data acquisition.

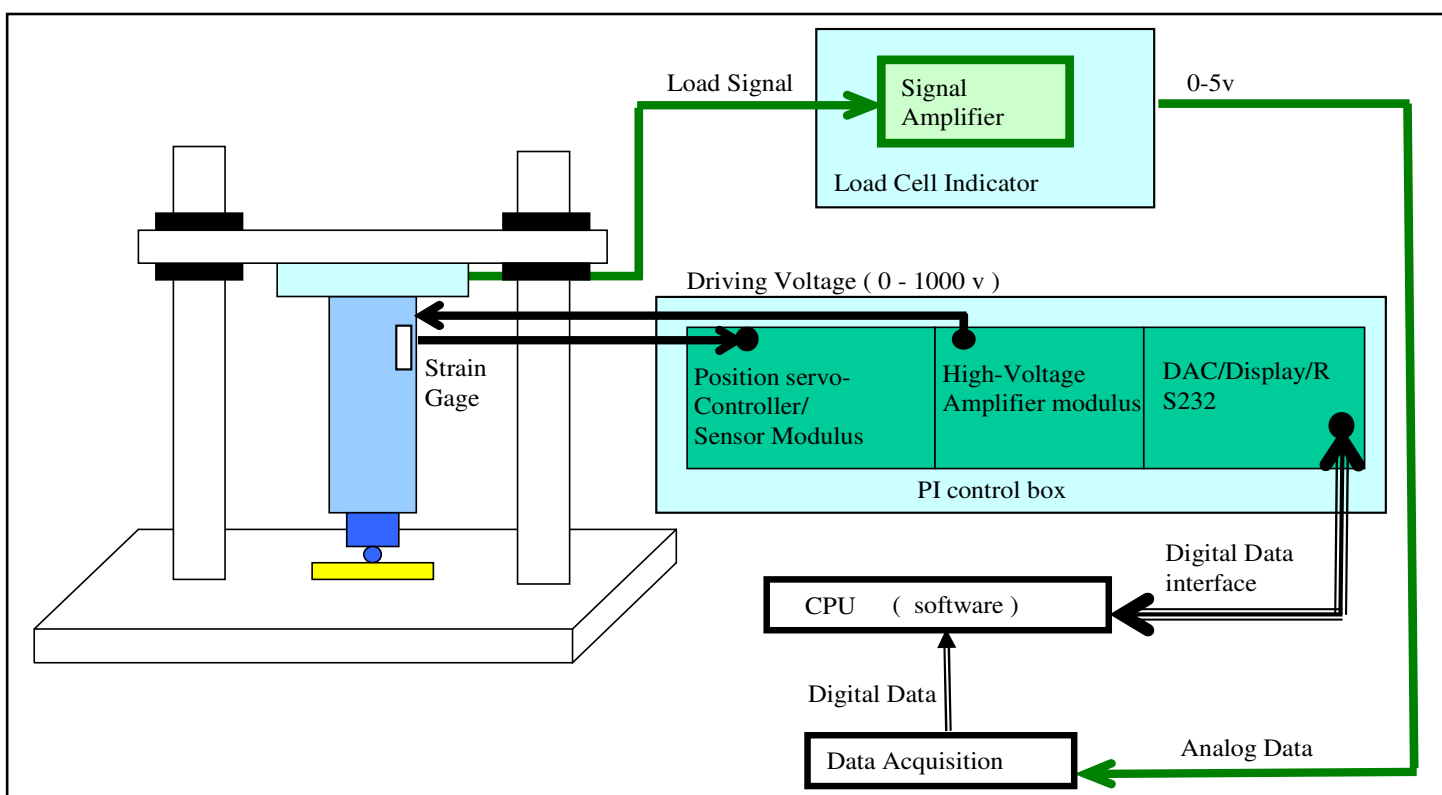

Figure 3.3 Conventional Indentation System using Digital Control Method

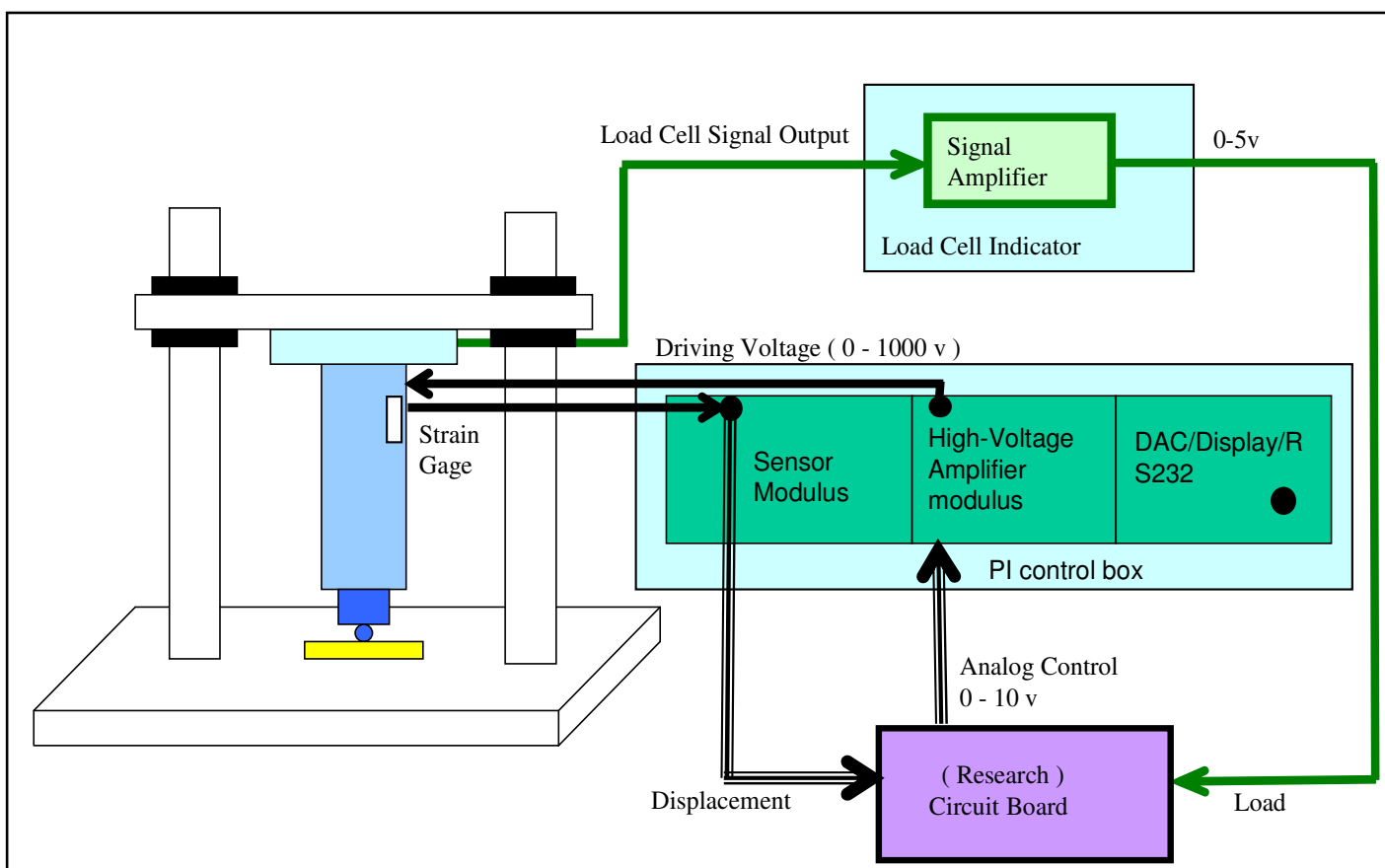

Figure 3.4 Research Circuit Board Indentation System using Analog Control Method 
In order to achieve a load-control method in the circuit board, the hardware system was designed with four fundamental functions in mind. The block diagram of the hardware setting is shown in figure (3.5). These principles include the micro-control unit, data conversion (DAC and ADC), data transmission (RS233 interface), and the voltage supplied system. The details of functionality are described as follows.

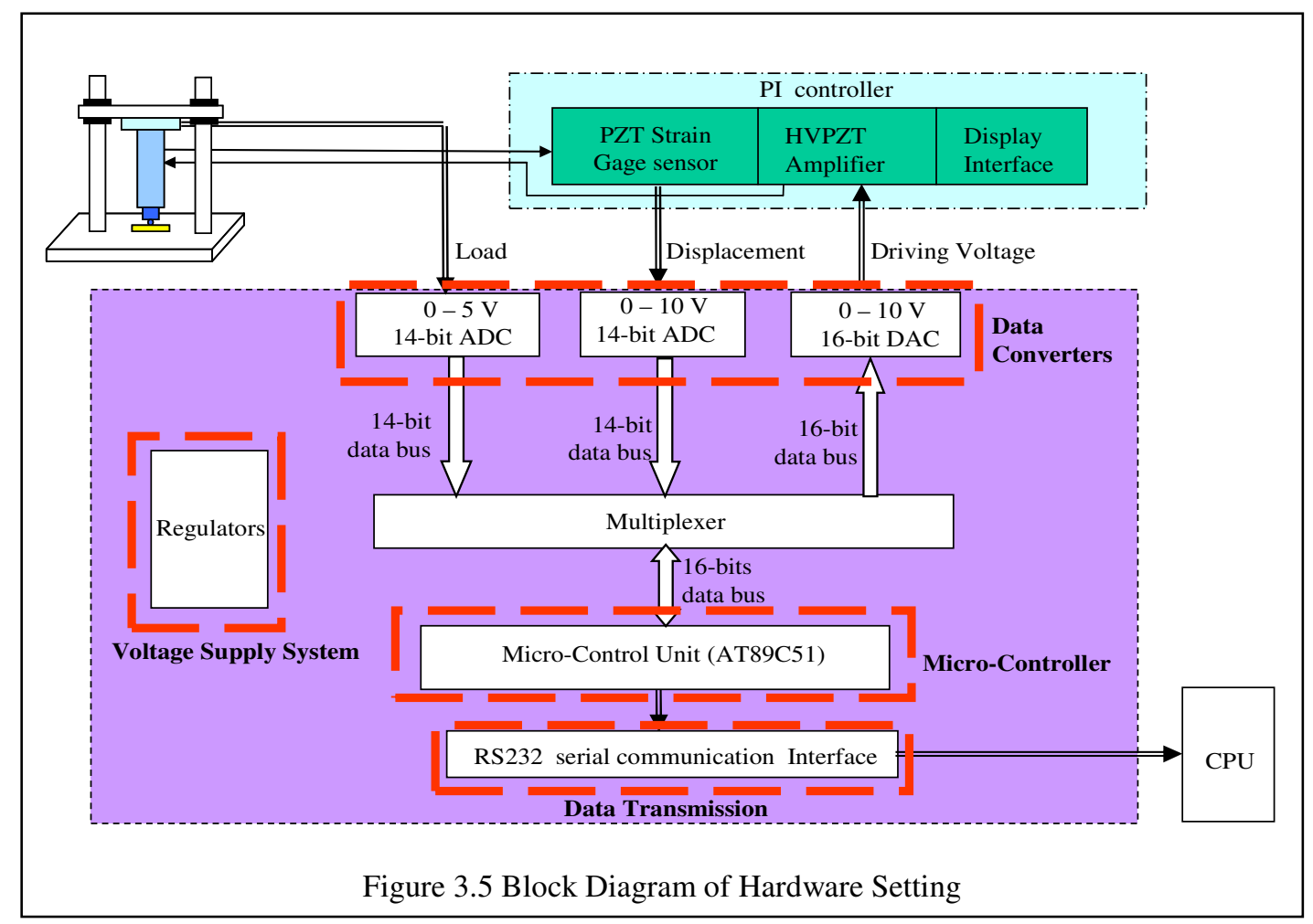

\subsubsection{Micro-Control Unit and the I/O Arrangement}

AT89C51, 8-bit reprogrammable micro processor is used in this work. It is manufactured by Atmel and compatible with the industry-standard MCS-51 instruction set. AT89C51 is composed of $4 \mathrm{~K}$ bytes of flash, 128 bytes of RAM, $32 \mathrm{I} / \mathrm{O}$ lines, two 16-bit timer / counter, a full duplex serial port, interrupt architecture, on chip oscillator and clock circuitry ${ }^{[18]}$. The on-chip oscillator needs an external crystal to define the operating 
frequency of the microprocessor. A machine cycle consists of a sequence of three steps that is performed continuously while a computer is in operation. Since one machine cycle will take 12 pulses of the crystal, instruction cycles of the AT89C51 can execute 12,000,000 / $12=1,000,000$ per second with a $12 \mathrm{MHz}$ crystal. Figure (3.6) shows the connection diagram of AT89C51. Port0 to port3 are multiplexed with Address and Data bus. Port 0 is used as a 3-bit open-drain. When using port 0 in output, external pull-up resistors are needed as shown in Figure (3.4). Port 3 serves the functions of various special features, such as RxD and TxD, which used for RS232 transmission.

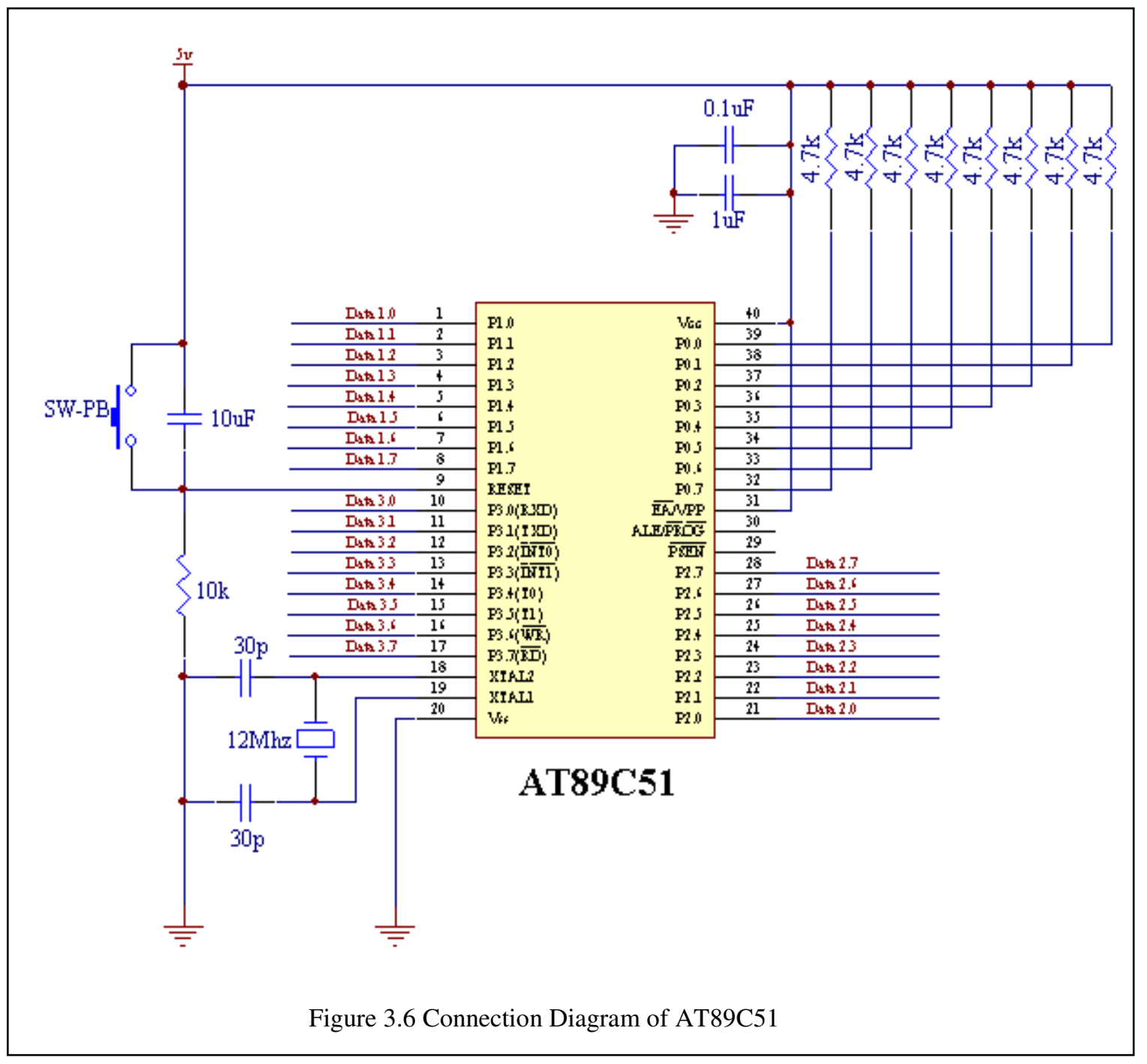




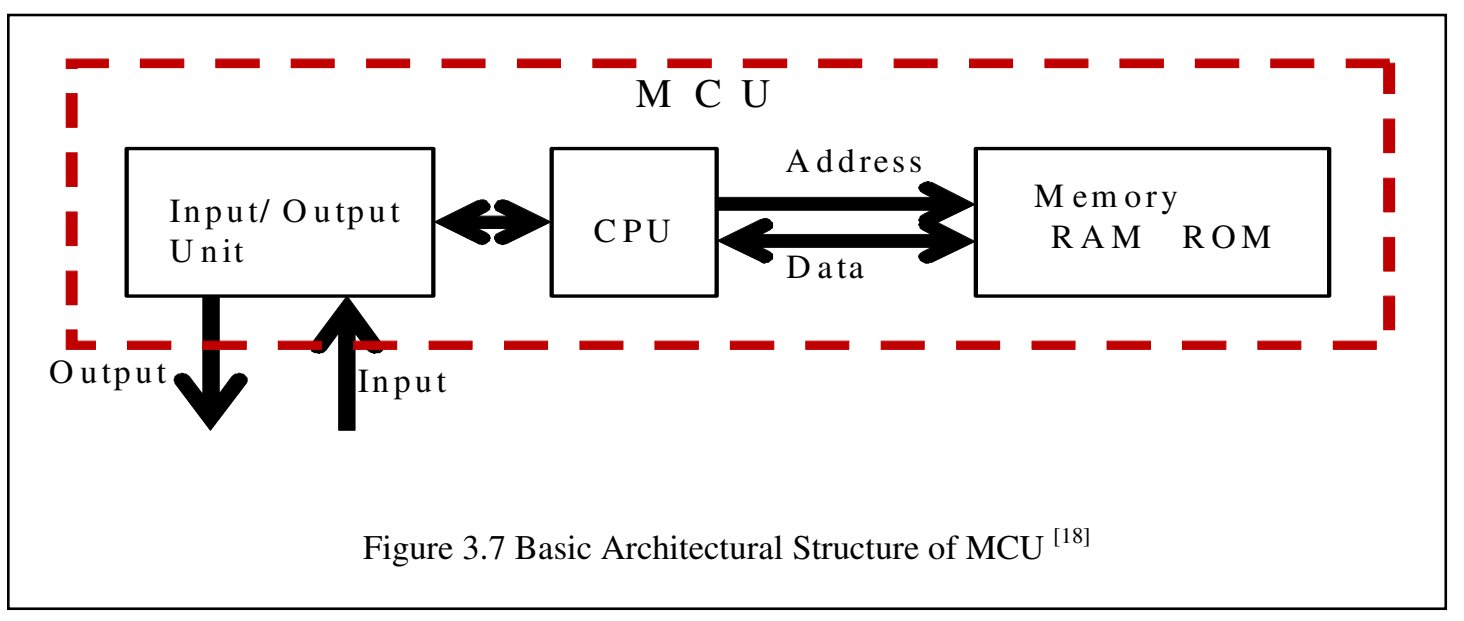

Figure (3.7) shows the block diagram of the MCU, which consists of CPU (Central Processing Unit), Memory (includes RAM and ROM), and I/O (input/output unit). The principle procedure of MCU is to pass digital data to the input unit. After processing and calculation by CPU, the output unit will have the result which is used to control the equipment, and provide information to the user. $\mathrm{CPU}$ is the core of MCU; it not only controls all the motions of MCU but also provides all kinds of function for operational analysis, arithmetic, logical calculations and adjustment. Memory is used for saving the program, constants, variables and stack. RAM (Random Access Memory) saves the variable of program; ROM (Read Only Memory) saves the constant of the program and the program itself ${ }^{[18]}$.

In order to reduce the response time of the data transmission, parallel interface of the DAC and ADC are used in this study. However, the parallel transmission transmits several bits simultaneously. Each I/O line of ADC and DAC needed to connect a corresponding MCU I/O pin as a data bit. This hardware circuit design contained two 14bit ADCs and one 16-bit DAC has the summation of $44 \mathrm{I} / \mathrm{O}$ lines. It is clear that the MCU $\mathrm{I} / \mathrm{O}$ port is not sufficient enough to support the data transmission. However, the problem 
can be solved by using 2 bus switches as the multiplexers. With 5 control lines, 44 I/O lines can be organized by 2 bytes as data transmission in Port 1 and port 2 . Port 0 is used for instruction command, and port 3 is for the special feature function.

\subsubsection{Data Conversion}

\subsubsection{Digital to Analog Converter}

Figure (3.8) shows the pin configuration of DAC715. DAC715 is a D/A converter with the output range from 0 to $+10 \mathrm{~V}$ with $\pm 12 \mathrm{~V}$ supplied. The parallel data input is D0 (LSB) to D15 (MSB). There are 4 control pins, A0, A1, WR and CLR, which represent the command function of DAC715. The corresponding truth table is shown in Figure (3.9) ${ }^{[19]}$. For analog output configuration of DAC715, a digital input of 7FFFH represents a full scale output, while $8000 \mathrm{H}$ represents a zero output. The theoretical calibration of output voltage is shown in Figure (3.10) ${ }^{[19]}$.

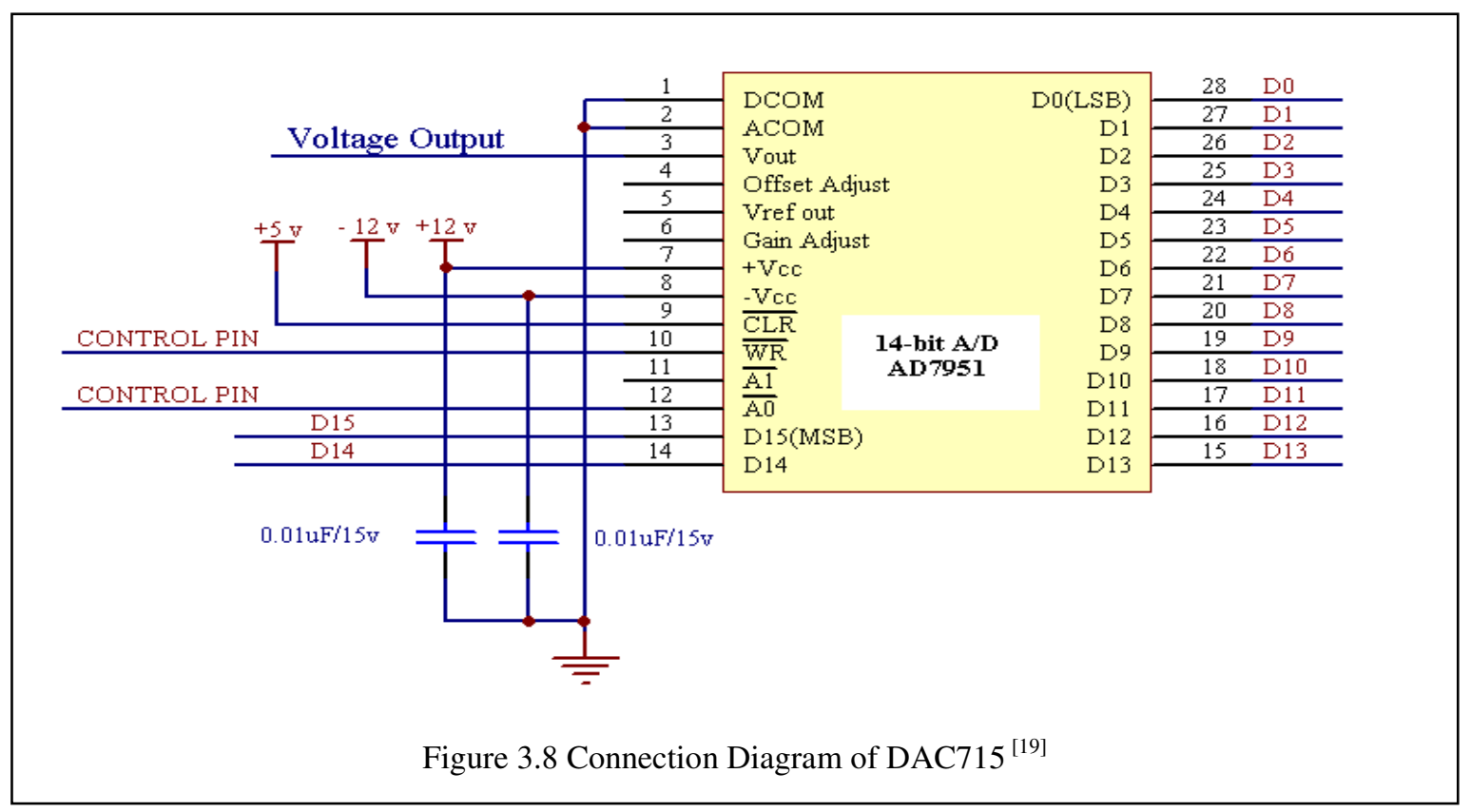




\begin{tabular}{|c|c|c|c|c|}
\hline$\overline{A_{0}}$ & $\overline{A_{1}}$ & $\overline{\text { WR }}$ & $\overline{\text { CLR }}$ & DESCRIPTION \\
\hline 0 & 1 & $1 \rightarrow 0 \rightarrow 1$ & 1 & Load Input Latch \\
1 & 0 & $1 \rightarrow 0 \rightarrow 1$ & 1 & Load D/A Latch \\
1 & 1 & $1 \rightarrow 0 \rightarrow 1$ & 1 & No Change \\
0 & 0 & 0 & 1 & Latches Transparent \\
$X$ & $X$ & 1 & 1 & No Change \\
$X$ & $X$ & $X$ & 0 & Reset D/A Latch \\
\hline
\end{tabular}

Figure 3.9 DAC715 Command Truth Table ${ }^{[19]}$
DAC715 CALIBRATION VALUES 1 LEAST SIGNIFICANT BIT $=152 \mu \mathrm{V}$ DIGITAL INPUT CODE $\quad$ ANALOG BINARY TWO'S COMPLEMENT, BTC

\begin{tabular}{|c|c|c|}
\hline $7 \mathrm{FFF}_{\mathrm{H}}$ & 9.999847 & Full Scale -1LSB \\
\hline $4000_{H}$ & 7.5 & 3/4 Scale \\
\hline $0001_{H}$ & 5.000152 & Half Scale +1 LSB \\
\hline $0000_{H}$ & 5 & Half Scale \\
\hline$\underset{\mid}{\mathrm{FFFF}_{\mathrm{H}}}$ & 4.999847 & Half Scale - 1LSB \\
\hline$\underset{\mid}{\mathrm{COOOO}_{\mathrm{H}}}$ & 2.5 & 1/4 Scale \\
\hline $8000_{H}$ & 0 & Zero \\
\hline
\end{tabular}

Figure 3.10 Digital Input and Analog Output Voltage ${ }^{[19]}$

\subsubsection{Analog to Digital Converter}

The load and displacement data output are analog and can be read by ADC. The AD7951 is a 14-bit analog-to-digital converter fabricated by Analog Devices, Inc. It can accommodate four different analog input ranges: 0 to $+5 \mathrm{~V}, 0$ to $+10 \mathrm{~V}, \pm 5 \mathrm{~V}$, and $\pm 10 \mathrm{~V}$. Figure (3.11) shows the connection diagram for AD7951 using the parallel data interfaces in this study. AD7951 contains a high speed 14-bit sampling ADC, conversion clock, and both serial and parallel system interface ports. A falling edge on pin CNVST samples the analog input on IN+ with respect to a ground sense, IN-. The corresponding data reading timing is shown in Figure (3.12 ${ }^{[20]}$. 

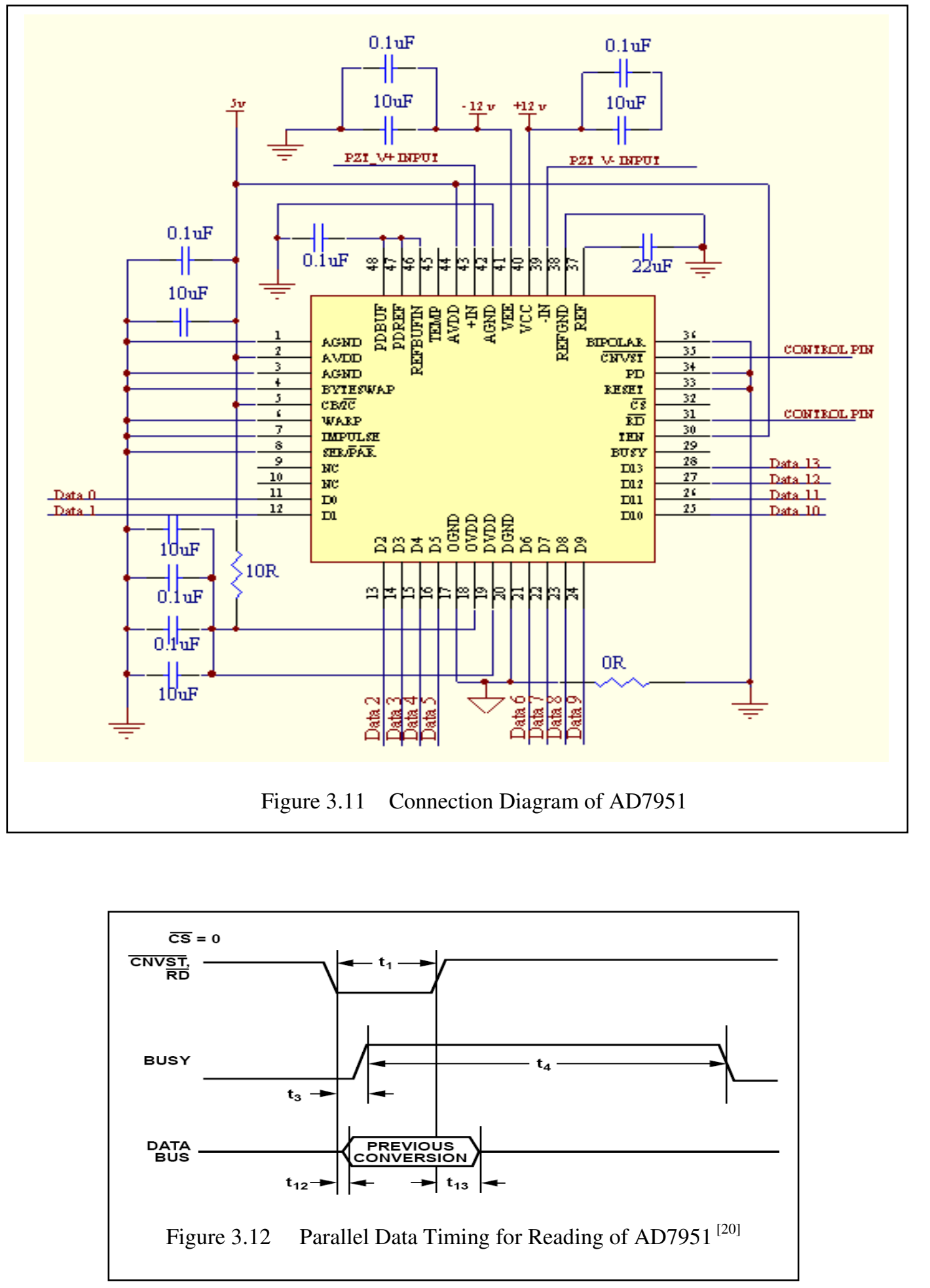

Figure (3.13) shows the chart of transfer characteristics of digital output codes and the corresponding different analog input ranges, $\mathrm{V}_{\mathrm{IN}}{ }^{[20]}$. Two different analog input voltage 
ranges are used in this study: one for load detection, which is 0 to $+5 \mathrm{~V}$, and the other for measuring the PZT actuator displacement, which is 0 to $+10 \mathrm{~V}$.

\begin{tabular}{|c|c|c|c|c|c|c|}
\hline \multirow[b]{2}{*}{ Description } & \multicolumn{4}{|c|}{$V_{\text {REF }}=5 \mathrm{~V}$} & \multicolumn{2}{|c|}{ Digital Output Code } \\
\hline & $V_{\mathbb{N}}=5 \mathrm{~V}$ & $V_{1 N}=10 \mathrm{~V}$ & $V_{1 N}= \pm 5 \mathrm{~V}$ & $V_{\mathbb{N}}= \pm 10 \mathrm{~V}$ & Straight Binary & Twos Complement \\
\hline FSR-1 LSB & $4.999695 \mathrm{~V}$ & $9,999389 \mathrm{~V}$ & $+4.999389 \mathrm{~V}$ & $+9.998779 \mathrm{~V}$ & $0 \times 3 \mathrm{FFF}^{1}$ & OX1FFF' \\
\hline FSR - 2LSB & $4.999390 \mathrm{~V}$ & $9.998779 \mathrm{~V}$ & $+4.998779 \mathrm{~V}$ & $+9.997558 \mathrm{~V}$ & $0 \times 3 F F E$ & Ox1FFE \\
\hline Midscale + 1 LSB & $2.500305 \mathrm{~V}$ & $5.000610 \mathrm{~V}$ & $+610.4 \mu \mathrm{V}$ & $+1.221 \mathrm{mV}$ & $0 \times 2001$ & $0 \times 0001$ \\
\hline Midscale & $2.5 \mathrm{~V}$ & $5.000000 \mathrm{~V}$ & ov & ov & $0 \times 2000$ & $0 \times 0000$ \\
\hline Midscale - 1 LSB & $2.499695 \mathrm{~V}$ & $4.999389 \mathrm{~V}$ & $-610.4 \mu \mathrm{V}$ & $-1.221 \mathrm{mV}$ & 0x1FFF & $0 \times 3 F F F$ \\
\hline$-F S R+1 L S B$ & $305.2 \mu \mathrm{V}$ & $610.4 \mu V$ & $-4.999389 \mathrm{~V}$ & $-9.998779 \mathrm{~V}$ & $0 \times 0001$ & $0 \times 2001$ \\
\hline$-F S R$ & ov & OV & $-5 \mathrm{~V}$ & $-10 \mathrm{~V}$ & $0 \times 0000^{2}$ & $0 \times 2000^{2}$ \\
\hline
\end{tabular}

\subsubsection{Data Transmission}

RS232 serial communication interface is used for data transmission in this study. The transmission algorithm is called UART (Universal Asynchronous Receiver Transmitter), which consists of a single start bit followed by the data bits, the optional parity bit, and the stop bit or bits in the transmission. Depending on the data length, the transmission mode can be setup as mode 0 , mode 1 , mode 2 or mode 3 . The 8 -bit data transmitted character representing mode 1 is used for this study. Besides the data length, baud rate also needs to be specified as the parameter in the UART format. Baud rate is defined in terms of the oscillator frequency applied with the MCU. In this study, the baud rate is set to be 2400 bps. Once the communication protocol has been set, the data transferring can preceded. Figure (3.14) shows the RS232 pin assignment and its corresponding function. Pin 2, the data received, is the function bit serves as data transmission from MCU to CPU in this thesis. Besides, AT89C51 micro-controller is TTL (Transistor-transistor logic) device. MAX232, the dual driver/receiver, is then used to 
convert the TTL/CMOS input levels into RS232 levels. Figure (3.15) shows the application of MAX232 in the circuit design.
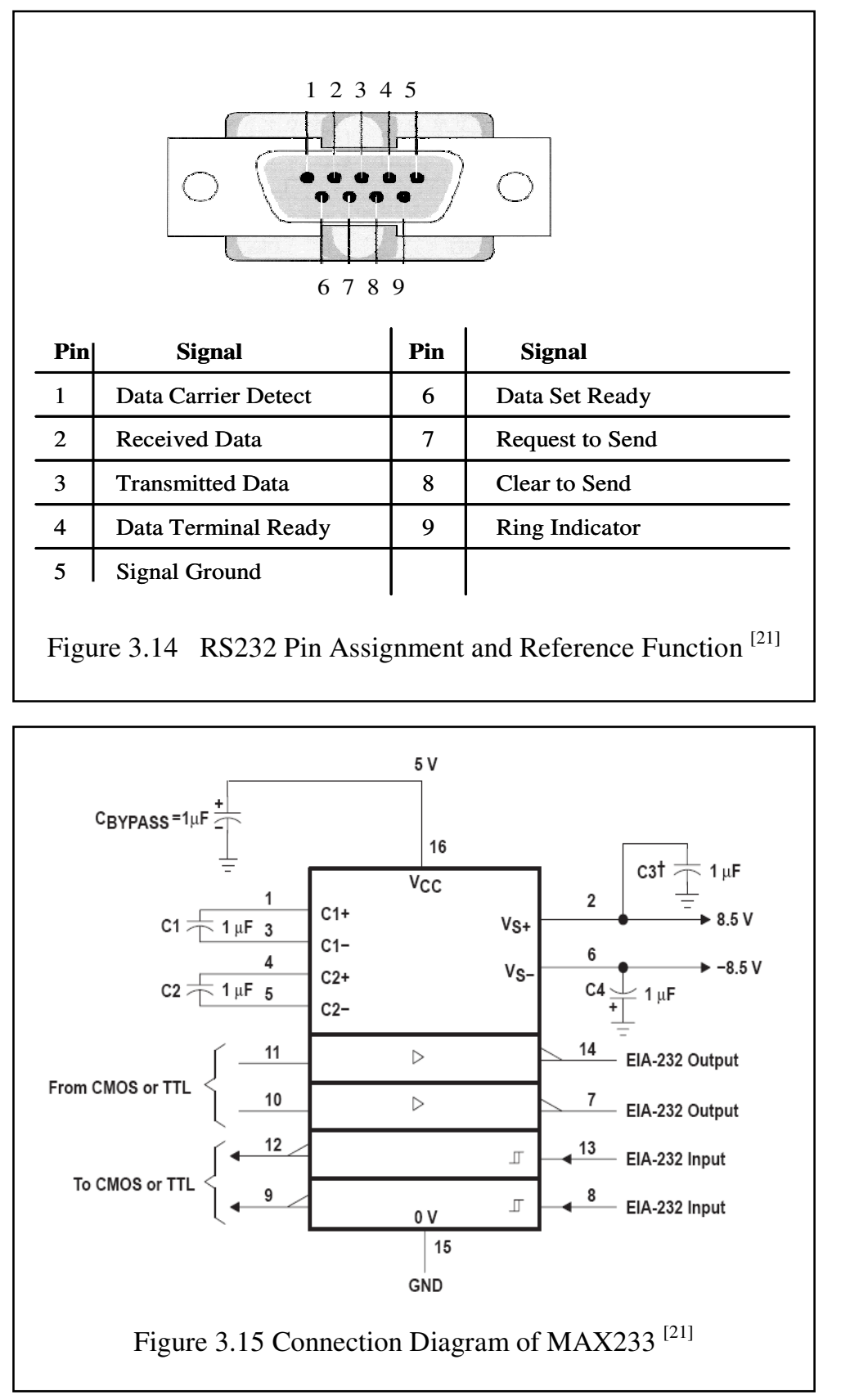

\subsubsection{Voltage Regulators}

The integrated circuits are supplied with steady voltages of $+5 \mathrm{~V},+12 \mathrm{~V}$ and, $-12 \mathrm{~V}$. 
The following voltage regulators are selected to meet the requirement. Figure (3.16) shows the circuit diagram of $78 \mathrm{XX}$ series. 7805 is a three-terminal positive regulator. It can regulate a fixed $+5 \mathrm{~V}$ with up to $1 \mathrm{Amp}$ current. Regulator 7812 is similar to 7805.7812 provides a steady $+12 \mathrm{~V}$ with up to $1 \mathrm{Amp}$ current.

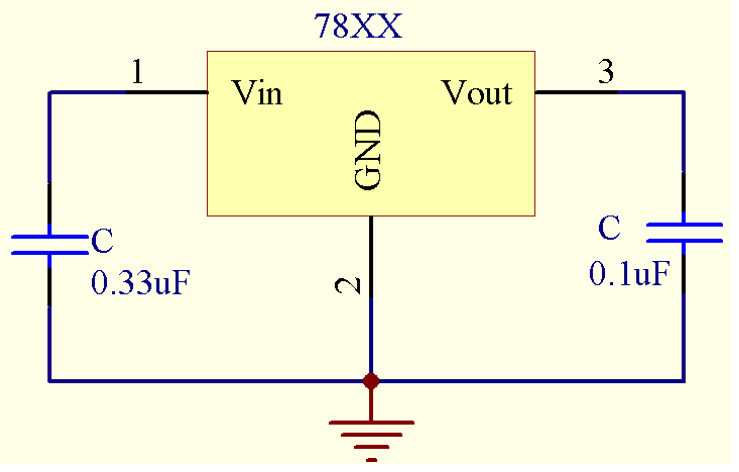

Figure 3.16 Connection Diagram of 78xx series

TI LT1054 is a bipolar voltage converter. It applies at the full supply-voltage range of $+3.5 \mathrm{~V}$ to $+15 \mathrm{~V}$. Figure (3.17) shows the Pin diagram of the negative voltage generation. $-12 \mathrm{~V}$ can be adjusted by the resistances of $\mathrm{R} 1$ and $\mathrm{R} 2$.

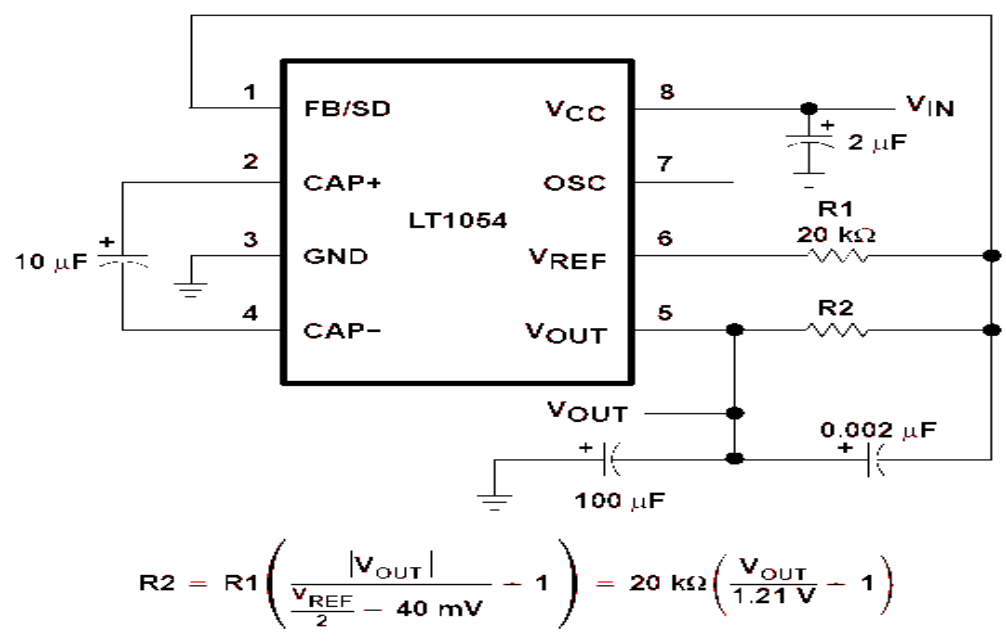

Figure 3.17 The Application of Converter LT1054 ${ }^{[22]}$ 


\subsubsection{System Design}

Protel 99SE, a PCB design/layout tool, is used to produce the schematic drawing of the circuit design. Figure (3.18) shows the photograph of the circuit board layout. The corresponding unit functions of the circuits are described as following: 1. Voltage Regulator 7805 (+5 Volt power source) and $7812(+12$ Volte power source); 2. D/A Converter DAC715 (0 to 10 Volt PZT actuator driving voltage); 3. Voltage Converter LT1054 (-12 Volt power source); 4. RS232 Serial data transmission; 5. Micro-Control Unit AT89C51; 6. EEPROM AT93C46; 7. Multiplexers; 8. NPN general purpose amplifier; 9. A/D Converters AD7951 (load and displacement detection). Sketching the circuitry first to plan for the connection distribution is the foundation in developing the circuit module. Each IC function can be examined by the correct hardware setup. Testing the program coding furthermore provides a support to the inspection. Thus, the MCU is the essential element in serving the application of the functional testing and troubleshooting to the peripheral components.

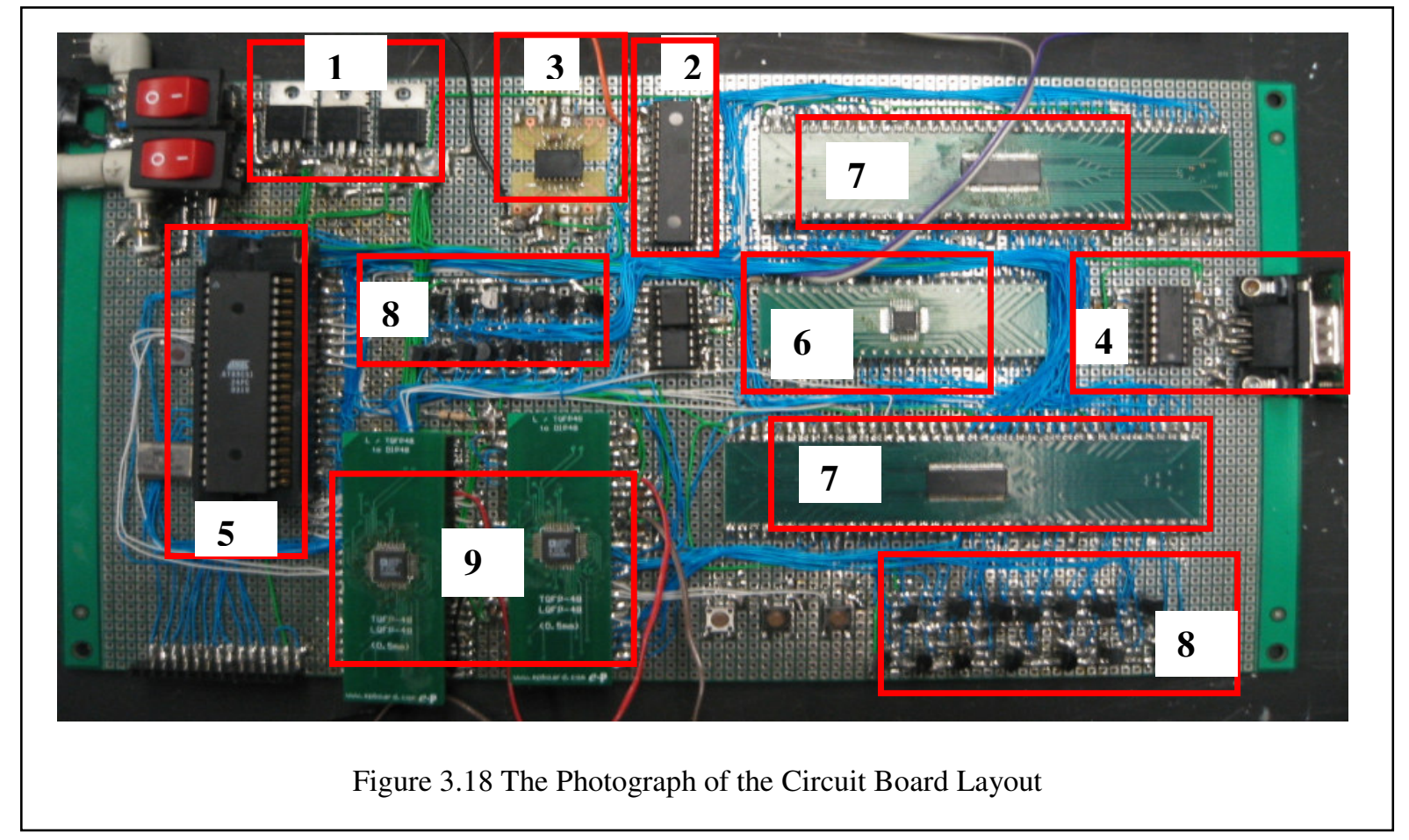




\subsection{Software Design}

Figure (3.19) is the block diagram comparison of conventional closed-loop positioning control and research circuit board closed-loop load control. In the positioning control system, the digital input signal will pass through a voltage amplifier and drive the actuator to move. The signal adjustment by the feedback of positioning signal will maintain the constant positioning.

In the load control system, the analog input signal will also pass through a voltage amplifier and drive the actuator to expand. After the actuator making an indentation on the specimen, the load cell will sense the load and feedback the signal to keep adjusting the driving voltage to fit a constant load.

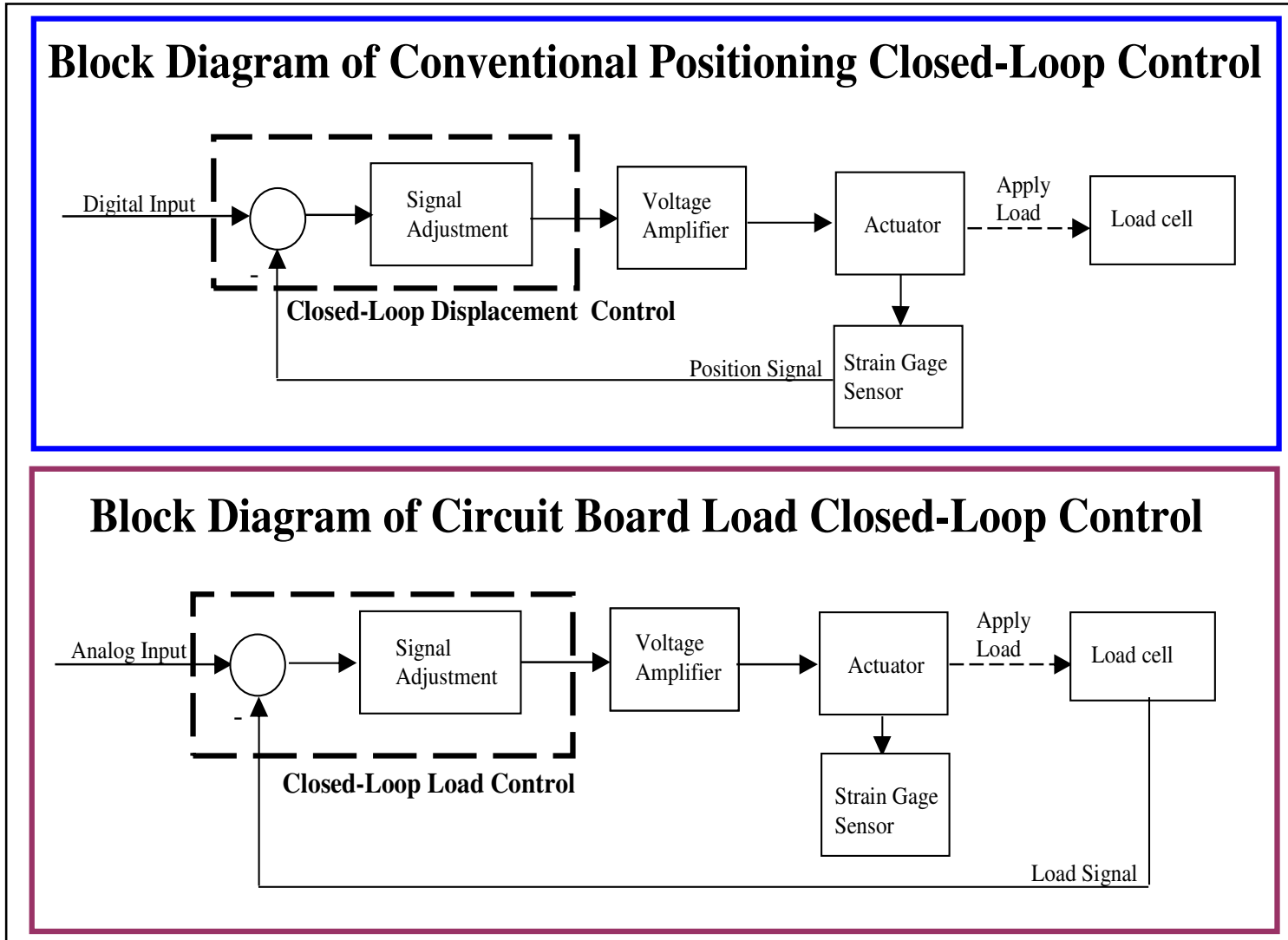

Figure 3.19 Block Diagram Comparison of Positioning Control and Load Control 
The flowchart explains the main functions of the program, Figure (3.20). Creep test mode and the multiple partial unloading indentation test mode are contained in the program. Before performing the test, the testing mode, applied load and loading/unloading step numbers are specified by the parameter setup in terms of the experimental function. The details of program flowchart and parameter setup are described in the following section.

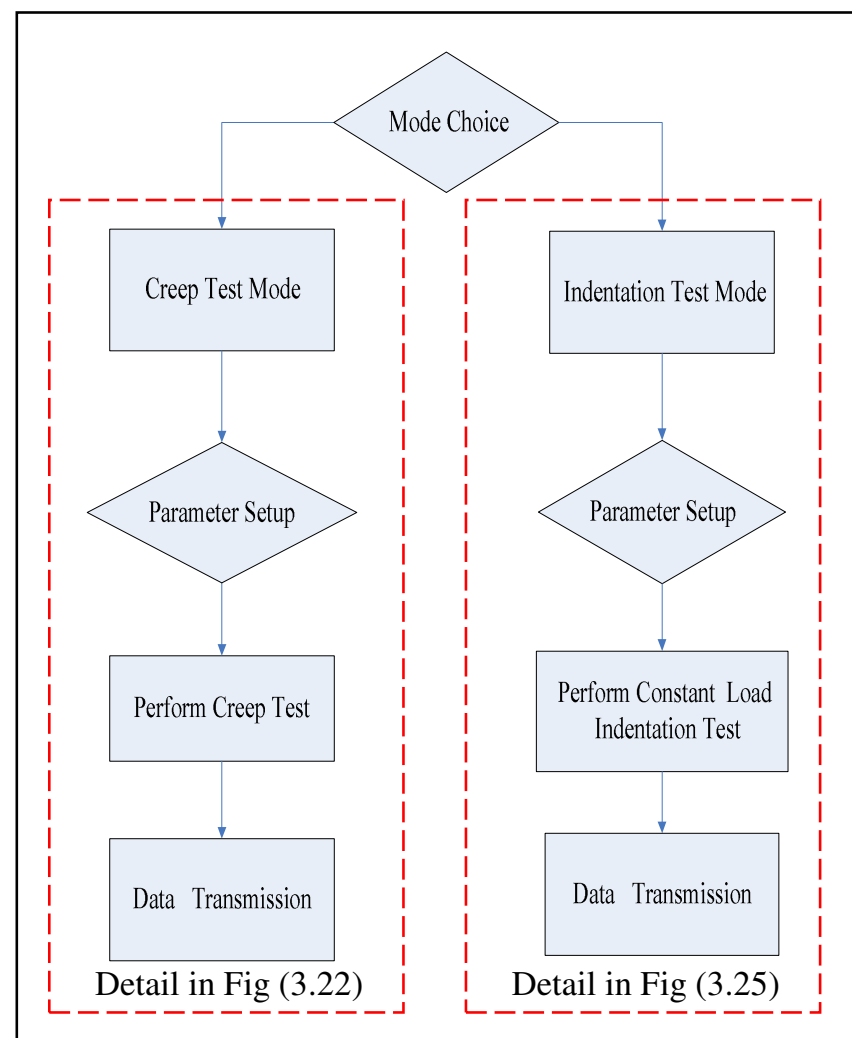

Figure 3.20 Main Flow Chart of Software Function

\subsubsection{Load Control Algorithm for Creep Experiment}

The main objective of this algorithm is to maintain a constant load while performing indentation creep test. Figure (3.21) shows the load-time curve under creep indentation experiment. 


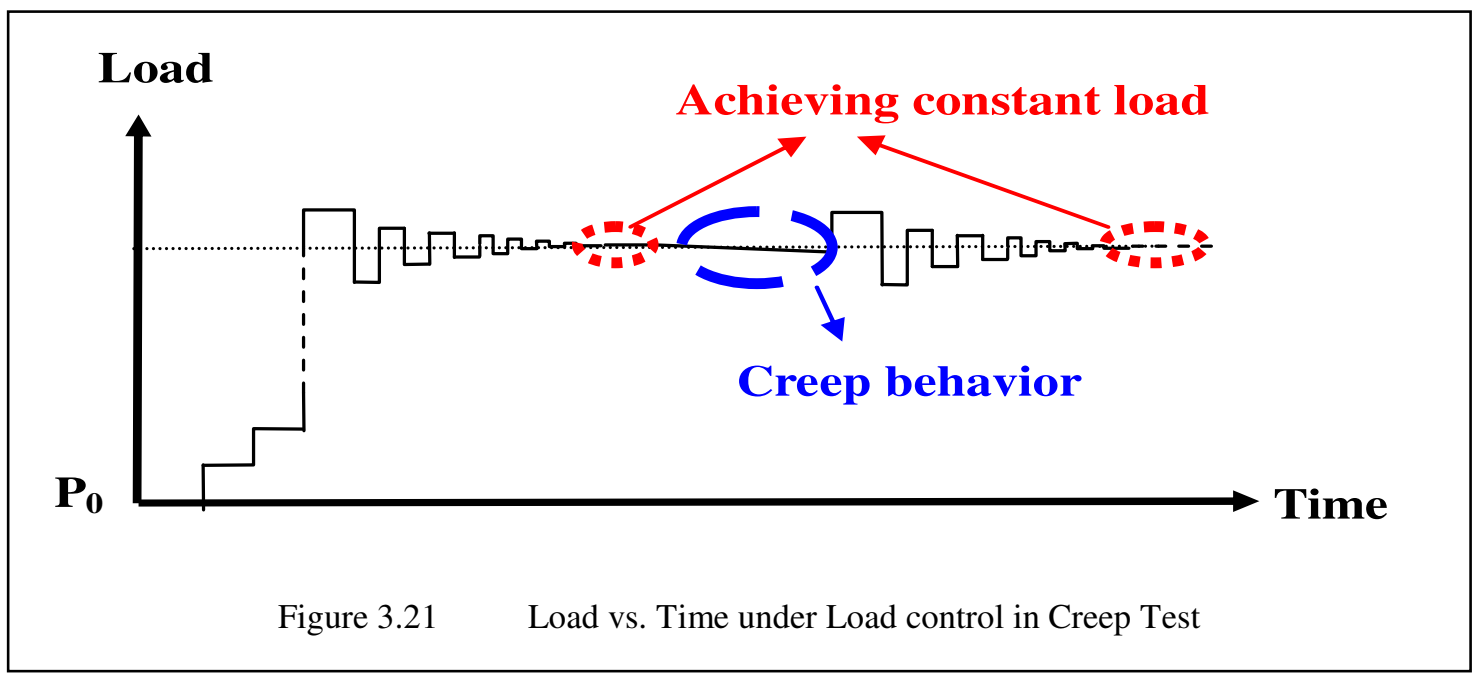

At the initial stage, to avoid a sudden crashing on the specimen in the beginning, the initial driving voltage has to set as $0 \mathrm{~V}$. The driving voltage then slowly increases until a load response is received from the load cell. After fitting the target load, the system will then remain at the constant load by a closed-loop control. The creep phenomenon of the specimen will occur during a period of time and the load will start to decrease. Additional adjustment will contribute to maintain the constant load. The program steps are shown in Figure (3.22). 


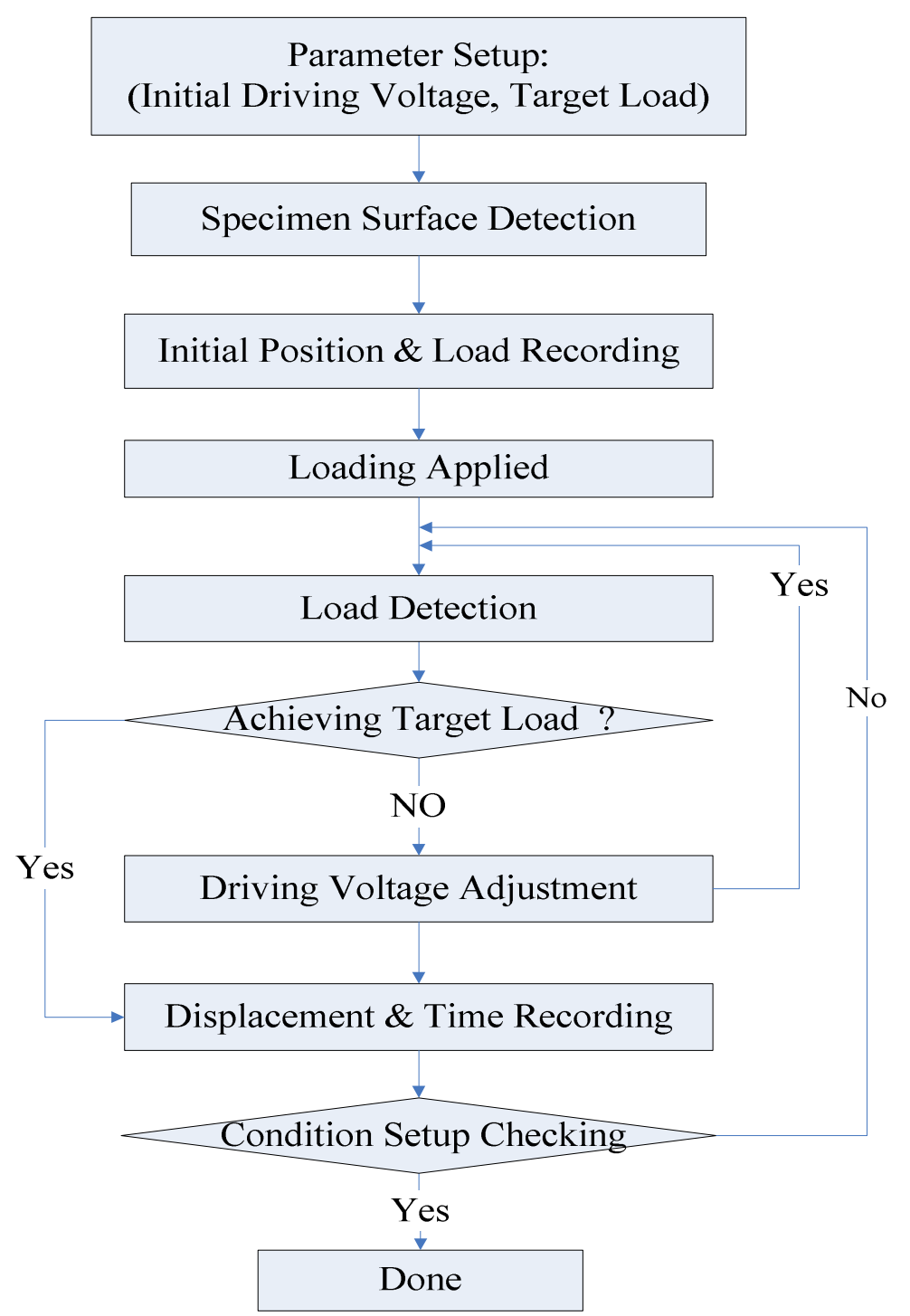

Figure 3.22 Creep Test Program Flow Chart

Figure (3.23) shows an example of an indentation creep experiment target load parameter setup. 
Example for creep experiment parameter setup :

120 um travel range PZT and 5-lb load cell are used.

Apply constant load sets as $1 \mathrm{lb}$.

Target load voltage parameter determine :

$$
\begin{aligned}
& \frac{1 \mathrm{lb}}{5 \mathrm{lb}}=\frac{x_{1}}{3 F F F} \longrightarrow \text { ADC full range hex data } \\
& x_{1}=0 \mathrm{CCC} \rightarrow \text { Target load of hex parameter setup }
\end{aligned}
$$

Figure $\quad 3.23$ The Example of Parameter Setup for Creep Test

\subsubsection{Load Control Algorithm for Multi-Partial Unloading Indentation Experiment}

Figure (3.24) is the plot of the driving voltage versus time under a load controlled multiple partial unloading indentation experiment.

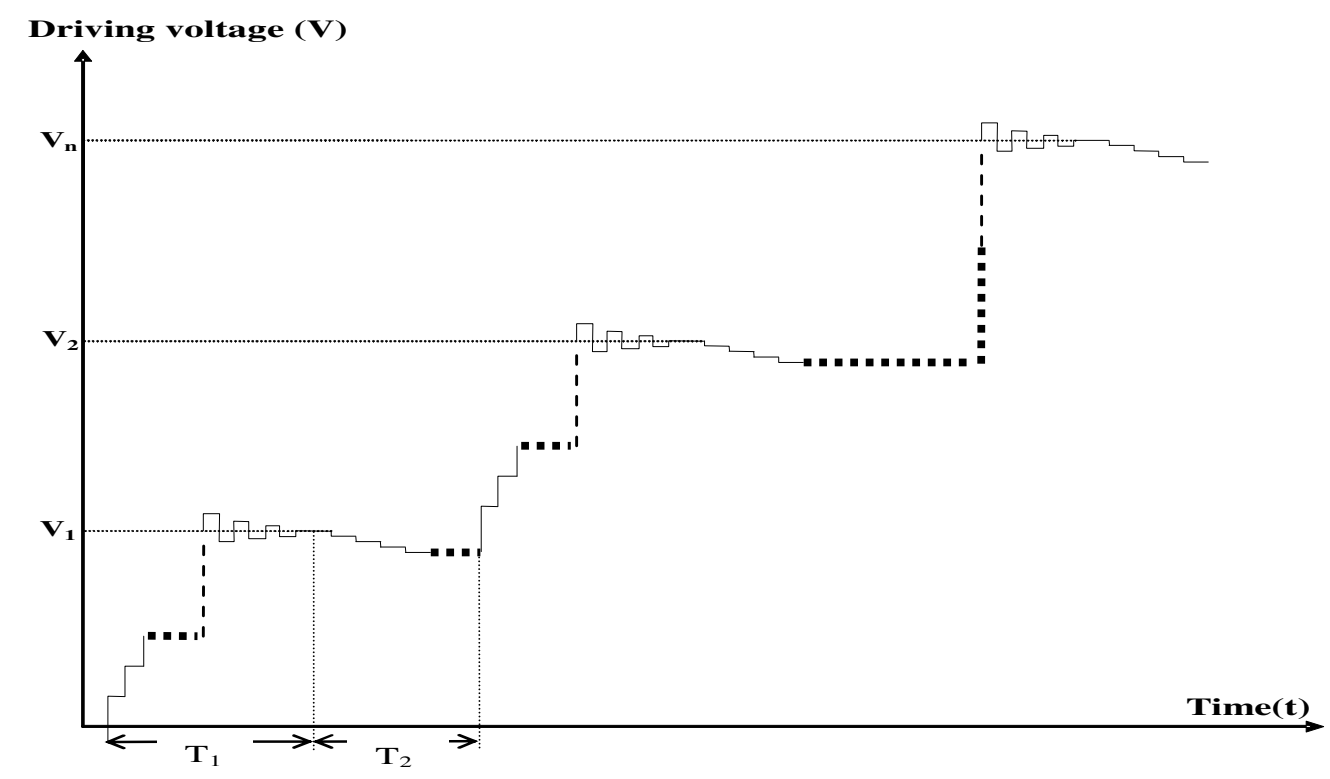

Figure 3.24 Driving Voltage vs. Time of Constant Load Multi-Partial Unloading Indentation Experiment 
In the first, the driving voltage will keep increasing until the load on the specimen achieves the target load. The driving voltage of the constant load represents as $\mathrm{V}_{1}, \mathrm{~V}_{2} \ldots . \mathrm{V}_{\mathrm{n}}$ in the Figure (3.24). $T_{1}$ is the settled time which includes the loading steps and the constant load closed-loop control adjustment. $\mathrm{T}_{2}$ is the time for unloading steps. To consider the response time of the PZT actuator and the load cell indicator, every driving voltage output with time delay $500 \mathrm{~ms}$ is required in the program. Once the constant load is set, the load and the corresponding displacement will be recorded. The following unloading procedures will then be performed in steps. Since the target of the unloading is to acquire the $\mathrm{dh} / \mathrm{dp}$, there is no constant load control during the unloading step. Every unloading step will have a record of its corresponding load and displacement to collect the unloading data for the slope. When the unloading is finished, the whole loading-unloading step is repeated until the number of target step is achieved.

The relationship of load-displacement curve can be described as shown in Figure (3.25). When the load reaches a constant load $\left(\mathrm{P}^{*}\right)$, an unloading will be performed.

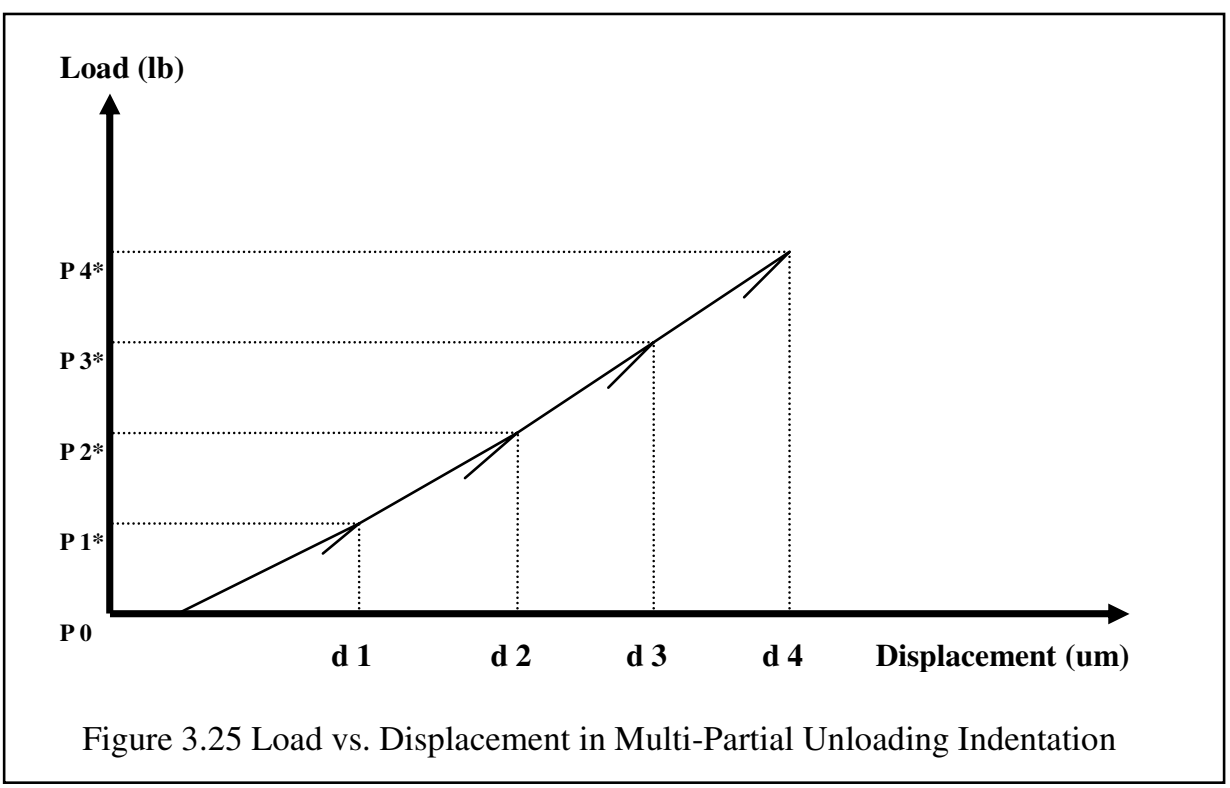


The program flowchart shows in Figure (3.26) while the example for program parameter setup shows in figure (3.27).

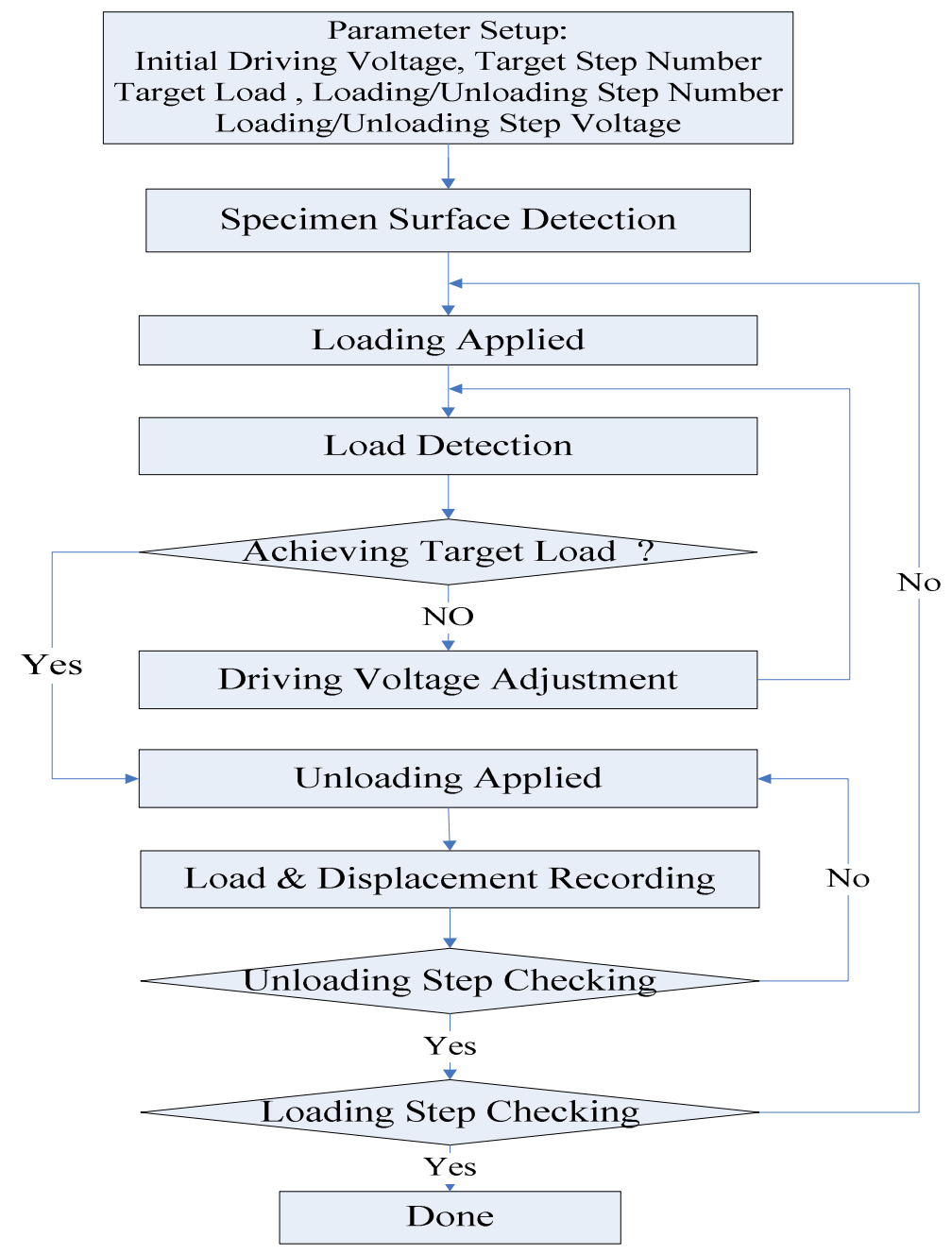

Figure 3.26 Load-Controlled Algorithm of Multi-Partial Unloading Indentation Flow Chart

Example for Multi-Partial Unloading Indentation Experiment Setup

120 travel range PZT and 100- $\mathrm{lb}$ load cell is used.

Assuming the maximum load is $60 \mathrm{lbs}$ and $10 \mathrm{lbs}$ as a single loading step. 
The target step number would be $60 \mathrm{lb} / 10 \mathrm{lb}=6$

Target load voltage

$$
\frac{10 \mathrm{lb}}{100 \mathrm{lb}}=\frac{x_{1}}{3 F F F} \longrightarrow \text { ADC full range hex data }
$$

$x_{2}=0666(\mathrm{H}) \rightarrow$ Target load hex parameter for $10 \mathrm{lbs}$

Assuming the loading step number is 10 ,

The every loading step would be approximately $10 \mathrm{lb} / 10=1 \mathrm{lb}$

For the proportional to DAC output,

The loading step voltage will be

$$
\frac{1 \mathrm{lb}}{100 \mathrm{lb}}=\frac{x_{2}}{F F F F} \longrightarrow \text { DAC full range hex data }
$$

$x_{2}=028 \mathrm{~F}(\mathrm{H}) \rightarrow$ DAC hex parameter setup for every loading step

(Since there is no constant load control during loading step, the load does not excatly equal $1 \mathrm{lb}$ )

Assuming unloading is $1 / 5$ of loading, the unloading will be approximately $10 \mathrm{lb} / 5=2$ (lb)

Assuming Unloading step number is 10 ,

The single unloading load will be approximately equals $2 / 10=0.2$ (lb)

$$
\frac{0.2 \mathrm{lb}}{100 \mathrm{lb}}=\frac{x_{3}}{F F F F} \longrightarrow \text { DAC full range hex data }
$$

$x_{3}=0083(\mathrm{H}) \rightarrow$ DAC hex parameter setup for single unloading step

(Since the $\mathrm{dh} / \mathrm{dp}$ is the purpose of unloding applied, there is no constant control during unloading. The single unloading step does not exactly equal $0.2 \mathrm{lbs}$.)

According to the example, the plot of driving voltage and time can be described as Figure (3.26)

The $\mathrm{V}_{1} *, \mathrm{~V}_{2} * \ldots \mathrm{V}_{6} *$ represent the voltage of constant load achievement. 


\section{Driving Voltage (Volt )}

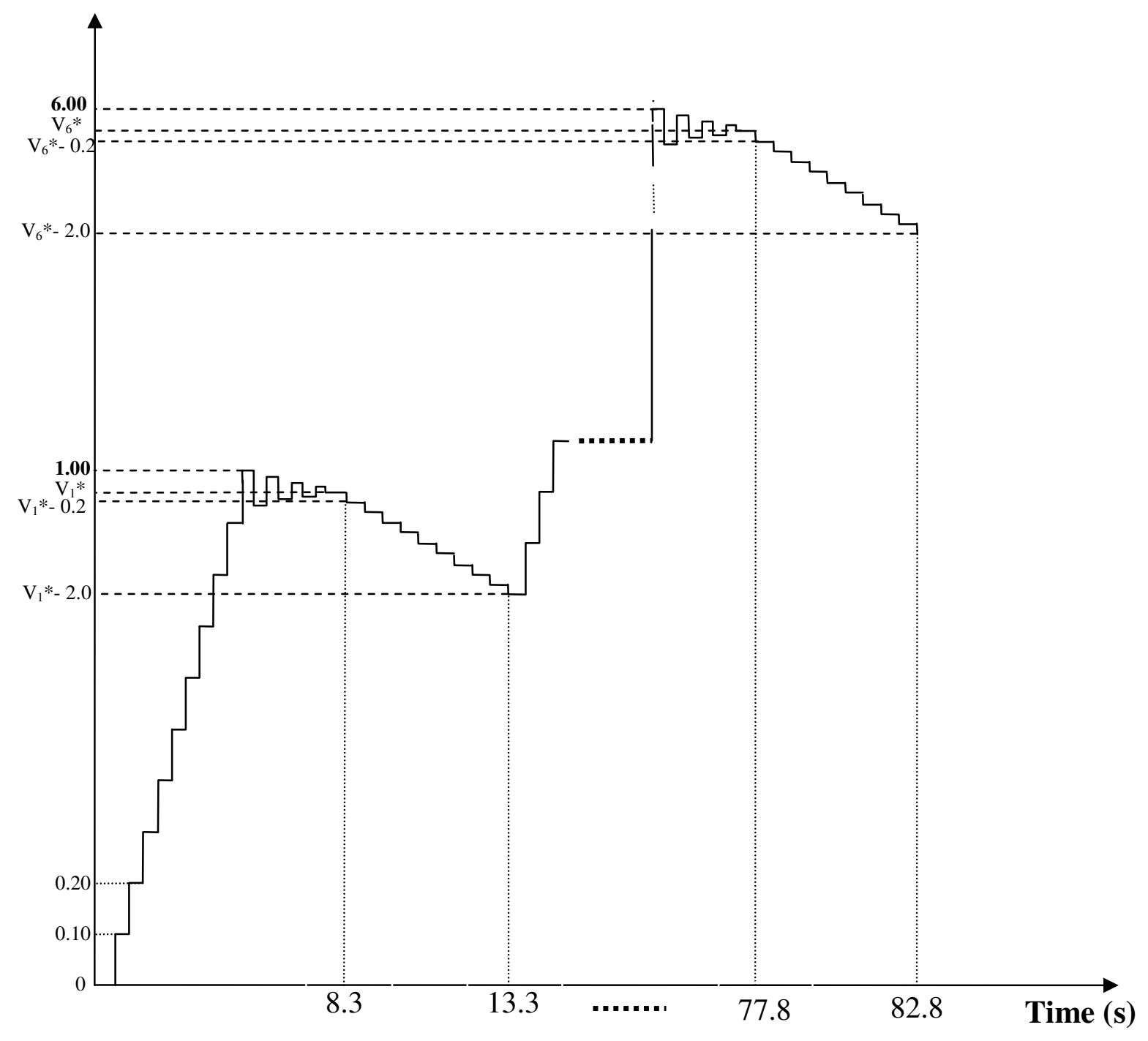

Figure 3.27 Driving Voltage vs. Time under Multi-Partial Unloading Indentation 


\section{CHAPTER 4}

\section{RESULTS AND DISCUSSION}

\subsection{Load Control Evaluation}

The functionality of the load control system can be verified by performing creep experiments. In room temperature, creep phenomenon can be demonstrated using solder materials with a time scale. $\mathrm{Sn}-37 \mathrm{~Pb}$ is the material used for the creep experiment since the homologous temperature is 0.42 under the room temperature. The material properties of $\mathrm{Sn}-37 \mathrm{~Pb}$ are shown in Figure (4.1) and (4.2) ${ }^{[23]}$.

\begin{tabular}{|l||l|l|}
\hline Property & Sn-3.5Ag & Sn-37Pb \\
\hline Melting Point, ${ }^{\circ} \mathrm{C}$ & 221 & $\mathbf{1 8 3}$ \\
\hline \hline Ultimate Tensile Strength, MPa & 55 & $\mathbf{3 1 - 4 6}$ \\
\hline Elongation, $\%$ & 35 & $\mathbf{3 5 - 1 7 6}$ \\
\hline Shear Strength, MPa & 32.1 & $\mathbf{2 8 . 4}$ \\
\hline Young's Modulus $\S, \mathrm{GPa}$ & $56 \S$ & $\mathbf{3 5} \S$ \\
\hline
\end{tabular}

Figure 4.1 Elastic Properties of Sn-37Pb (eutectic) and Sn-3.5Ag ${ }^{\text {[23] }}$

\begin{tabular}{|l|c|c|c|}
\hline \multirow{2}{*}{ Alloy } & \multicolumn{2}{c|}{ Norton } \\
\cline { 3 - 4 } \multicolumn{2}{c|}{} & Tensile & Creep \\
\hline Sn-3.5Ag & Q & 12 & 11.3 \\
\hline & $\mathbf{n}$ & 108.5 & 79.5 \\
\hline Sn-37Pb & $\mathbf{Q}$ & & $\mathbf{6 . 2}$ \\
\hline & $\mathbf{6 4}$ \\
\hline
\end{tabular}

Figure 4.2 Parameters for Strain Rate (Norton Equation, de/dt A. $\mathrm{s}^{\mathrm{n}} \cdot \exp (-\mathrm{Q} / \mathrm{RT})^{[23]}$ 
The following experiments present the load control function under $1.5 \mathrm{lbs}, 2.0 \mathrm{lbs}$, $2.5 \mathrm{lbs}$, and $3.0 \mathrm{lbs}$ applied load. Figure (4.3) to Figure (4.10) show the corresponding results. The 120 um travel range PZT actuator and the $5 \mathrm{lb}$-load cell is used.

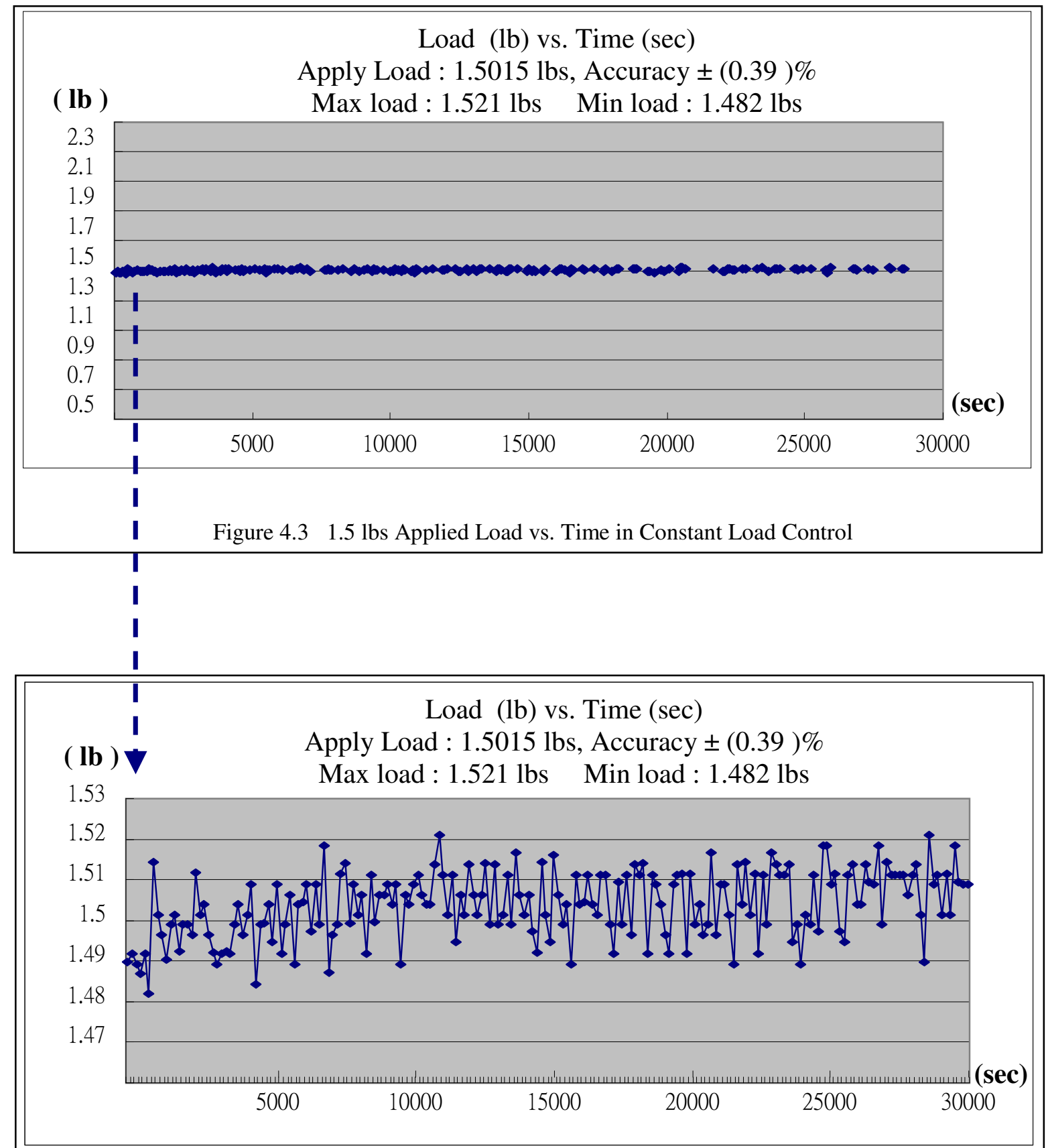

Figure 4.4 The Enlarge Plot of 1.5 lbs Applied Load vs. Time in Constant Load Control 


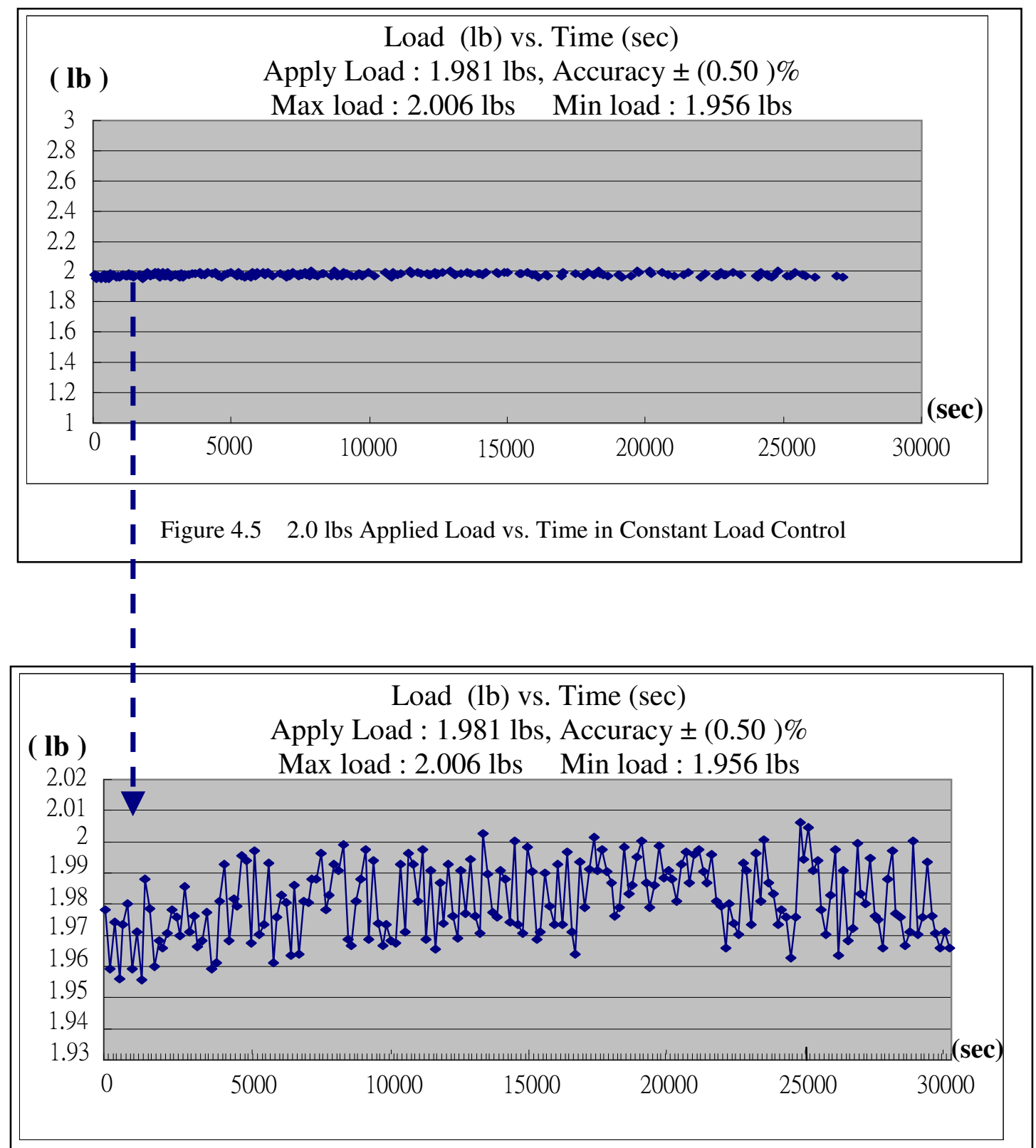

Figure 4.6 The Enlarge Plot of 2.0 lbs Applied Load vs. Time in Constant Load Control 


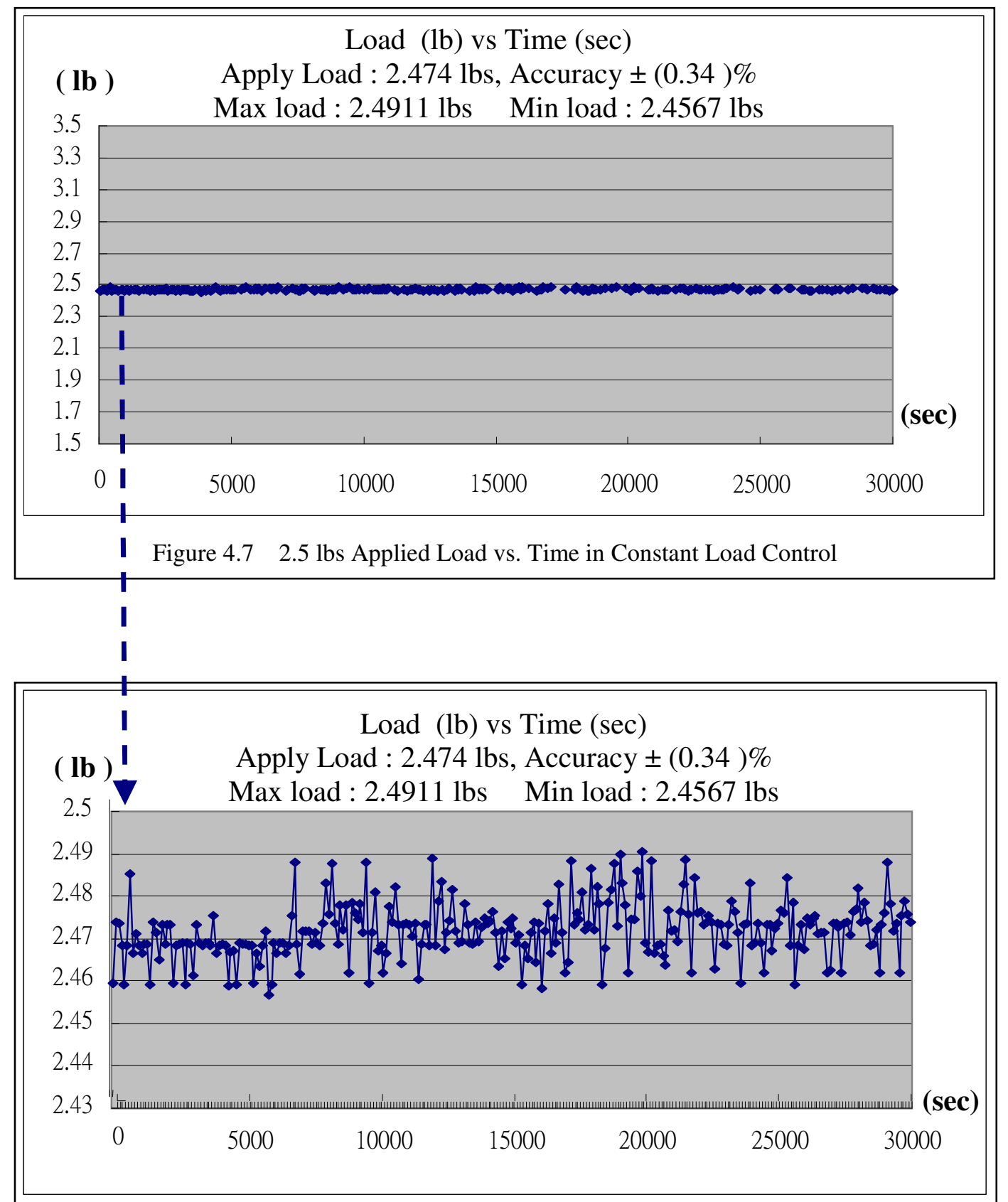

Figure 4.8 The Enlarge Plot of 2.5 lbs Applied Load vs. Time in Constant Load Control 


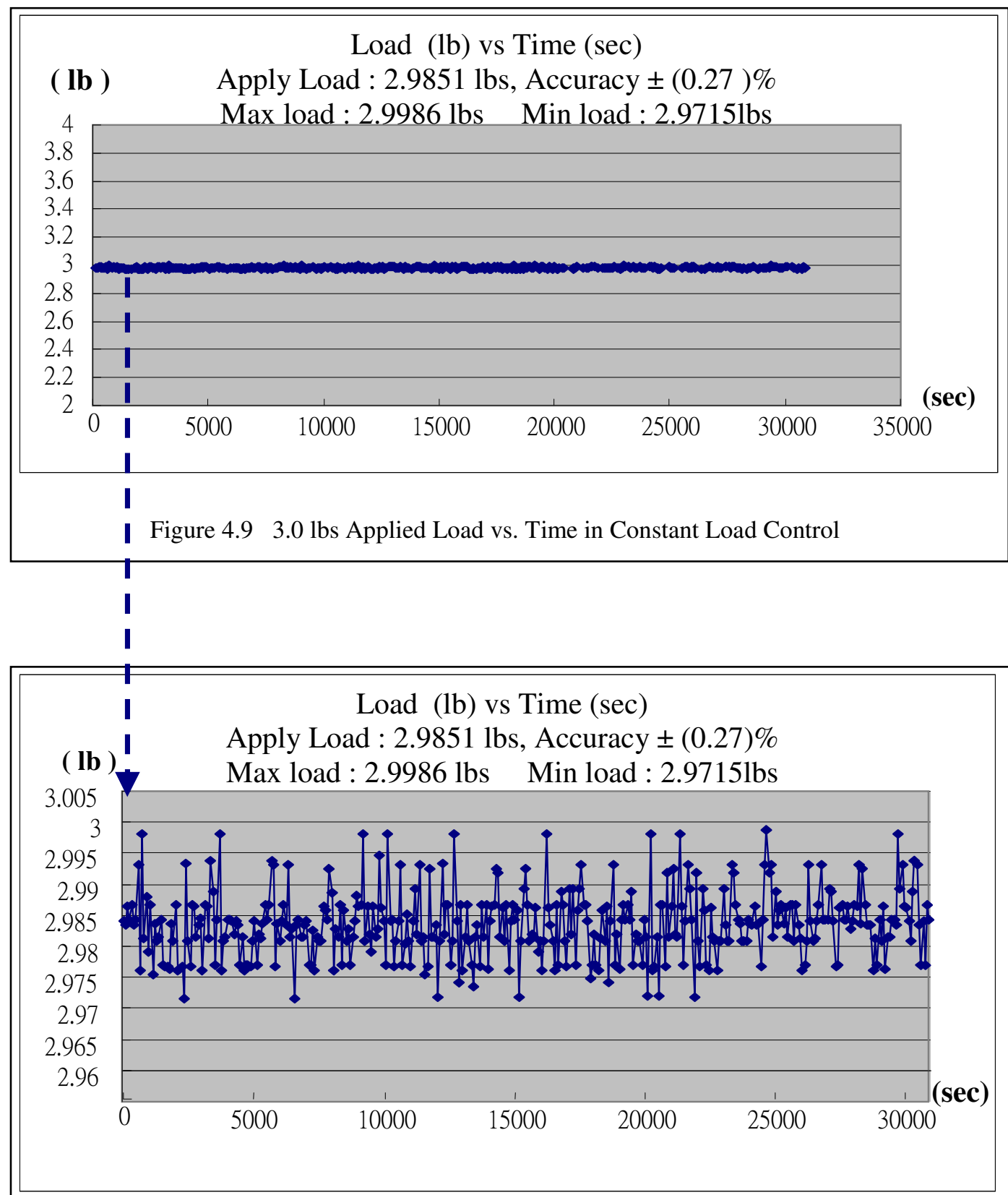

Figure 4.10 The Enlarge Plot of 3.0 lbs Applied Load vs. Time in Constant Load Control

The operative time of creep experiments is set to about 30,000 seconds. From the experimental verification of the load control method, the accuracy lies within $\pm 0.39 \%$ under $1.5 \mathrm{lbs}$ applied load, $\pm 0.5 \%$ under $2.0 \mathrm{lbs}$ applied load, $\pm 0.344 \%$ under $2.5 \mathrm{lbs}$ 
applied load, and $\pm 0.271 \%$ under $3.0 \mathrm{lbs}$ applied load. These results indicate the closedloop control algorithm can successfully achieve constant load control with a minimum accuracy of $\pm 0.5 \%$.

\subsection{Stress Exponent Measurement}

The strain rate of $\mathrm{Sn}-37 \mathrm{~Pb}$ can be derived from the displacement-time curve depicted in Figure (4.11). The following analysis illustrates the methodology. The displacement represented in the graph is the real indentation depth, which is the initial displacement subtracted from the measured displacement.

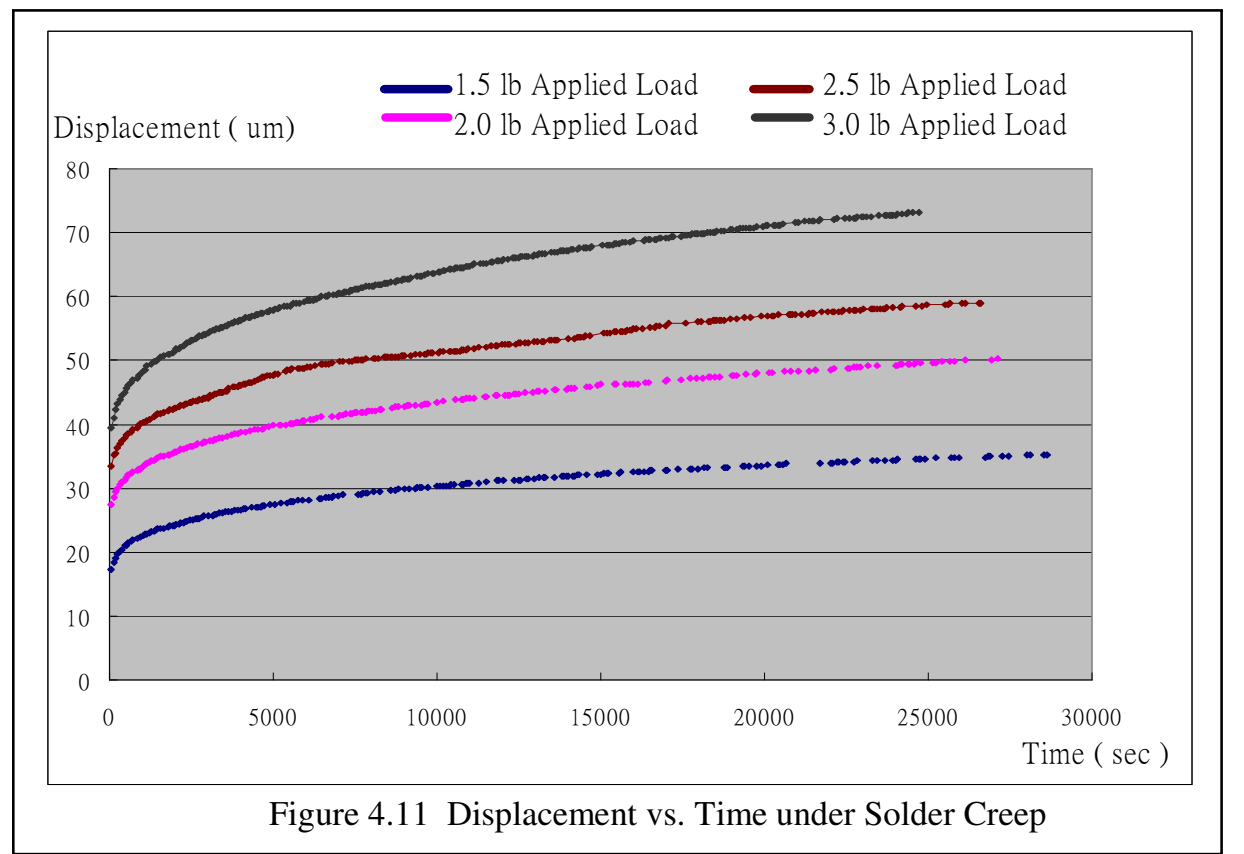

Displacement can then be converted to contact radius by the following equations:

$$
\frac{a}{D}=c * \sqrt{\frac{h p}{D}}=>a=c * \sqrt{\frac{h p}{D}}
$$

Where a is contact radius, $\mathrm{D}$ is indenter diameter, $\mathrm{C}$ is $\sqrt{2}$ (for Hertzian Elastic case), and hp is depth of indentation 
The curve of contact radius versus time is shown in Figure (4. 12)

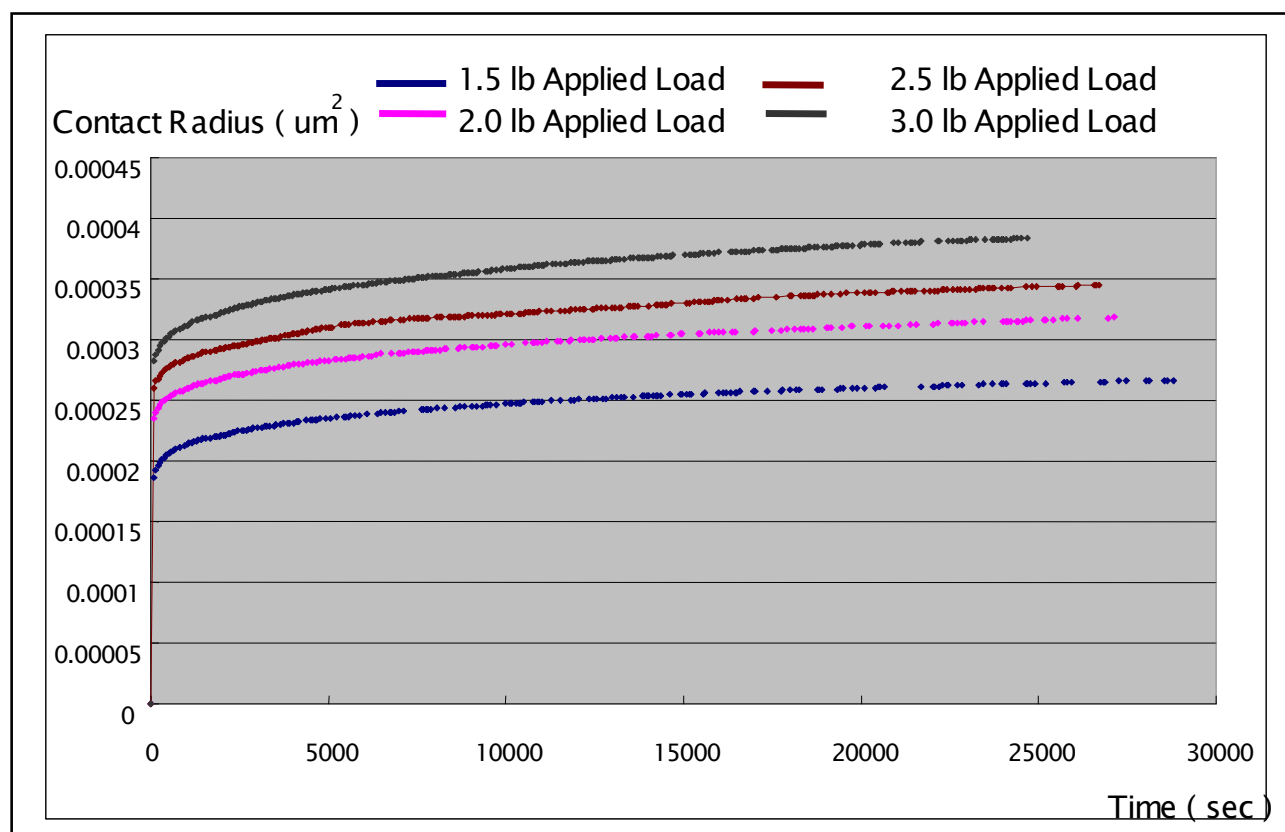

Figure 4.12 Contact Radiuses vs. Time under Solder Creep

From Tabor's empirical relation formula (4.2-2), $\varepsilon$ versus time can be described as:

$$
\varepsilon=0.2 \frac{a}{D}
$$

The valid data range is those greater than $3 \%$ of strain. Therefore, it is more efficient to use the data range after 5,000 seconds. The valid data range for the curve is shown in Figure (4.13). 


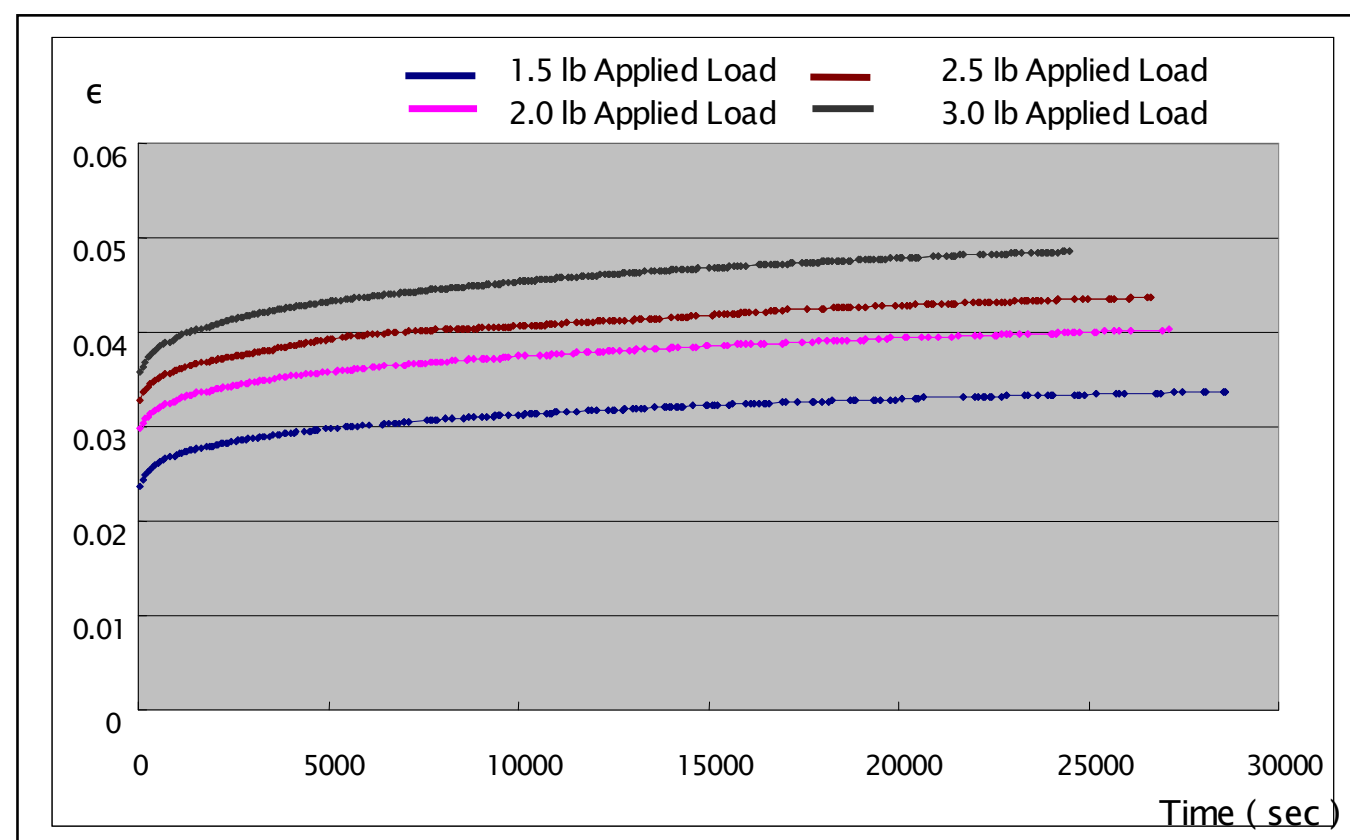

Figure 4.13 Strains vs. Time under Solder Creep

From the strain time curve, the relationship of strain and time is known as following formula:

$$
\begin{gathered}
\varepsilon=\varepsilon_{0} \mathrm{t}^{\mathrm{m}} \\
\rightarrow \log (\varepsilon)=\log \left(\varepsilon_{0}\right)+\mathrm{m}^{*} \log (\mathrm{t}) \\
\rightarrow \quad m=\frac{\log (\varepsilon)-\log \left(\varepsilon_{0}\right)}{\log (t)}
\end{gathered}
$$

m can derived from the plot $\log (\mathrm{t})$ and $\log (\varepsilon)$, which is shown in Figure (4.14).

Where,

$\mathbf{m}=0.0723$ for $1.5 \mathrm{lbs}$ applied load, $\mathbf{m}=0.0725$ for $2.0 \mathrm{lbs}$ applied load, $\mathbf{m}=0.0724$ for $2.5 \mathrm{lbs}$ applied load and $\mathbf{m}=0.0767$ for $3.0 \mathrm{lbs}$ applied load. 


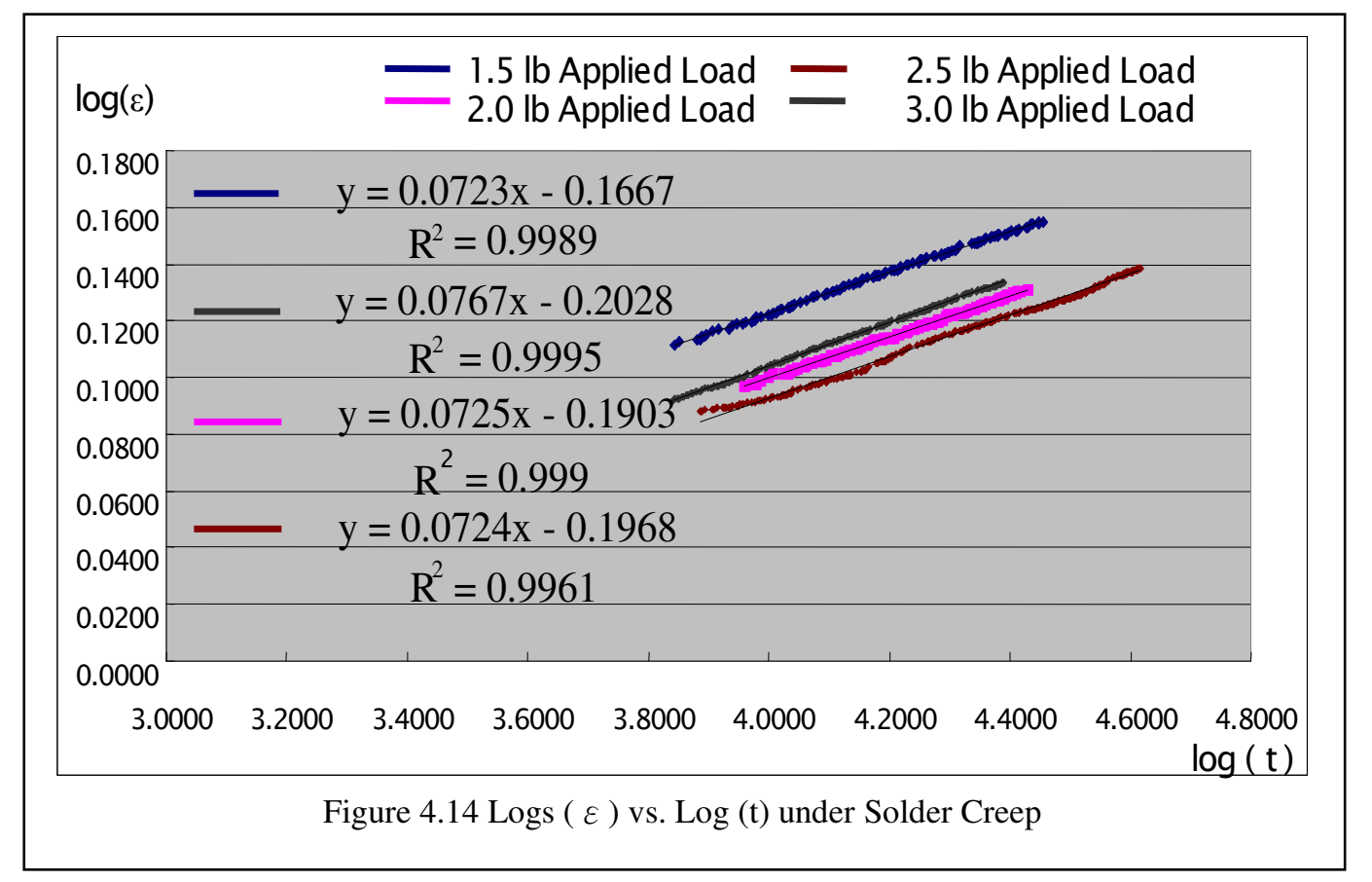

Myer's stress formula, $\sigma=\frac{P}{c * \pi * a^{2}}$, is used to obtain the stress value.

Where $\sigma$ is stress, $\mathrm{P}$ is applied load, c equals correction term 2.8, a is contact radius,

$$
\begin{aligned}
& \dot{\mathcal{\varepsilon}}=\varepsilon_{0} * m * t^{m-1}=A \sigma^{N} \\
\rightarrow \quad & \log (\dot{\varepsilon})=\log \left(\varepsilon_{0} * m * t^{m-1}\right)=\log (A)+N * \log (\sigma) \\
\rightarrow \quad & N=\frac{\left[\log \left(\varepsilon_{0} * m * t^{m-1}\right)-\log (A)\right]}{\log (\sigma)}
\end{aligned}
$$

Figure (4.15) shows the plot of $\log (\sigma)$ versus $\log \left(\varepsilon_{0} * \mathrm{~m} * \mathrm{t}^{\mathrm{m}-1}\right)$, and $\mathrm{N}$ can be derived by the slope. 


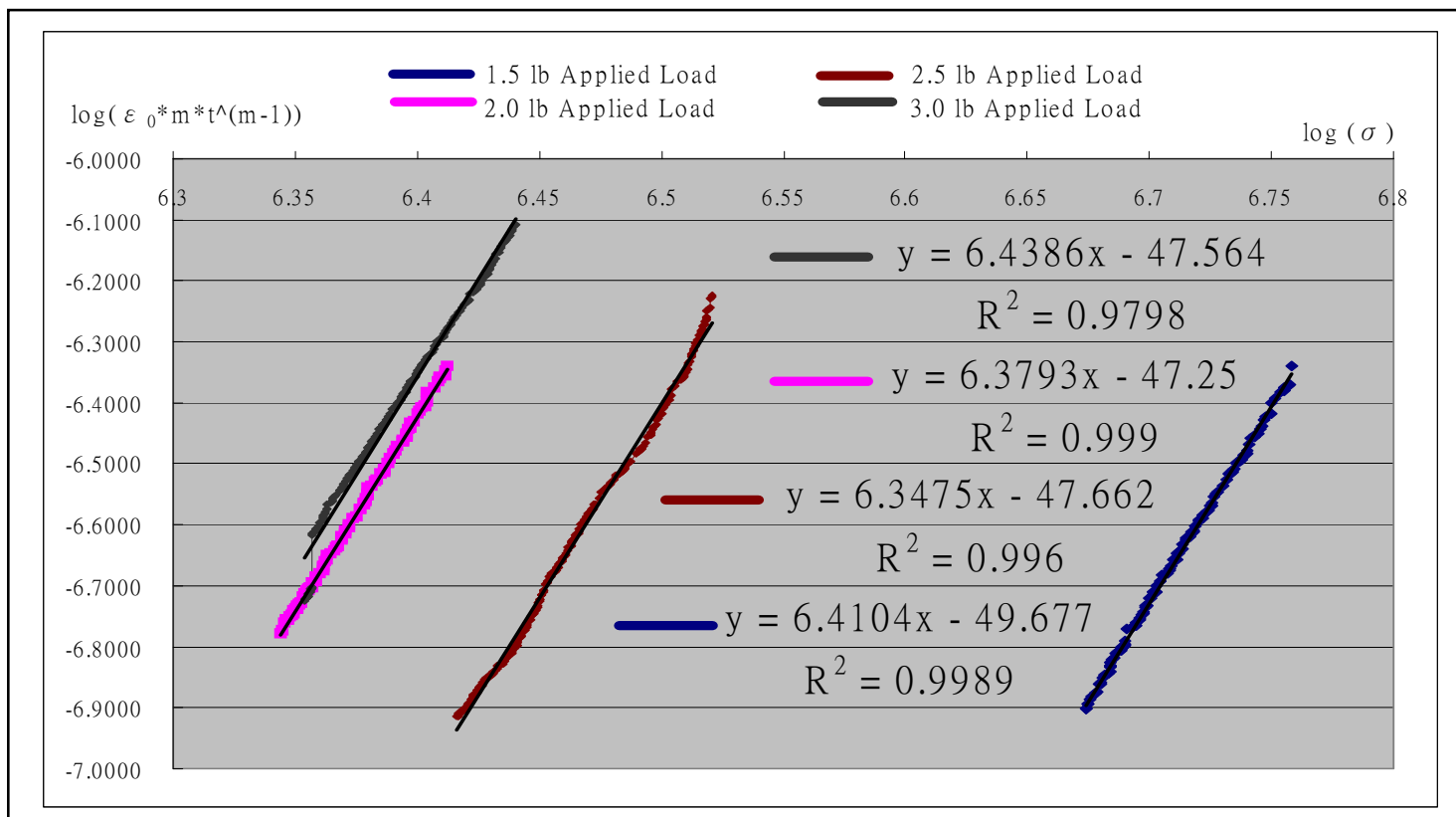

Figure 4.15 Plot of $\log (\varepsilon)$ vs. $\log (\sigma)$

The average stress exponent is equal to $6.394 \pm 0.7124 \%$, and the comparison is demonstrated in Table (4.16). The accuracy lies in $3.129 \%$.

\begin{tabular}{|c|c|c|c|c|}
\hline \multicolumn{1}{|c||}{ Alloy Sn-37Pb } & \multicolumn{5}{|c|}{ Stress Exponent (n) Under Creep Test } \\
\hline Book Value $^{[23]}$ & \multicolumn{4}{|c|}{6.2} \\
\hline Experiment Value & 6.4386 & 6.3793 & 6.3475 & 6.4104 \\
\hline Average Experiment Value & \multicolumn{5}{|c|}{6.394} \\
\hline
\end{tabular}

Figure 4.16 The Stress Exponent Comparison of Book Value and Experiment Value for $\mathrm{Sn}-37 \mathrm{~Pb}$ under Creep Test. 


\subsection{Young's Modulus Measurement}

Aluminum and steel are the specimens used for the verification of the load control multiple partial unloading indentation method. The elastic properties of aluminum, steel and selected engineering materials are shown in Figure (4.17). ${ }^{[24]}$

\begin{tabular}{|c|c|c|c|c|}
\hline Material & $\begin{array}{l}\text { Density } \\
\left(\mathrm{kg} / \mathrm{m}^{3}\right)\end{array}$ & $\begin{array}{l}\text { Young's Modulus } \\
\qquad 10^{9} \mathrm{~N} / \mathrm{m}^{2}\end{array}$ & $\begin{array}{l}\text { Ultimate Strength } \mathrm{S}_{\mathrm{u}} \\
\qquad 10^{6} \mathrm{~N} / \mathrm{m}^{2}\end{array}$ & $\begin{array}{l}\text { Yield Strength } S_{y} \\
\qquad 10^{6} \mathrm{~N} / \mathrm{m}^{2}\end{array}$ \\
\hline Steel & 7860 & 200 & 400 & 250 \\
\hline Aluminum & 2710 & 70 & 110 & 95 \\
\hline Glass & 2190 & 65 & 50 & $\ldots$ \\
\hline Concrete $^{c}$ & 2320 & 30 & 40 & $\ldots$ \\
\hline Wood $^{\text {d }}$ & 525 & 13 & 50 & $\ldots$ \\
\hline Bone & 1900 & 9 & 170 & $\ldots$ \\
\hline Polystyrene & 1050 & 3 & 48 & $\ldots$ \\
\hline
\end{tabular}

Figure 4.17 Elastic Properties of Selected Engineering Materials ${ }^{[24]}$

A 120 um travel range PZT actuator and a $100 \mathrm{lb}$ load cell are used in the experiment. Before performing the indentation test, a small applied load was set to establish the initial contatct. The parameter setup and the corresponding process graph are manifested in Figure (4.18). 


\begin{tabular}{|c|c|c|c|c|c|c|c|}
\hline \multirow{2}{*}{} & \multicolumn{7}{|c|}{ Aluminum } \\
\cline { 2 - 8 } & $\begin{array}{c}\text { Initial } \\
\text { load }\end{array}$ & $\begin{array}{c}\text { Loading } \\
\text { step }\end{array}$ & Loading & Max load & $\begin{array}{c}\text { Unloading } \\
\text { Step }\end{array}$ & Unloading & $\begin{array}{c}\text { Total } \\
\text { Unloading }\end{array}$ \\
\hline Parameter (lb) & 10 & 5 & 5 & 30 & 25 & 0.1 & 2.5 \\
\hline Parameter (N) & 44.8 & & 22.24 & 133.44 & & 0.4448 & 11.12 \\
\hline
\end{tabular}

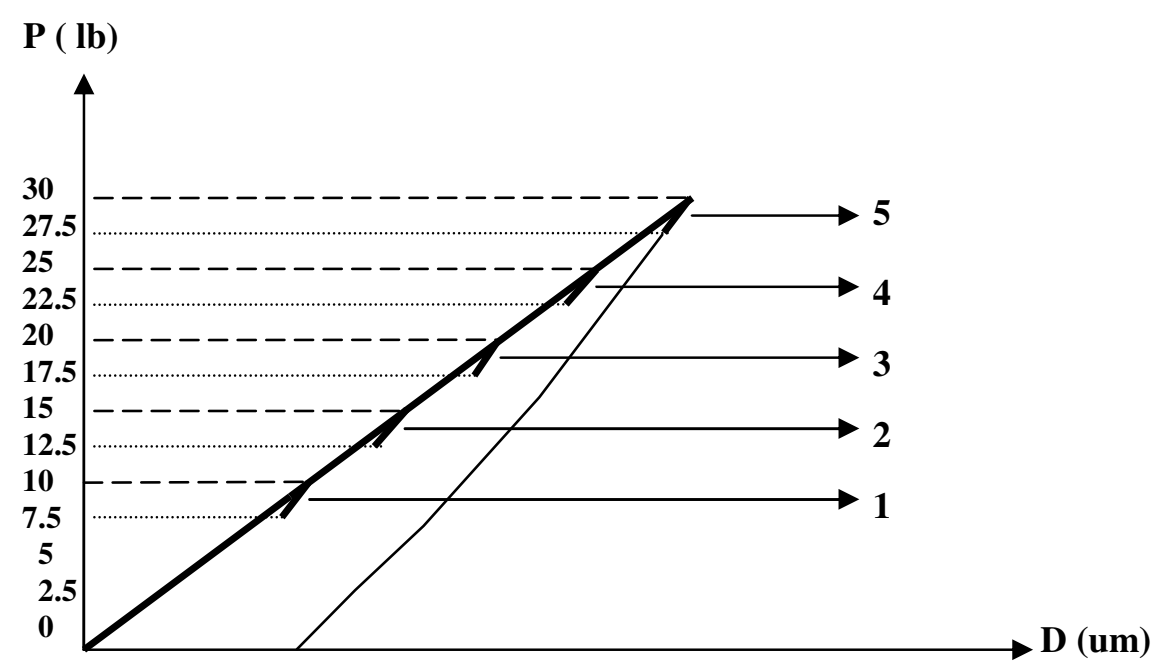

Figure 4.18 Parameter and Process setup for Aluminum Multi-Partial Unloading Indentation Algorithm

The slopes obtained from the unloading curve represent dh/dp. Figures (4.19) to (4.23) illustrate each corresponding unloading curve.

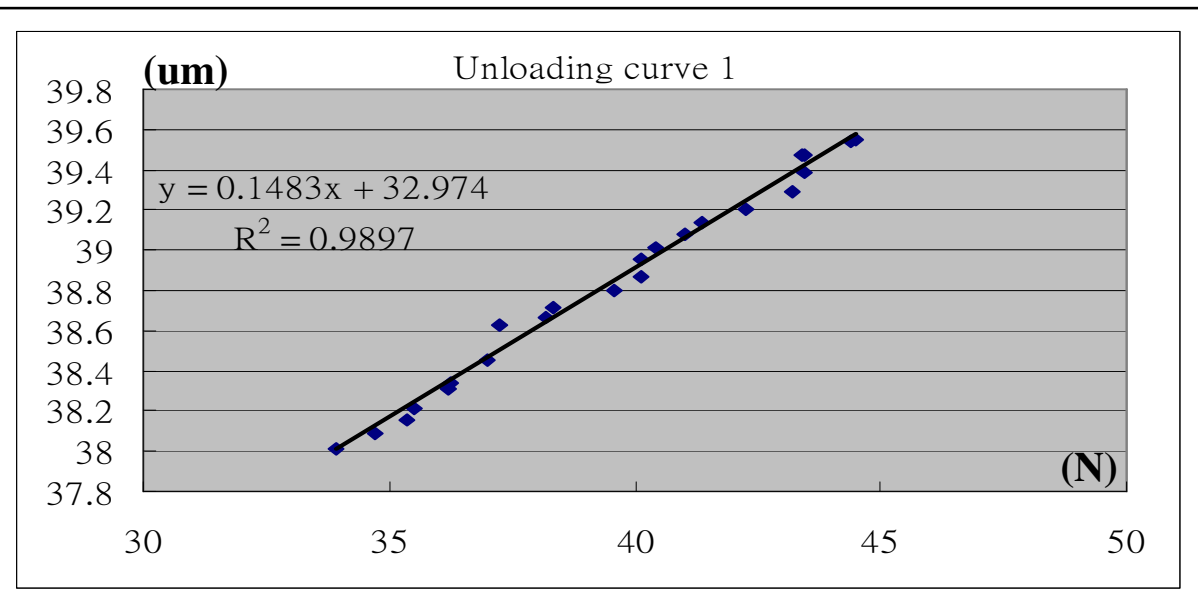

Figure 4.19 The First Unloading Curve which $\mathrm{dh} / \mathrm{dp}=0.1483$ 


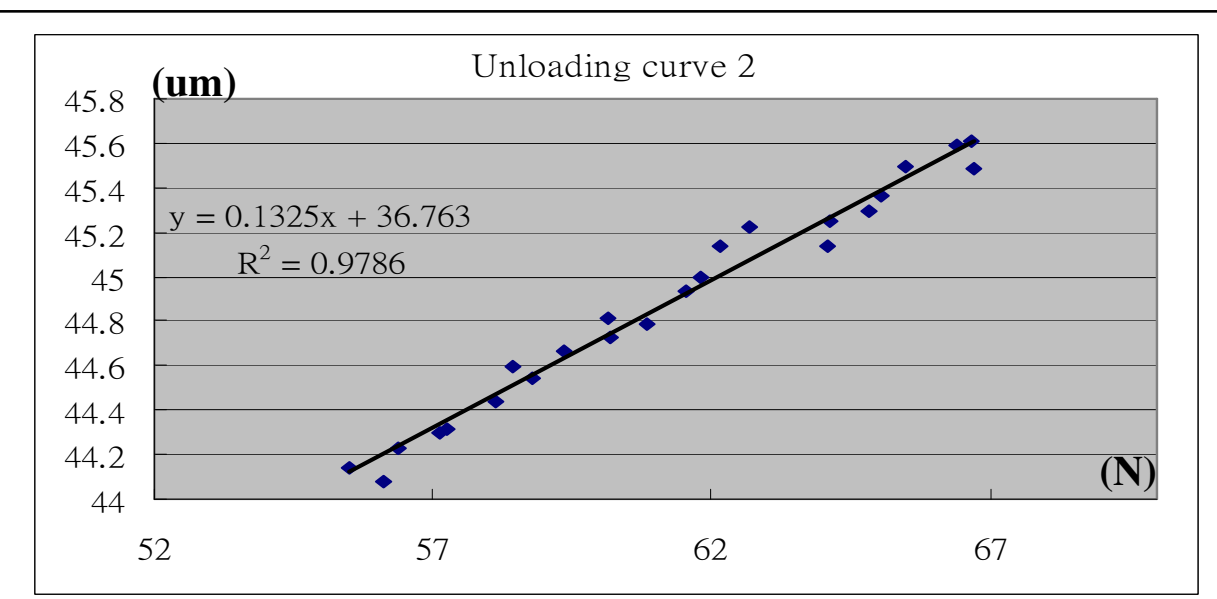

Figure 4.20 The Second Unloading Curve which $\mathrm{dh} / \mathrm{dp}=0.1325$

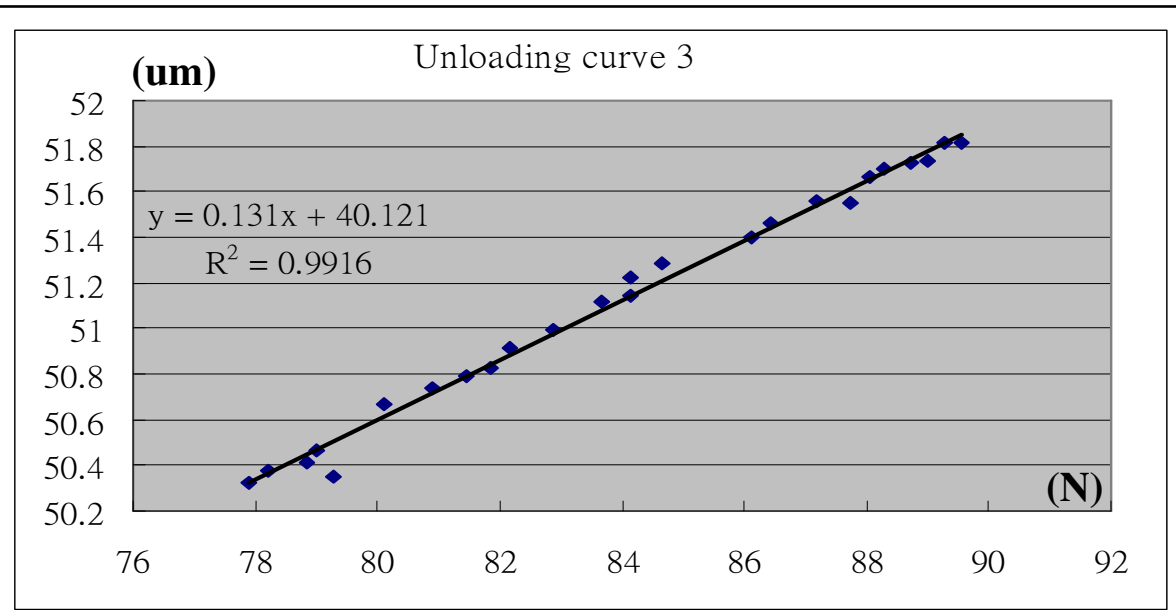

Figure 4.21 The Third Unloading Curve which $\mathrm{dh} / \mathrm{dp}=0.131$

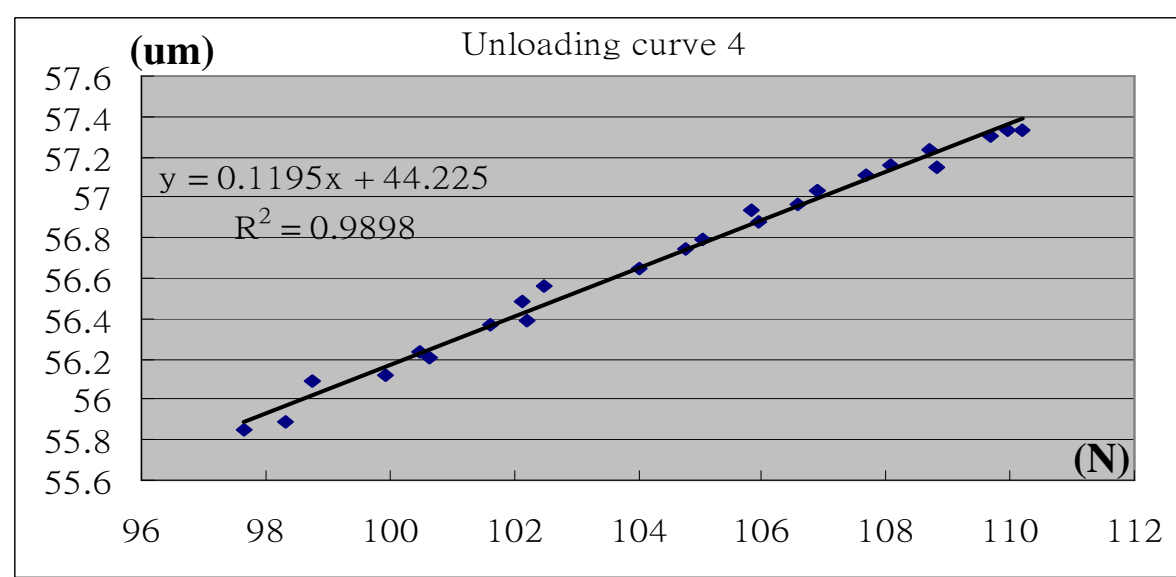

Figure 4.22 The Fourth Unloading Curve which $\mathrm{dh} / \mathrm{dp}=0.1195$ 


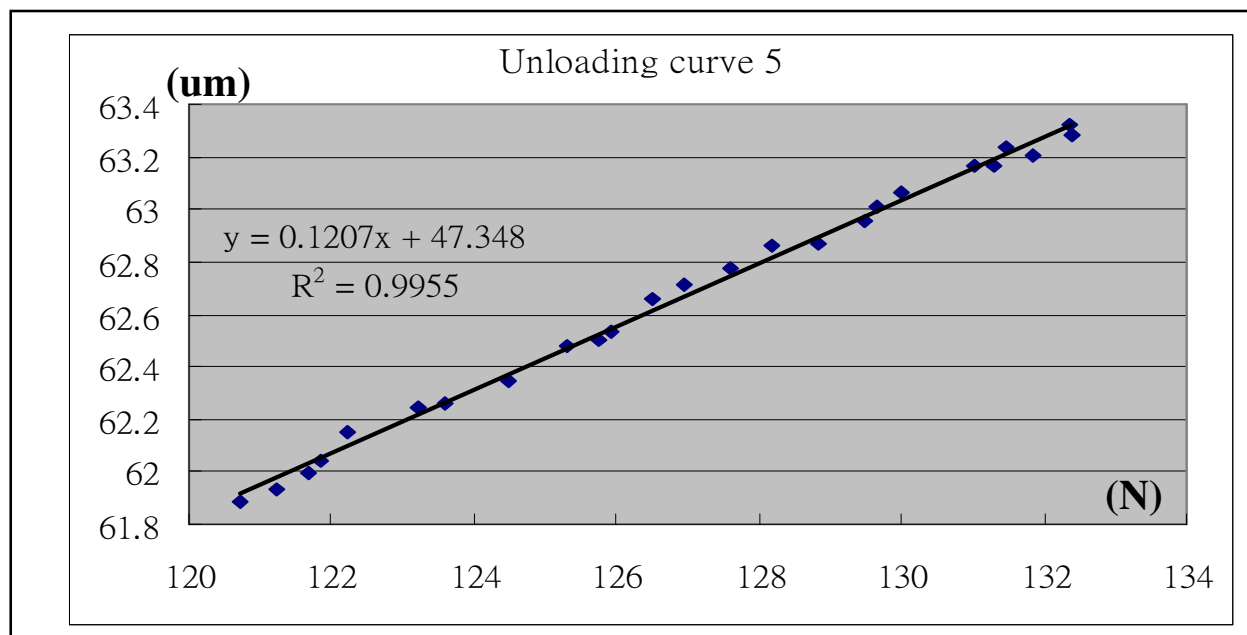

Figure 4.23 The Fifth Unloading Curve Which dh/dp $=0.1207$

Each unloading slope represents a dh/dp data. As illustrated in Figure (4.24), slope $\mathrm{C}$ can be derived from the curve of $\mathrm{dh} / \mathrm{dp}$ and the corresponding constant load $\mathrm{P}^{-(1 / 3)}$.

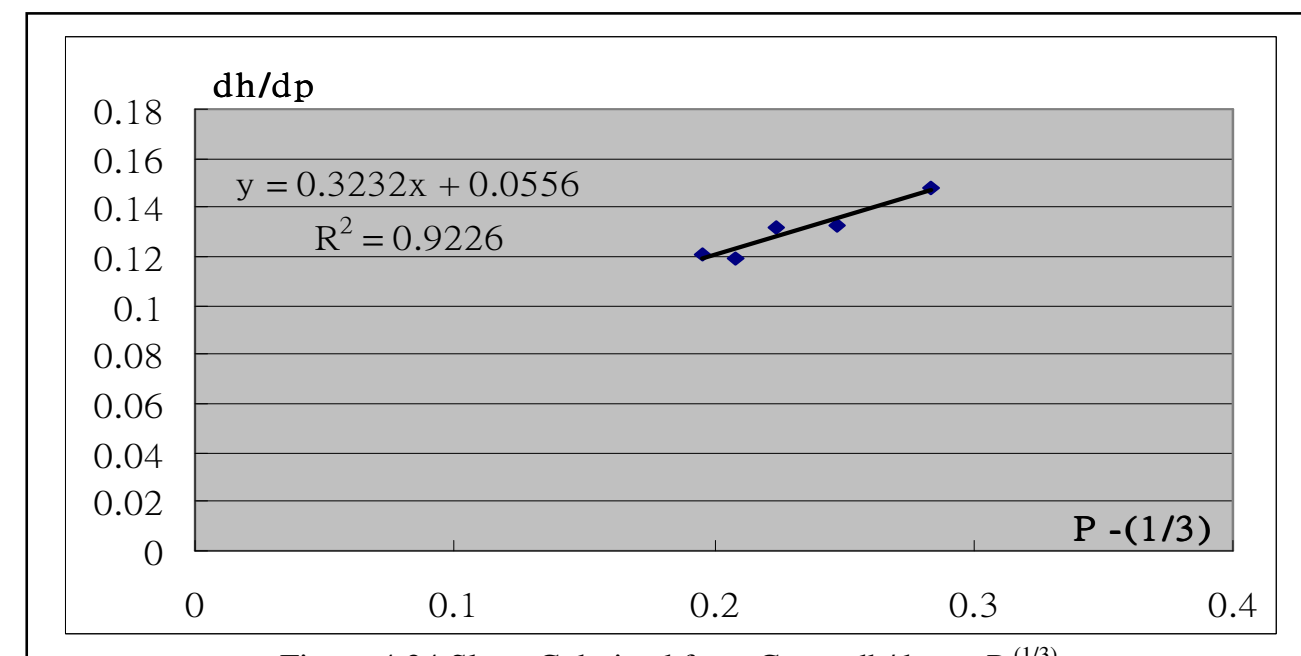

Figure 4.24 Slope C derived from Curve dh/dp vs. $\mathrm{P}^{-(1 / 3)}$

From equation (2.2-6) $\frac{d h_{0}}{d p}=\left(6 R E_{\exp }{ }^{2}\right)^{\frac{-1}{3}}\left(p^{\frac{-1}{3}}\right)=C\left(p^{\frac{-1}{3}}\right)$

$$
E_{\text {exp }}=\sqrt{\frac{C^{-3}}{6 R}} \quad, \quad E_{\text {exp }}=\sqrt{\frac{0.3232^{-3}}{6 * 793.75}} \quad, \quad E_{\exp }=0.078863
$$


Assume v=0.3, $E_{0}=0.7, v_{0}=0.26$ (for tungsten carbide indenter)

Young's Modulus derived from the following equation: $\quad E=\frac{1-v^{2}}{\frac{1}{E_{\exp }}-\frac{1-v_{0}^{2}}{E_{0}}}$

Therefore, $\quad E=\frac{1-0.3^{2}}{\frac{1}{0.078863}-\frac{1-0.26^{2}}{0.7}}=0.0802 \mathrm{GPa}$

Figure 4.25 shows the first result of Young's Modulus for Aluminum.

\begin{tabular}{|c|c|c|c|c|}
\hline \multicolumn{5}{|c|}{ Aluminum } \\
\hline Test1 & $\mathbf{P}^{-(1 / 3)}$ & $\mathbf{d h} / \mathbf{d p}$ & $\mathbf{C}$ & E (MPa) \\
\cline { 1 - 3 } Unloading curve 1 & 0.2832 & 0.1483 & & \\
\cline { 1 - 3 } Unloading curve 2 & 0.2474 & 0.1325 & & \multirow{2}{*}{0.3232} \\
\cline { 1 - 3 } Unloading curve 3 & 0.2236 & 0.1318 & & \\
\cline { 1 - 3 } Unloading curve 4 & 0.2087 & 0.1195 & & \\
\cline { 1 - 3 } Unloading curve 5 & 0.1960 & 0.1207 & & \\
\hline
\end{tabular}

Figure 4.25 The Result of Multi-Partial Unloading Indentation for Test1

A total of 4 sets of indentation testing were done using Aluminum, and the experiment results are presented in Figure (4.26), (4.27), and (4.28). 


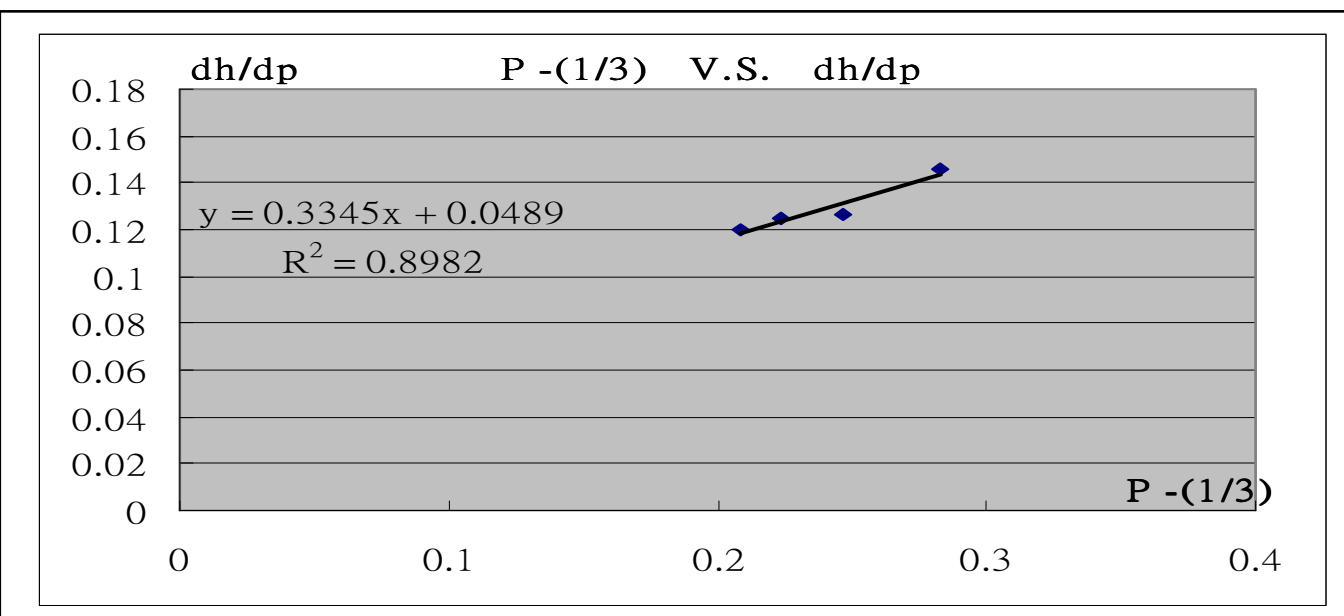

\begin{tabular}{|c|c|c|c|c|}
\hline \multicolumn{5}{|c|}{ Aluminum } \\
\hline Test 2 & $P^{-(1 / 3)}$ & dh/dp & $\mathbf{C}$ & E (MPa) \\
\hline Unloading curve 1 & 0.2828 & 0.146 & \multirow{4}{*}{0.3345} & \multirow{4}{*}{0.0757} \\
\hline Unloading curve 2 & 0.2471 & 0.1261 & & \\
\hline Unloading curve 3 & 0.2237 & 0.1252 & & \\
\hline Unloading curve 4 & 0.2081 & 0.1199 & & \\
\hline
\end{tabular}

Figure 4.26 The Result of Multi-Partial Unloading Indentation for Test2

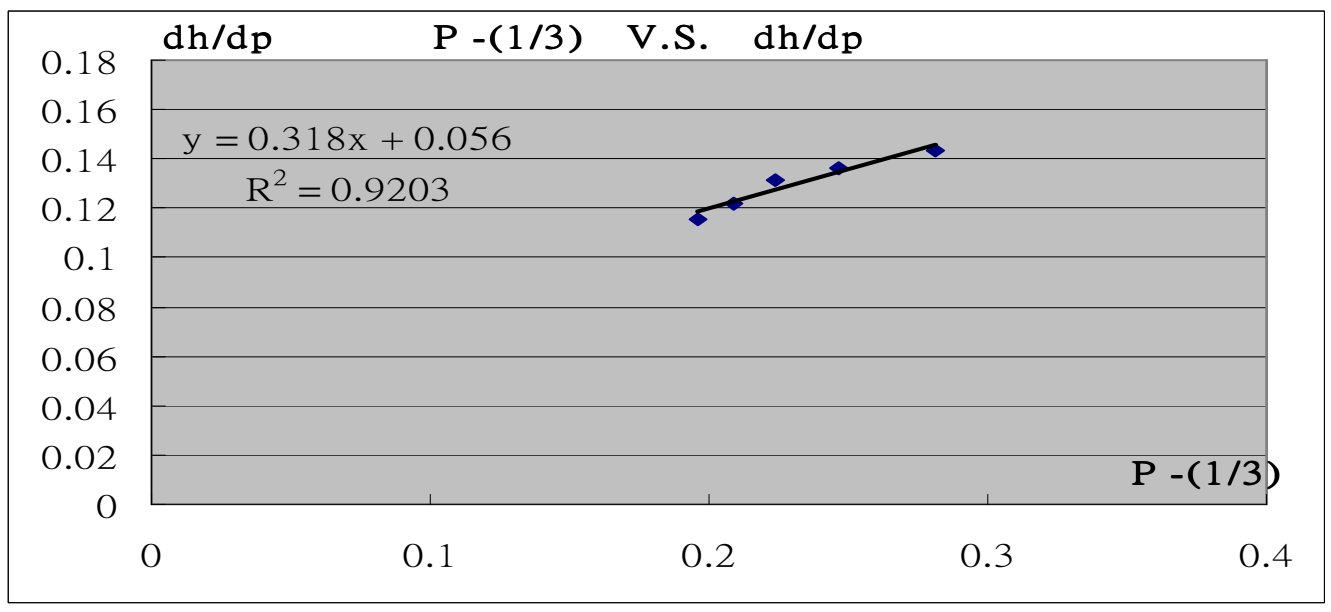

\begin{tabular}{|c|c|c|c|c|}
\hline \multicolumn{5}{|c|}{ Aluminum } \\
\hline Test 3 & $\mathbf{P}^{-(1 / 3)}$ & dh/dp & C & E (MPa) \\
\hline Unloading curve 1 & 0.2814 & 0.1431 & & \\
Unloading curve 2 & 0.2470 & 0.1362 & \multirow{2}{*}{0.318} & \multirow{2}{*}{0.0824} \\
\hline Unloading curve 3 & 0.2239 & 0.1318 & & \\
\cline { 1 - 3 } Unloading curve 4 & 0.2090 & 0.1216 & & \\
\hline Unloading curve 5 & 0.1961 & 0.1153 & & \\
\hline
\end{tabular}

Figure 4.27 The Result of Multi-Partial Unloading Indentation for Test3 


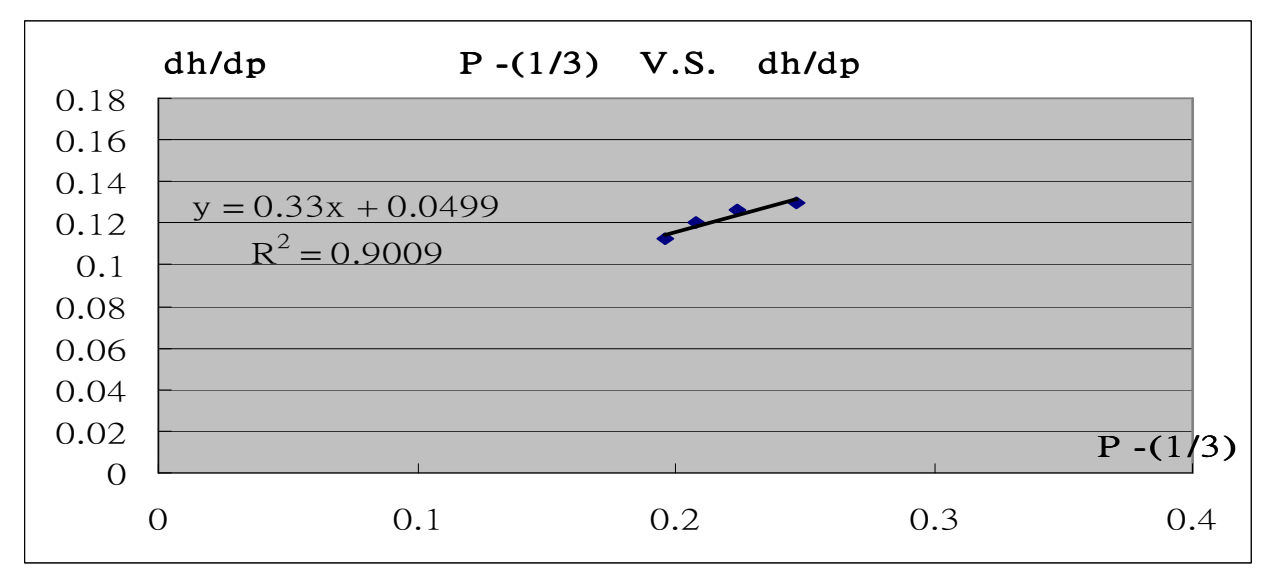

\begin{tabular}{|c|c|c|c|c|}
\hline \multicolumn{5}{|c|}{ Aluminum } \\
\hline Test 4 & $\mathbf{P}^{-(1 / 3)}$ & dh/dp & C & E (MPa) \\
\hline Unloading curve 1 & 0.2465 & 0.1295 & \multirow{4}{*}{0.33} & \multirow{4}{*}{0.0774} \\
\hline Unloading curve 2 & 0.2237 & 0.1261 & & \\
\hline Unloading curve 3 & 0.2082 & 0.1202 & & \\
\hline Unloading curve 4 & 0.1963 & 0.1123 & & \\
\hline
\end{tabular}

Figure 4.28 The Result of Multi-Partial Unloading Indentation for Test4

The average experiment result of Young's modulus for Aluminum is calculated as follows:

$(0.0802+0.0757+0.0824+0.0774) / 4=0.0789(\mathrm{MPa})=78.94 \pm 4.24 \%(\mathrm{GPa})$. Aluminum

Young's modulus comparison of book value and experiment value shows in Table (4.29).

\begin{tabular}{|c|c|c|c|c|}
\hline Aluminum $^{\mid}$ & \multicolumn{4}{|c|}{ Young's Modulus (E) MPa } \\
\hline Book Value $^{[24]}$ & \multicolumn{4}{|c|}{70} \\
\hline Experiment Value $^{24}$ & 80.2 & 75.71 & 82.4 & 77.44 \\
\hline
\end{tabular}

Table 4.29 Comparison Young's Modulus of Book Value and Experiment Result for Aluminum Indentation Test.

For steel, 2 repeat indentation testing were done. Figure (4.30) manifests the process and parameter. 


\begin{tabular}{|c|c|c|c|c|c|c|c|}
\hline & \multicolumn{2}{|c|}{ Steel } \\
\cline { 2 - 4 } & $\begin{array}{c}\text { Initial } \\
\text { load }\end{array}$ & $\begin{array}{c}\text { Loading } \\
\text { step }\end{array}$ & Loading & Max load & $\begin{array}{c}\text { Unloading } \\
\text { Step }\end{array}$ & Unloading & $\begin{array}{c}\text { Total } \\
\text { Unloading }\end{array}$ \\
\hline Parameter_1 (lb) & 3 & \multirow{2}{*}{10} & 3 & 30 & & 0.1 & 2.1 \\
\cline { 1 - 4 } & & & 13.344 & 133.440 & 21 & 0.448 & 9.341 \\
\hline
\end{tabular}

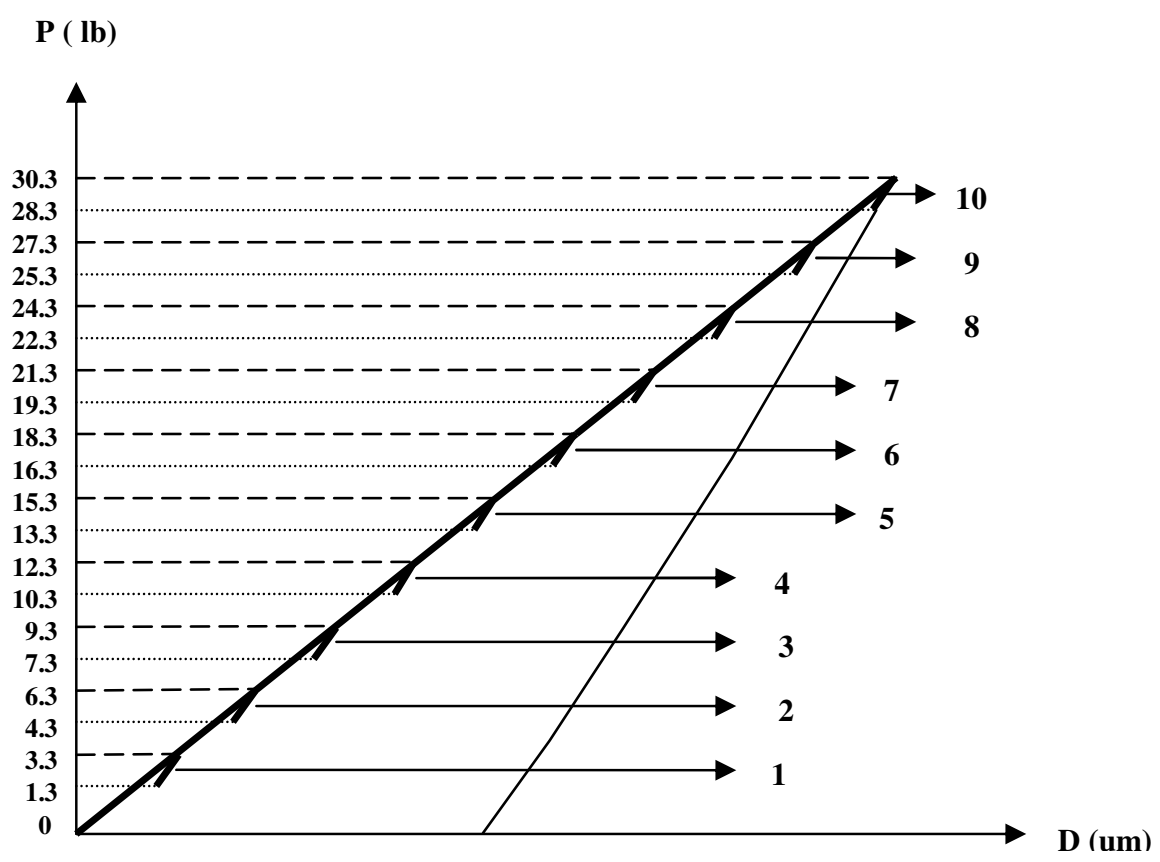

Figure 4.30 Parameter and Process setup for Steel Multi-Partial Unloading Indentation Algorithm

The experiment results are presented in Figure (4.31) and (4.32) respectively. To observe the influence caused by the small loading, 2 results are calculated. The first plot of Figure (4.31) is the curve with 10 unloading data. The slope and Young's Modulus represent as $\mathrm{C} 1$ and E1. The second plot of Figure (4.31) is the curve minus the first two unloading data. The slope and Young's Modulus represent as C2 and E2. A repeat experiment shows in Figure (4.32). 

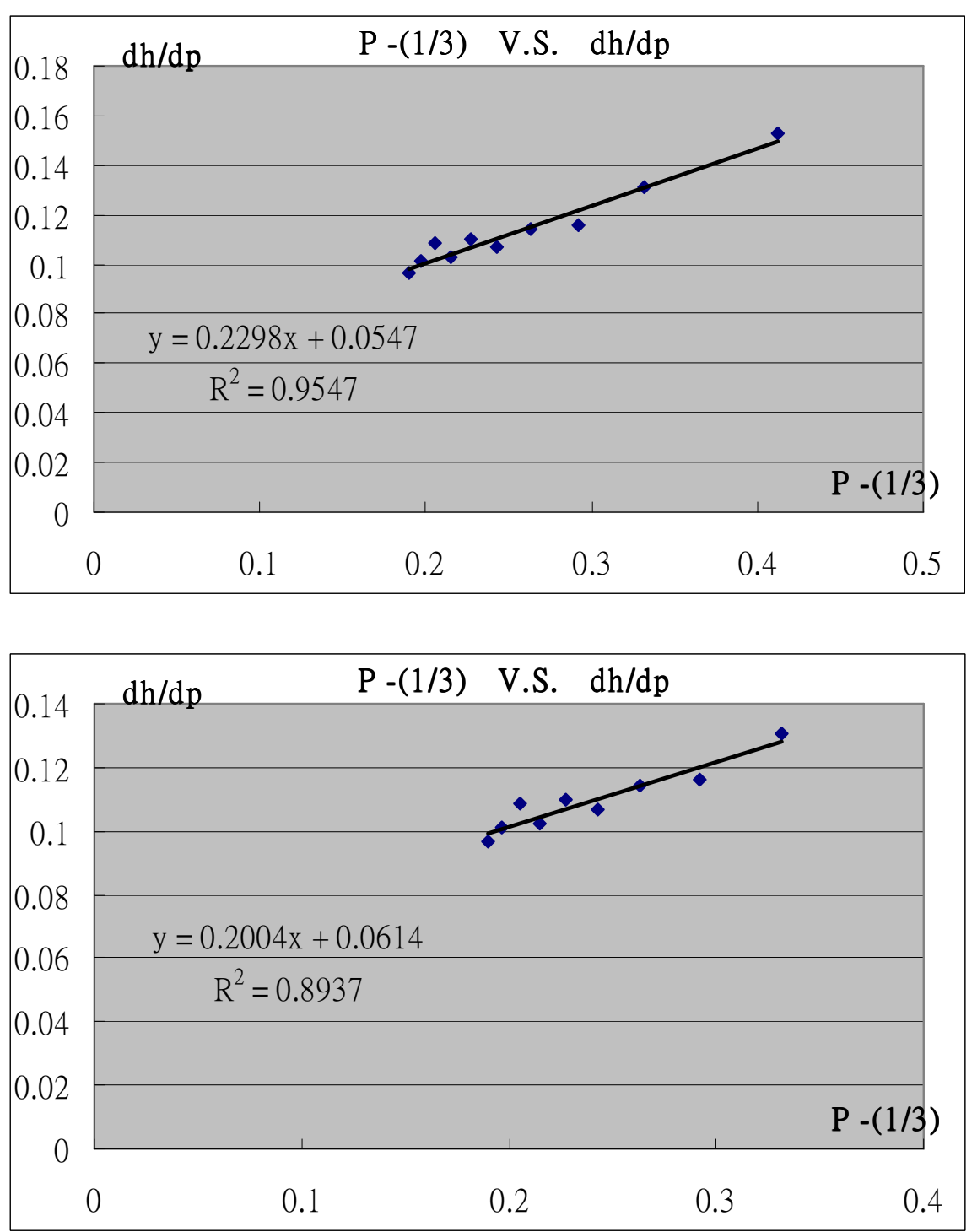

\begin{tabular}{|l|c|c|c|c|c|c|}
\hline \multicolumn{9}{|c|}{ Steel } \\
\hline Steel_Test4 & $\mathbf{P}^{-(1 / 3)}$ & dh/dp & \multicolumn{2}{|c|}{ C } & \multicolumn{2}{|c|}{ E (MPa) } \\
\hline Unloading curve 1 & 0.4126 & 0.1526 & & & & \\
\hline Unloading curve 2 & 0.3317 & 0.1308 & & & & \\
\hline Unloading curve 3 & 0.2917 & 0.1161 & & & & \\
\hline Unloading curve 4 & 0.2627 & 0.1141 & \multirow{2}{*}{ C1 } & C2 & E1 & E2 \\
\hline Unloading curve 5 & 0.2429 & 0.1069 & & & & \\
\hline Unloading curve 6 & 0.2277 & 0.1099 & 0.2298 & 0.2004 & 0.150 & 0.197 \\
\hline Unloading curve 7 & 0.2154 & 0.1026 & & & & \\
\hline Unloading curve 8 & 0.2051 & 0.1083 & & & & \\
\hline Unloading curve 9 & 0.1968 & 0.1011 & & & & \\
\hline Unloading curve 10 & 0.1897 & 0.0967 & & & & \\
\hline
\end{tabular}

Figure 4.31 The Result of Steel Indentation for Test1 

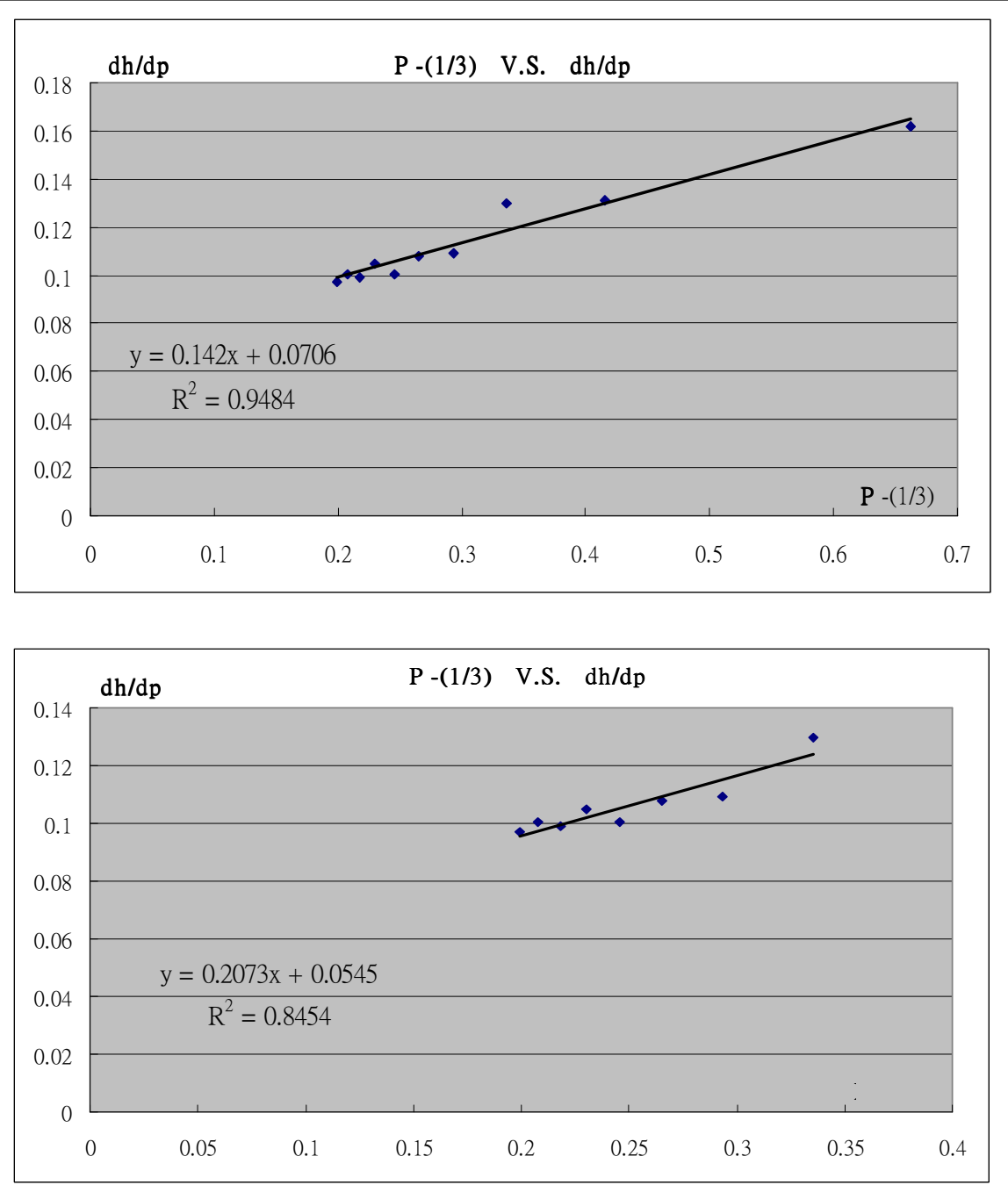

\begin{tabular}{|c|c|c|c|c|c|c|}
\hline \multicolumn{7}{|c|}{ Steel } \\
\hline Steel_Test4 & $\mathbf{P}^{-(1 / 3)}$ & dh/dp & & & E (N & Pa) \\
\hline Unloading curve 1 & 0.6626 & 0.1616 & \multirow{5}{*}{$\mathrm{C} 1$} & \multirow{5}{*}{$\mathrm{C} 2$} & \multirow{5}{*}{ E1 } & \multirow{5}{*}{ E2 } \\
\hline Unloading curve 2 & 0.4155 & 0.1312 & & & & \\
\hline Unloading curve 3 & 0.3355 & 0.13 & & & & \\
\hline Unloading curve 4 & 0.2923 & 0.1093 & & & & \\
\hline Unloading curve 5 & 0.2654 & 0.1078 & & & & \\
\hline Unloading curve 6 & 0.2456 & 0.1003 & \multirow[t]{5}{*}{0.142} & \multirow[t]{5}{*}{0.2073} & \multirow[t]{5}{*}{425} & \multirow[t]{5}{*}{184} \\
\hline Unloading curve 7 & 0.2299 & 0.105 & & & & \\
\hline Unloading curve 8 & 0.2179 & 0.0991 & & & & \\
\hline Unloading curve 9 & 0.2075 & 0.1005 & & & & \\
\hline Unloading curve 10 & 0.1990 & 0.0973 & & & & \\
\hline
\end{tabular}

Figure 4.32 The Result of Steel Indentation for Test2 
The average experiment result of Young's modulus for Steel is calculated as follows: $(184+197) / 2=190 \pm 3.42 \%(\mathrm{GPa})$. The comparison of the book value and experiment value shows in Table (4.33).

\begin{tabular}{|c|c|c|}
\hline \multicolumn{1}{|c|}{ Steel } & \multicolumn{2}{|c|}{ Young's Modulus (E) MPa } \\
\hline Book Value & \multicolumn{2}{|c|}{200} \\
\hline Experiment Value & 197 & 184 \\
\hline
\end{tabular}

Table 4.33 Steel Young's Modulus Comparison of Book Value and Experiment Result 


\section{CHAPTER 5}

\section{CONCLUSIONS AND RECOMMENDATIONS}

\subsection{Conclusions}

To improve the load control precision, a high resolution DAC and ADC are applied in this thesis. The 16-bit DAC can divide the driving voltage, which is 0 to $+10 \mathrm{~V}$, into $2^{16}$ level range. The theoretical resolution is shown below:

$$
\frac{10(V)}{2^{16}}=0.000153(V)
$$

Applied load is detected by the 14-bit ADC. With the maximum voltage of $+5 \mathrm{~V}$, the theoretical resolution is shown below:

$$
\frac{5(V)}{2^{14}}=0.000305(V)
$$

The theoretical accuracy of data converters lies in $\pm 0.0062 \%$; however, the result of the actual experiment can be influenced by the electrical noise, mechanical factors and $2 \%$ accuracy limit of the load cell and the load cell indicator.

One can achieve good results within $\pm 0.5 \%$ precision by utilizing the closed-loop control circuit board with constant load control for the indentation creep test. The results demonstrated by the indentation creep experiment give an indication for the validity and usability of the load control system. Consequently, this provides an authenticated proof in using the same system to perform the multiple partial unloading indentation experiments. 
From the multiple partial unloading indentation experiments, since $p^{\frac{-1}{3}}$ and $\frac{d h}{d p}$ are the key factors to deriving the Young's modulus, a tiny variation of the load will contribute to a big change in the result. It was found that ground effect between the circuit and load cell contributed the greatest influence to the signal noise. Signal noise is usually generated either from the wire resistance, vibration, or the ground effect. Ground loop is a condition where an unintended connection to ground is made through an interfering electrical conductor. Ground loop accrues when two or more devices are connected to a common ground through different paths. In the circuit board, ground loop connection exists when a load cell (signal-) is connected directly through ADC (signal-) to the electrical ground. To prevent ground loops, all signal grounds need to connect to one common point.

Figure (5.1) is the original circuit connection with ground effect. Figure (5.2) shows the recommended connection diagram to reduce the noise by connecting GND of the circuit board to (signal -) of ADC.

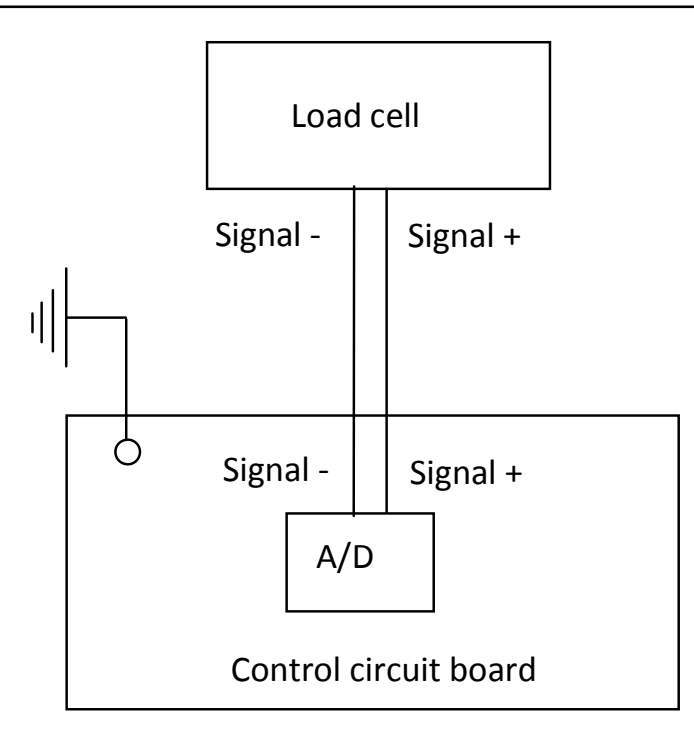

Figure 5.1 Connections with Ground Effect

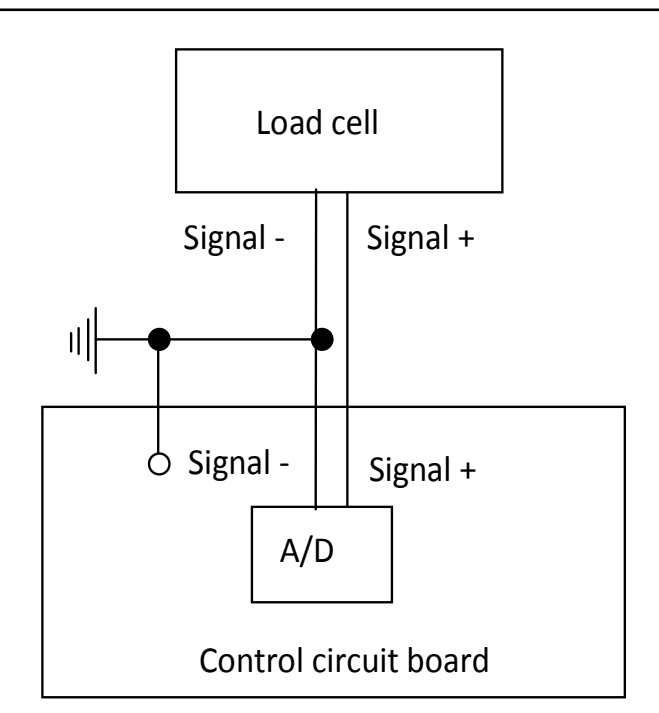

Figure 5.2 Connections without Ground Effect 
Figure (5.3) shows the plot of voltage versus time of the original connection. The plot indicates accuracy lines in $\pm 3.5 \%$ during constant load control while Figure (5.4) shows $\pm 2 \%$ accuracy with ground effect prevention. It is apparent that the ground effect is responsible for more than $\pm 1.5 \%$ inaccuracy in experimental results.
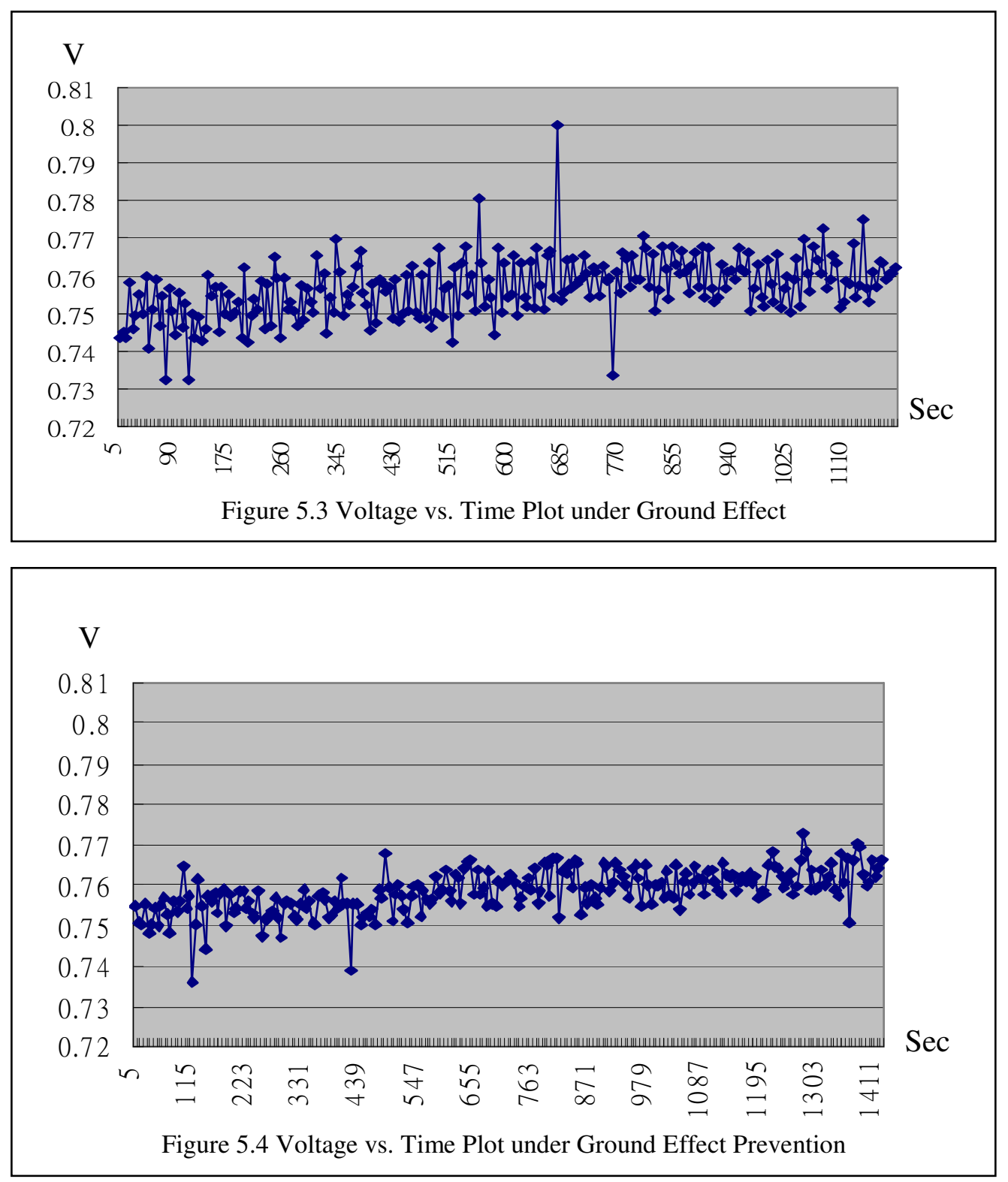

Furthermore, small loading will also create an inaccurate result. If fewer than 30(N) loading data were used, the result will present an fallacious outcome. 


\subsubsection{Recommendations}

\subsubsection{PZT Calibration Factor}

Each PZT actuator has its unique calibration parameter, thus making it only equipped with a specific PZT controller. The controller is not only expansive, but also heavy. Therefore, it is more efficient to develop a unit which can be utilized to calibrate the PZT actuators before application. With the circuit board, the driving voltage and the corresponding displacement can be recorded. By finding the parameters from the curve in terms of $y=a x+b$, the specific calibration factor can be determined. Figure (5.5) shows the displacement versus driving voltage curve of 40um travel range actuator matched with its own controller. In order to make an observation of the repetition, three separate tests are performed. All three test results presented a consistent characteristic that is indicated by the slope of 3.981 in Figure (5.5).

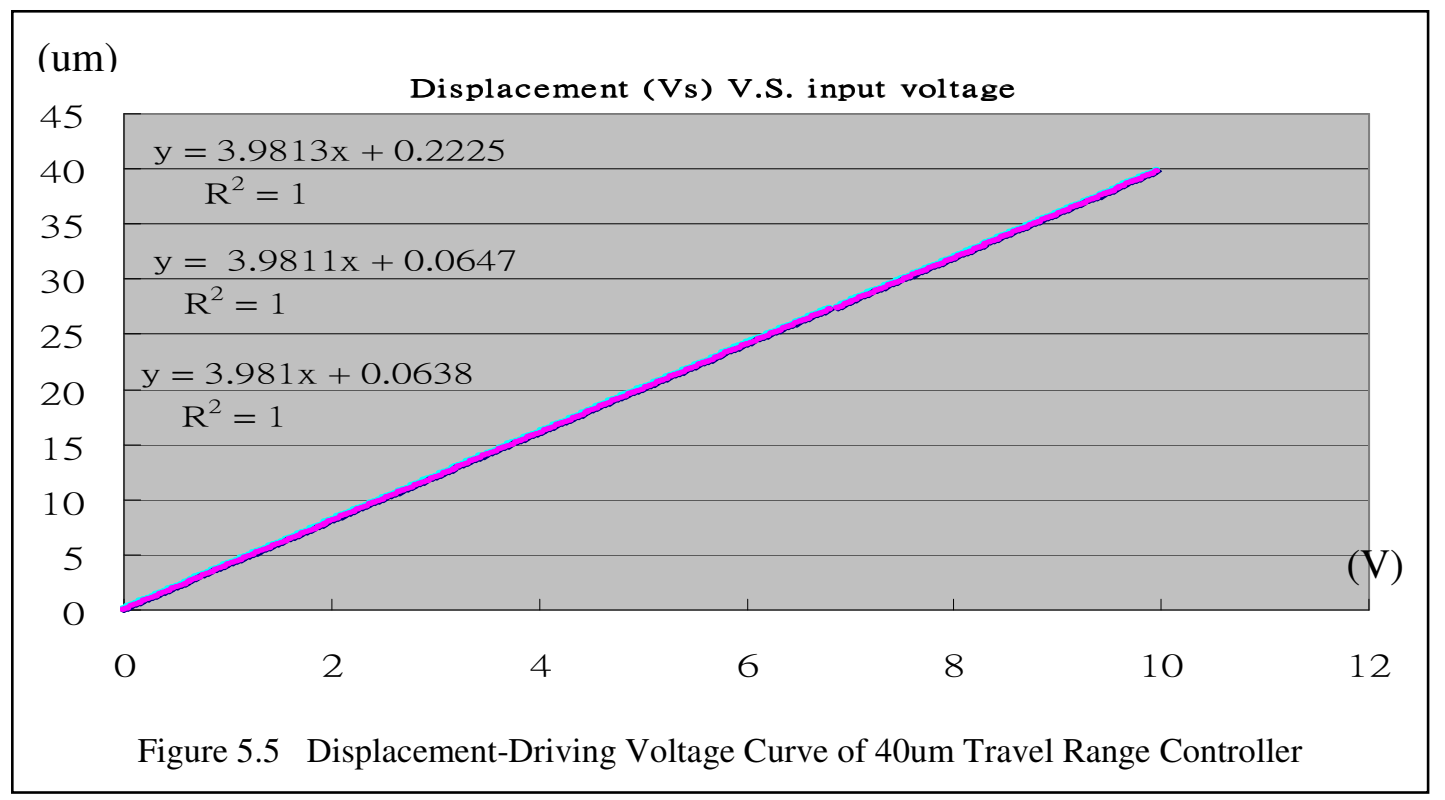


Figure (5.6) shows that the displacement versus driving voltage curve of 40um travel range actuator matching with $180 \mathrm{um}$ travel range controller. The three tests are repeated and again presented a consistent characteristic. The average slope is equal to $17.915 \pm 0.001 \%$.

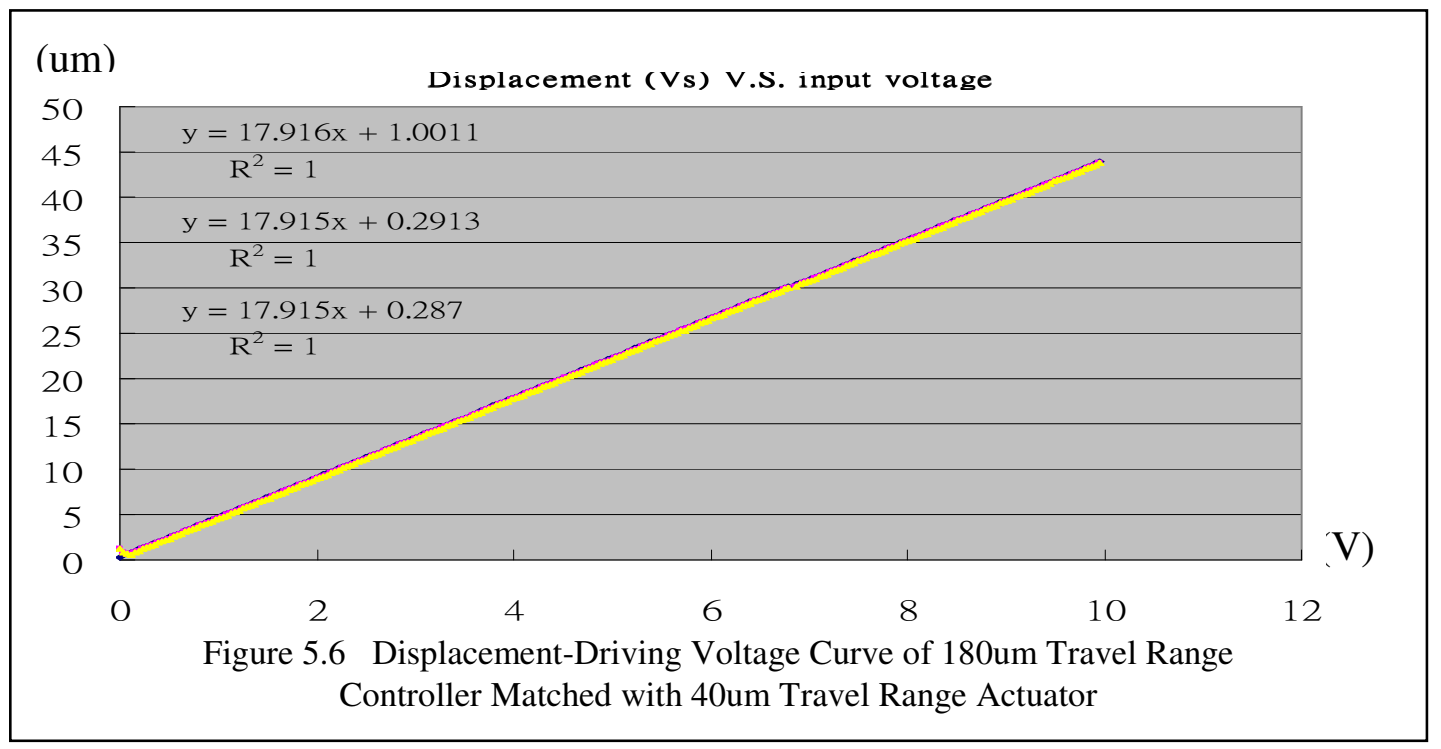

Figure (5.7) shows the displacement versus driving voltage curve of 40um travel range actuator matches with 120um travel range controller. The two tests are repeated and indicated an average slope equal to $17.938 \pm 0.001 \%$.

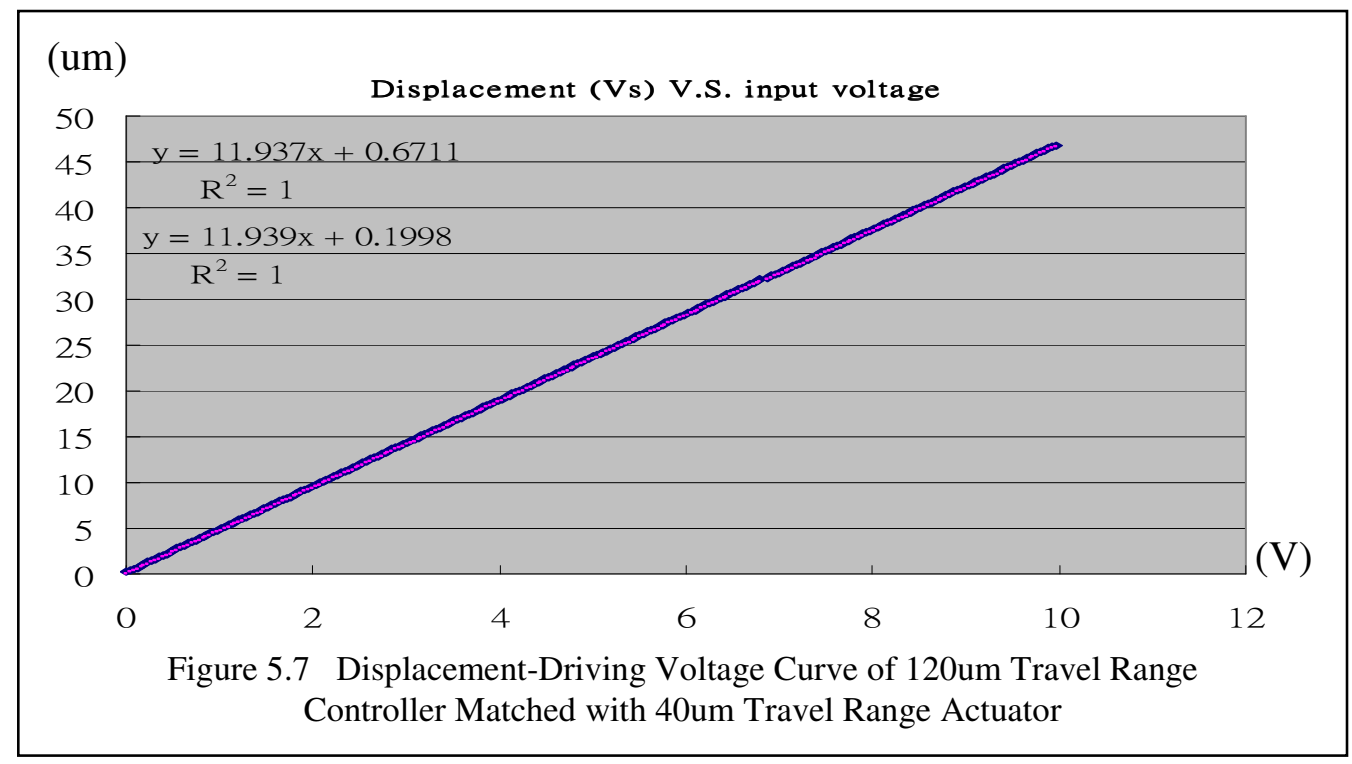


With all the experiment results stated above, it is demonstrated that one PZT actuator can be driven by a different PZT controller and the results perform linearity. The calibration factor is verified to be obtained by the application of the control board. Therefore, the closed-loop control circuit board can be used in various experiments with a suitable parameter calibration factor setup.

Conventional PZT controller can only function with a data acquisition and a computer. Space and cost are of concerns and will create an inconvenient situation in terms of portability. This research work designed contains load detection and EEPROM. The experiment result can be saved while performing the test and then transferred to a computer for data analysis at a later time. Based on this prototype, it is possible to investigate the development of portable controller.

\subsubsection{The Application of Creep and Material Properties Evaluation}

The combined function of the constant load and constant displacement control system, such as the creep and material properties evaluation, can be further implemented by this research work. Figure (5.8) shows the bi-function control system applied on the material evaluation. In conclusion, the control system possesses tremendous potential usage; not only in academic research environment, but also in industry settings. 


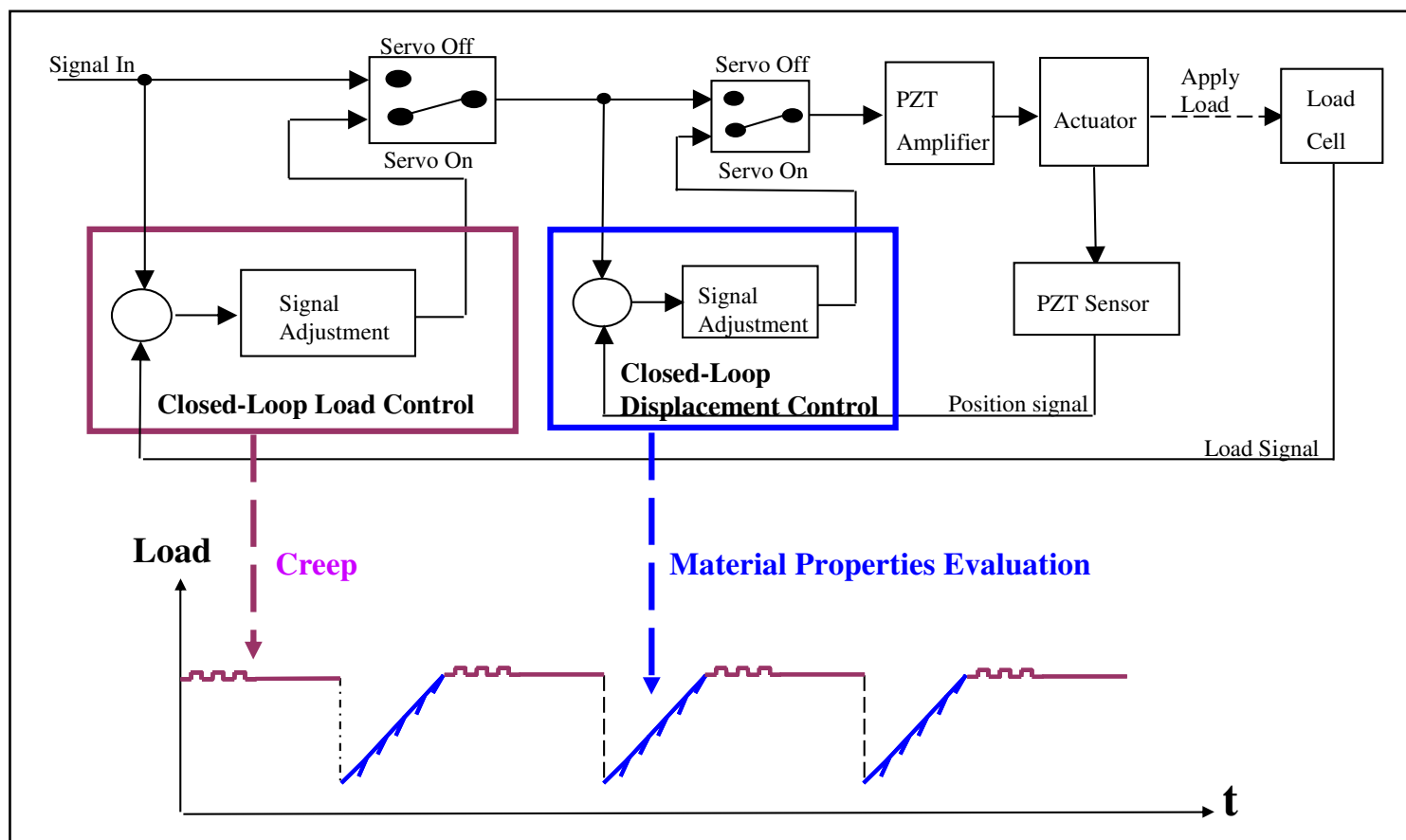

Figure 5.8 The Application of Creep and Material Properties Evaluation 


\section{REFERENCES}

[1] Ian N. Sneddon, The Relation between Load and Penetration in the Axisymmetric Boussinesq Problem for a Punch of Arbitrary Profile, Int. J. Engng Sci, Vol. 3, pp. 47-57, 1965.

[2] S.I. Bulychev, V.P. Alekhin, M. Kh. Shorshorov, A.P. Ternovskii and G.D. Shnyrev, Determine Young's modulus from the indentor penetration diagram, Industrial laboratory, Vol. 41, No.9, pp 1409-1412, Sep 1975.

[3] M. F. Doerner, W. D. Nix, A method for interpreting the data from depth-sensing indentation instruments, J. Mater. Res. 1(4), p601-609, Jul/Aug 1986

[4] W. C. Oliver, G. M. Pharr, An improved technique for determine hardness and elastic modulus using load and displacement sensing indentation experiments, JOURNAL OF MATERIALS RESEARCH, 7(6):1564-1583 June 1992.

[5] K.L. Johnson, Contact Mechanics, Cambridge University Press, 1985

[6] B. Taljat, T. Zacharia, New analytical procedure to determine stress-strain curve from.

[7] F. M. Haggag, Field Indentation Microprobe for structural integratity evaluation, U.S. U.S. Patent No. 4,852,397, August 1,1989.

[8] Claus Kleesattel, Method and apparatus for the measurement of hardness testing indentations, Patent No. 4,277,174, July 7, 1981. 
[9] Stefan Frank, Transpyramidal Indentation Viewing - New possibilities for mobile hardness testing, $15^{\text {th }}$ World Conference on Non-Destructive Testing, October 2000 in Rome.

[10] M.Sakaia and N.Hakiri, T. Miyajima, J. Mater. Res., Vol. 21,No. 9, Sep 2006, p2298-2303, Instrumented indentation microscope: A powerful tool for the mechanical characterization in microscales.

[11] C. Feng, B. Kang, A transparent Indenter Measurement Method for Mechanical Property Evaluation, Experimental Mechanics, p91-103, Vol.46, No.1, Feb 2006.

[12] C.Feng, B. Kang, Yung's modulus measurement using a simplified transparent indenter measurement technique, submit to Experimental Mechanics, Oct, 2006, accepted for publication.

[13] T. MIYAJIMA and M. Sakaia, Philosophical Magazine, Vol. 86, Nos. 33-35, 21 Nov.-11 Dec. 2006, 5729-5737, Optical indentation microscopy - a new family of instrumented indentation testing.

[14] Paul E. Labossiere, University of Washington, ME 354 Mechanics and Materials Laboratory, autumn 2007, Ch.8.

[15] A. I. Lure, Three-dimensional problems in the theory of elasticity[in Russian], Gostekhizdat, Moscow(1955)

[16] F. M.Haggag, R. K. Nanstad, J. T. Hutton, D. L. Thomas, and R. L. Swain, Use of Automated Ball Indentation to Measure Flow Properties and Estimate Fracture Toughness in Metallic Materials, Applications of Automation Technology to Fatigue and Fracture Testing, ASTM 1092, A. A. Braun, N. E. Ashbaugh, and F. M. Smith, Eds., American Society for Testing and Materials, Philadelphia, 1990, pp. 188-208 
[17] B. Taljat, and T. Zacharia, New analytical procedure to determine stress-strain curve from spherical indentation data, Int. J. Solids structures, Vol. 35, No. 33, pp. 44114426, 1998.

[18] Atmel Corporation, AT89C51 datasheet, 2000.

[19] Texas Instruments, DAC715 Datasheet, 2000.

[20] Analog Devices Inc. AD7951 Datasheet, 2006

[21] Texas Instruments, MAX232 Datasheet, 2008.

[22] Linear Technology Corporation, LT1054 Datasheet

[23] National Institute of Standards and Technology, Properties of Lead-Free Solders, Database for Solder Properties with Emphasis on New Lead-free Solders. Release 4.0

[24] C.R. Nave of Georgia State University, 2005, http://hyperphysics.phyastr.gsu.edu/hbase/permot3.html 